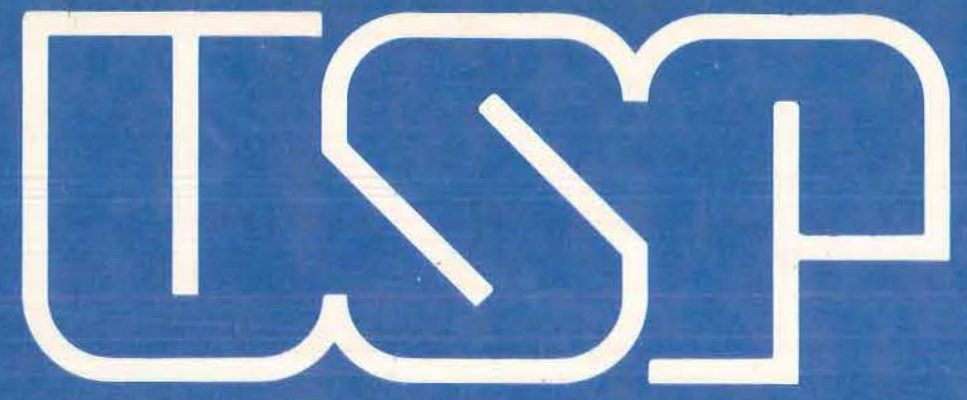

- Campus de São Carlos

"Identificação paramétrića de um motor de indução trifásico através de ensaio degrau em corrente contínua"

Evandro Boldarini Couto

citi

i. Orientador

Prof. Dr. Manoel Luis de Aguiar

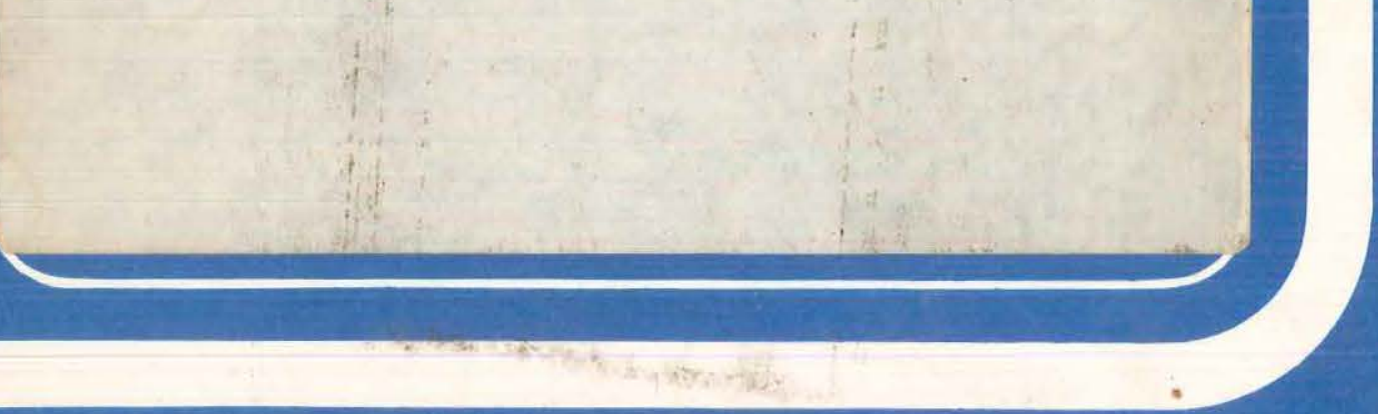

UNIVERSIDADE DE SÃO PAULO

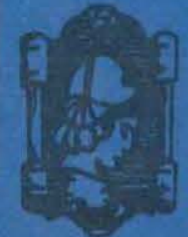


UNIVERSIDADE DE SÃO PAULO

ESCOLA DE ENGENHARIA DE SÃO CARLOS

DEPARTAMENTO DE ENGENHARIA ELÉTRICA

IDENTIFICAÇÃO PARAMÉTRICA DE UM MOTOR DE INDUÇÃO

TRIFÁSICO ATRAVÉS DE ENSAIO DEGRAU

EM CORRENTE CONTÍNUA

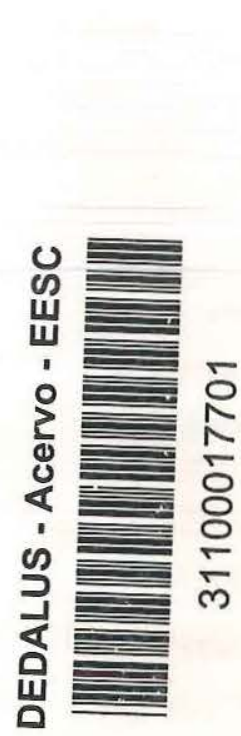

Dissertação apresentada junto ao Departamento de Engenharia Elétrica da EESC / USP como parte dos requisitos para obtenção do título de Mestre em Engenharia Elétrica

Autor: Evandro Boldarini Couto

Orientador: Dr. Manoel Luis de Aguiar 
Clase. $\frac{\text { TF SF \& }}{1719}$
Cutt. $\frac{179}{299196}$

st 0746439

Ficha catalográfica preparada pela Seção de Tratamento da Informação do Serviço de Biblioteca - EESC-USP

Couto, Evandro Boldarini

Identificação paramétrica de um motor de indução trifásico através de ensaio degrau em corrente contínia / Evandro Boldarini Couto. -São Carlos, 1996.

Dissertação (Mestrado). -- Escola de Engenharia de São Carlos-Universidade de São Paulo, 1996.

Orientador: Prof. Dr. Manoel Luis de Aguiar.

1. Estimação de parâmetros. 2. Motor de indução. 3. Efeito pelicular. I. Título 


\section{FOLHA DE APROVAC̃̃O}

Dissertação defendida e aprovada em 21-10-1996 pela Comissão Julgadora:

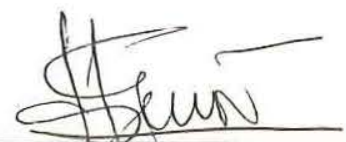

Prof. Doutor MANOEL LUIS DE AGUIAR (Orientador)

(Escola de Engenharia de São Carlos - Universidade de São Paulo)

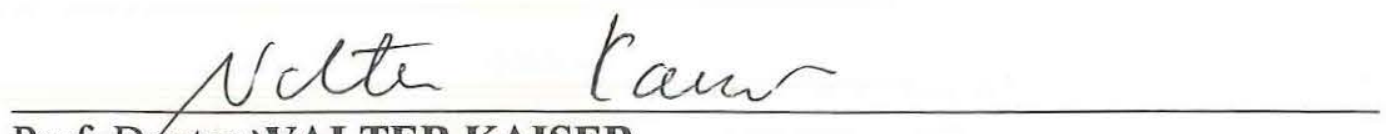

Prof. Døutor WALTER KAISER

(Escola Politécnica - Universidadede São Paulo)

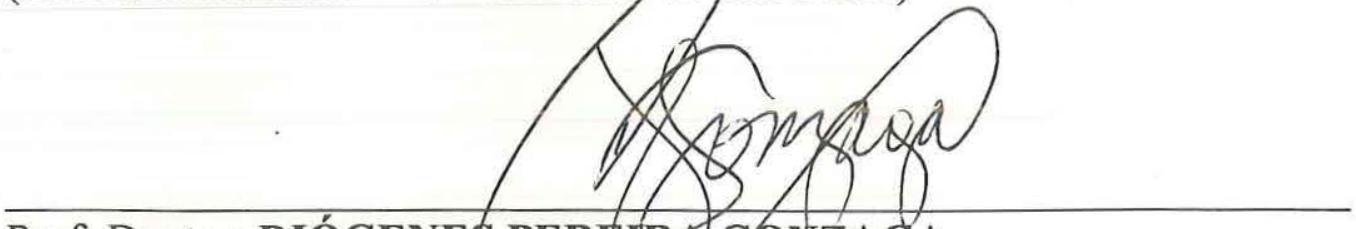

Prof. Doutor DIÓGENES PEREIIRA GONZAGA

(Escola de Engenharia de São Carfos Universidade de São Paulo)

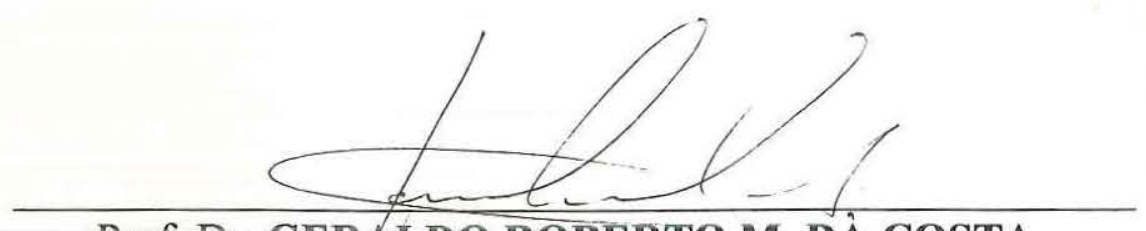

Prof. Dr. GERALDO ROBERTO M. DÀ COSTA

Coordenador da área - Engenharia Elétrica

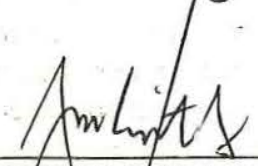

JOSE CARLOS A. CINTRA

Presidente da Comissão de Pós-Graduação 
Ao meu pai que foi sempre meu espelho profissional. À minha mãe, por sua força e otimismo nos momentos dificeis.

À minha irmã, companheira de todas as horas. 
Aos meus tios Luís e Yolanda e a minha avó Francisca, pela força e carinho demonstrados durante este mestrado. 


\section{AGRADECIMENTOS}

A Deus, por ter me dado força para superar todos os obstáculos de minha vida e sem o qual nada seria possível.

Ao Professor Dr.Manoel Luis de Aguiar, pela confiança, paciência, atenção e segura orientação na realização deste trabalho.

In memorian aos meus avós Cândido, Custódia e Primo que certamente se orgulhariam por mais esta conquista de minha vida.

À minha namorada Cristiane pela compreensão e incentivo nos momentos difíceis.

Aos Professores Dr. Diógenes Pereira Gonzaga e Dra.Vilma A. de Oliveira, pelas sugestões na Qualificação.

À Professora Marli Soubhia, pela amizade e colaboração.

Aos amigos de pós-graduação, especialmente ao Alexandre Sampaio pela valiosa contribuição neste trabalho.

Aos amigos de República por tornarem esta fase da minha vida mais agradável.

Aos funcionários da Biblioteca Central, especialmente a Helena e a Heleninha pela ajuda na obtenção dos artigos.

Aos funcionários do Departamento de Engenharia Elétrica.

À CAPES pela concessão da bolsa de mestrado.

À todos aqueles que direta ou indiretamente colaboraram para a realização deste trabalho. 


\section{Sumário}

Lista de Símbolos e Abreviações........................................................................... i

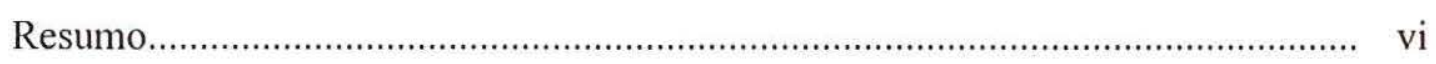

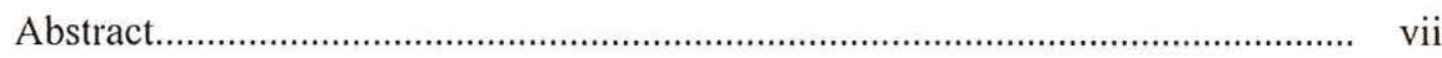

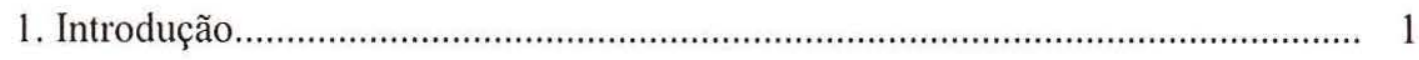

2. Modelagem Vetorial do Motor de Indução Trifásico....................................... 5

2.1 Notação Vetorial................................................................................... 5

2.2 O Motor de Indução Trifásico na Notação Vetorial........................................ 8

2.3 Modelagem do MIT em um Referencial Genérico.................................... 16

2.4 Modelagem do MIT no Referencial de Campo........................................... 20

3. Metodologia de Estimação.......................................................................... 23

3.1 Modelagem do Motor de Indução para Excitação CC.................................... 24

3.2 Modelagem Mecânica do Motor de Indução................................................ 33

4. Algoritmos de Identificação Paramétrica........................................................... 36

4.1 Método dos Mínimos Quadrados............................................................ 36

4.2 Método dos Mínimos Quadrados Recursivo.............................................. 39

4.2.1 Método dos Mínimos Quadrados Recursivo Estendido (RELS).......... 43

4.3 Método de Gauss-Newton................................................................... 45

4.4 Estimação Paramétrica Utilizando o Método Simplex de Nelder-Mead........ 49

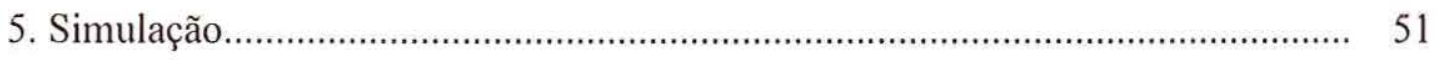

5.1 Simulação - Parâmetros Elétricos............................................................... 51

5.1.1 Método dos Mínimos Quadrados Recursivo (RLS)........................... 54 
5.1.2 Método de Gauss-Newton

5.1.3 Estimação com o Método Simplex de Nelder-Mead............................ 57

5.2 Simulação - Parâmetros Mecânicos................................................................. 57

5.2.1 Método de Gauss-Newton............................................................... 58

5.2.2 Estimação com o Método Simplex de Nelder-Mead............................. 59

6. Implementação.......................................................................................... 61

6.1 Descrição do Sistema para Estimação dos Parâmetros Elétricos.................... 61

6.2 Descrição do Sistema para Estimação dos Parâmetros Mecânicos................. 63

7. Resultados Experimentais............................................................................ 64

7.1 Parâmetros Elétricos.......................................................................................... 65

7.1.1 Método dos Mínimos Quadrados Recursivo Estendido (RELS).......... 65

7.1.2 Método de Gauss-Newton................................................................ 67

7.1.3 Estimação com o Método Simplex de Nelder-Mead.............................. 69

7.2 Parâmetros Mecânicos....................................................................................... 71

7.2.1 Método de Gauss-Newton.................................................................. 71

7.2.2 Estimação com o Método Simplex de Nelder-Mead.............................. 73

7.3 Validação do Modelo........................................................................... 74

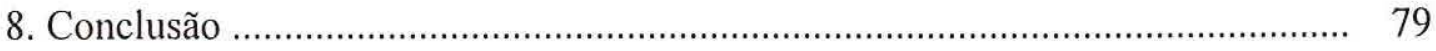

9. Referências Bibliográficas............................................................................. 81

Apêndice A - Identificação paramétrica a partir do ensaio com rotor bloqueado e em vazio. 


\section{Lista de Símbolos e Abreviações}

\section{Símbolos}

$a_{1}, a_{2}$

$\mathrm{A}(\mathrm{z})$

$\mathrm{A}_{0}, \mathrm{~A}_{1}, \mathrm{~A}_{2}$

$\mathrm{b}_{1}, \mathrm{~b}_{2}$

$\mathrm{B}(\mathrm{z})$

$\mathrm{C}(\mathrm{z})$

$\mathrm{D}(\mathrm{z})$

e

f

G(s)

$\mathrm{G}_{\mathrm{v}}(\mathrm{z}), \mathrm{G}_{\mathrm{p}}(\mathrm{z})$

h

$\overrightarrow{\mathrm{i}}_{\mathrm{mr}}$

$\overrightarrow{\mathrm{i}}_{\mathrm{r}}$

$\mathrm{i}_{\text {ra }}, \mathrm{i}_{\text {rb }}, \mathrm{i}_{\text {rc }}$

$\overrightarrow{\mathrm{i}}_{\mathrm{S}}$

$\mathrm{i}_{\mathrm{r}}, \mathrm{i}_{\mathrm{s}}$

$\mathrm{i}_{\mathrm{sa}}, \mathrm{i}_{\mathrm{sb}}, \mathrm{i}_{\mathrm{sc}}$

$\mathrm{i}_{\text {mr } \alpha}, \mathrm{i}_{\operatorname{mr} \beta}$

$\mathrm{i}_{\text {sd }}, \mathrm{i}_{\text {sq }}$
Parâmetros da equação diferença do processo discreto

Polinômio denominador da função de transferência no domínio $\mathrm{Z}$

Parâmetros relativos ao ensaio degrau

Parâmetros da equação diferença do processo discreto

Polinômio numerador da função de transferência no domínio Z

Polinômio denominador da função de transferência no domínio $\mathrm{Z}$

Polinômio numerador da função de transferência no domínio Z

Vetor erro do método dos mínimos quadrados recursivo

Freqüência

Função de transferência para funções contínuas no tempo

Função de transferência no domínio z

Profundidade da barra do rotor

Vetor de espaço da corrente de magnetização do rotor

Vetor de espaço da corrente de rotor

Valor instantâneo das correntes de rotor nas fases A, B e C respectivamente

Vetor de espaço da corrente de estator

Valor instântaneo das correntes de rotor e estator respectivamente

Valor instantâneo das correntes de estator nas fases A, B e C respectivamente

Respectivamente, componentes real e imaginária do vetor de espaço da corrente de magnetização do rotor no sistema de coordenadas genérico

Respectivamente, componentes real e imaginária do vetor de espaço da corrente de estator no sistema de coordenadas $\mathrm{d}-\mathrm{q}$ 


\begin{tabular}{|c|c|}
\hline$i_{s \alpha}, i_{s \beta}$ & $\begin{array}{l}\text { Respectivamente, componentes real e imaginária do vetor de espaço da } \\
\text { corrente de estator no sistema de coordenadas genérico }\end{array}$ \\
\hline$\underline{I}_{v}, \underline{I}_{k}$ & $\begin{array}{l}\text { Fasor corrente no estator nos ensaios em vazio e com rotor bloqueado } \\
\text { respectivamente }\end{array}$ \\
\hline $\mathrm{J}$ & Momento de Inércia \\
\hline $\mathrm{k}$ & Largura da barra do rotor \\
\hline $\mathrm{K}$ & Constante relativa ao ensaio degrau \\
\hline $\mathrm{K}_{\mathrm{D}}$ & Coeficiente de atrito dinâmico \\
\hline $\mathrm{K}_{\mathrm{w}}$ & Constante de torque \\
\hline$l_{\mathrm{ra}}, \mathrm{l}_{\mathrm{rb}}, \mathrm{l}_{\mathrm{rc}}\left(=\mathrm{l}_{\mathrm{r}}\right)$ & Indutância prória de rotor das fases $\mathrm{A}, \mathrm{B}$ e C respectivamente \\
\hline $1_{\mathrm{sa}}, 1_{\mathrm{sb}}, 1_{\mathrm{sc}}\left(=1_{\mathrm{s}}\right)$ & Indutância própria de estator das fases $\mathrm{A}, \mathrm{B}$ e $\mathrm{C}$ respectivamente \\
\hline $1_{\sigma r a}, 1_{\sigma r b}, 1_{\sigma r c}\left(=l_{\sigma r}\right)$ & Indutância de dispersão de rotor das fases $\mathrm{A}, \mathrm{B}$ e $\mathrm{C}$ respectivamente \\
\hline $1_{\sigma s a}, 1_{\sigma s b}, 1_{\sigma s c}\left(=1_{\sigma s}\right)$ & Indutância de dispersão de estator das fases $\mathrm{A}, \mathrm{B}$ e $\mathrm{C}$ respectivamente \\
\hline $\mathrm{L}_{\mathrm{r}}$ & Indutância de rotor no sistema ortogonal \\
\hline $\mathrm{L}_{\mathrm{ra}}, \mathrm{L}_{\mathrm{rb}}, \mathrm{L}_{\mathrm{rc}}$ & Indutância total de rotor das fases $\mathrm{A}, \mathrm{B}$ e $\mathrm{C}$ respectivamente \\
\hline $\mathrm{L}_{\mathrm{S}}$ & Indutância de estator no sistema ortogonal \\
\hline $\mathrm{L}_{\mathrm{sa}}, \mathrm{L}_{\mathrm{sb}}, \mathrm{L}_{\mathrm{sc}}$ & Indutância total de estator das fases $\mathrm{A}, \mathrm{B}$ e $\mathrm{C}$ respectivamente \\
\hline $\mathrm{L}_{0}, \mathrm{~m}_{\mathrm{r}}, \mathrm{m}_{\mathrm{s}}$ & Indutância mútua entre estator e rotor \\
\hline $\mathrm{m}$ & Ordem do sistema ou largura da ranhura do rotor ou indutância mútua \\
\hline $\mathrm{m}_{\mathrm{d} 0}$ & Conjugado em regime permanente \\
\hline$m_{d}$ & Conjugado eletromagnético \\
\hline $\mathrm{M}_{\mathrm{f}}$ & Coeficiente de atrito estático \\
\hline $\mathrm{M}_{1}$ & Conjugado de carga \\
\hline $\mathrm{n}$ & Vetor ruído do método dos mínimos quadrados recursivo \\
\hline $\mathbf{P}$ & Matriz covariância do método dos mínimos quadrados recursivo \\
\hline $\mathrm{R}_{\mathrm{r}}$ & Resistência de rotor \\
\hline $\mathrm{R}_{\mathrm{ra}}, \mathrm{R}_{\mathrm{rb}}, \mathrm{R}_{\mathrm{rc}}$ & Resistências de rotor das fases A, B e C respectivamente \\
\hline
\end{tabular}




\begin{tabular}{|c|c|}
\hline $\mathrm{R}_{\mathrm{s}}$ & Resistência de estator \\
\hline $\mathrm{R}_{\mathrm{sa}}, \mathrm{R}_{\mathrm{sb}}, \mathrm{R}_{\mathrm{sc}}$ & Resistências de estator das fases $\mathrm{A}, \mathrm{B}$ e $\mathrm{C}$ respectivamente \\
\hline $\mathrm{s}$ & Variável da transformada de Laplace \\
\hline $\mathrm{S}$ & Escorregamento \\
\hline $\mathrm{S}_{\mathrm{p}}$ & Escorregamento com conjugado máximo \\
\hline $\mathrm{T}_{\mathrm{s}}, \mathrm{T}_{\mathrm{r}}$ & Constante de tempo do estator e rotor respectivamente \\
\hline $\mathrm{T}_{\mathrm{rAC}}$ & Constante de tempo do rotor variável devido ao Efeito Pelicular \\
\hline $\mathrm{T}_{0}$ & Tempo de amostragem \\
\hline $\mathrm{T}_{1}, \mathrm{~T}_{2}, \mathrm{~T}_{\mathrm{d}}$ & Constantes de tempo relativas ao ensaio degrau \\
\hline u & Vetor entrada relativo ao método dos mínimos quadrados recursivo \\
\hline $\overrightarrow{\mathrm{u}}_{\mathrm{s}}$ & Vetor de espaço tensão de estator \\
\hline $\mathrm{u}_{\mathrm{sa}}, \mathrm{u}_{\mathrm{sb}}, \mathrm{u}_{\mathrm{sc}}$ & $\begin{array}{l}\text { Valor instantâneo das tensões de estator nas fases A, B e C } \\
\text { respectivamente }\end{array}$ \\
\hline $\mathrm{u}_{\mathrm{sA}}, \mathrm{u}_{\mathrm{sB}}$ & $\begin{array}{l}\text { Respectivamente, componentes real e imaginária do vetor de espaço } \\
\text { tensão do estator no sistema de coordenadas A-B (fixo no estator) }\end{array}$ \\
\hline $\mathrm{u}_{\mathrm{sd}}, \mathrm{u}_{\mathrm{sq}}$ & $\begin{array}{l}\text { Respectivamente, componentes real e imaginária do vetor de espaço } \\
\text { tensão do estator no referencial d-q }\end{array}$ \\
\hline $\mathrm{u}_{\mathrm{s} \alpha}, \mathrm{u}_{\mathrm{s} \beta}$ & $\begin{array}{l}\text { Respectivamente, componentes real e imaginária do vetor de espaço } \\
\text { tensão do estator no sistema de coordenadas genérico }\end{array}$ \\
\hline$\underline{U}_{v}, \underline{U}_{k}$ & $\begin{array}{l}\text { Fasor tensão de estator nos ensaios em vazio e com rotor bloqueado } \\
\text { respectivamente }\end{array}$ \\
\hline $\mathbf{v}$ & Vetor ruído do método dos mínimos quadrados recursivo \\
\hline V & Função de perdas do método dos mínimos quadrados recursivo \\
\hline $\mathrm{V}_{\mathrm{an}}, \mathrm{V}_{\mathrm{bn}}$ & Tensão de fase de rotor \\
\hline $\mathrm{V}_{\mathrm{AN}}, \mathrm{V}_{\mathrm{BN}}$ & Tensão de fase de estator \\
\hline y & Vetor saída do método dos mínimos quadrados recursivo \\
\hline$X_{0}, X_{s}, X_{\sigma}$ & Reatância mútua, de estator e de dispersão respectivamente \\
\hline $\mathrm{z}$ & Variável da transformada $\mathrm{z}=\mathrm{e}^{\mathrm{T}_{\mathrm{o}} \mathrm{s}}$ \\
\hline
\end{tabular}




\begin{tabular}{|c|c|}
\hline$\sigma_{\mathrm{AC}}$ & Fator de dispersão global variável devido ao Efeito Pelicular \\
\hline$\sigma_{\mathrm{r}}, \sigma_{\mathrm{s}}$ & Fator de dispersão do rotor e estator respectivamente \\
\hline$\theta$ & Vetor parâmetros do método dos mínimos quadrados recursivo \\
\hline$\theta_{1}, \theta_{2}, \theta_{3}$ & Parâmetros do método de Gauss-Newton \\
\hline$\gamma$ & $\frac{2 \pi}{3}$ ou coeficiente \\
\hline$\varphi_{\mathrm{v}}, \varphi_{\mathrm{k}}$ & $\begin{array}{l}\text { Defasagem entre tensão e corrente de estator nos ensaios em vazio e } \\
\text { com rotor bloqueado respectivamente }\end{array}$ \\
\hline$\rho, \varsigma$ & Coordenadas angulares \\
\hline$\lambda$ & Coordenada angular ou fator de esquecimento \\
\hline$\vec{\psi}_{s}, \vec{\psi}_{r}$ & Vetor de espaço fluxo no estator e no rotor respectivamente \\
\hline$\psi_{\mathrm{ra}}, \psi_{\mathrm{rb}}, \psi_{\mathrm{rc}}$ & Valor instantâneo dos fluxos de rotor nas fases A, B, C respectivamente \\
\hline$\psi_{\mathrm{sa}}, \psi_{\mathrm{sb}}, \psi_{\mathrm{sc}}$ & $\begin{array}{l}\text { Valor instantâneo dos fluxos de estator nas fases A, B, C } \\
\text { respectivamente }\end{array}$ \\
\hline$\psi$ & Vetor de dados do método dos mínimos quadrados recursivo \\
\hline$\alpha-\beta, A-B, d-q$ & Sistemas de coordenadas \\
\hline$x-y, a-b$ & \\
\hline$\varepsilon$ & Ângulo de rotação \\
\hline$\chi$ & Coeficiente \\
\hline$\omega$ & Velocidade mecânica do rotor \\
\hline$\omega_{0}$ & Velocidade mecânica de regime permanente \\
\hline$\omega_{\mathrm{s}}$ & Frequência angular de alimentação das tensões de estator. \\
\hline$\omega_{\mathrm{mr}}, \omega_{\lambda}$ & $\begin{array}{l}\text { Velocidade angular do sistema de coordenadas de campo e genérico } \\
\text { respectivamente }\end{array}$ \\
\hline$\psi, \gamma$, etc... & Matriz/Vetor \\
\hline$\hat{y}, \hat{\theta}$, etc... & Valores estimados \\
\hline
\end{tabular}




\section{Abreviações:}

$\begin{array}{ll}\text { ABNT } & \text { Associação Brasileira de Normas Técnicas } \\ \text { A/D } & \text { Conversor Analógico/Digital } \\ \text { ARMAX } & \text { Autoregressive moving average with exogenous variable } \\ \text { D/A } & \text { Conversor Digital/Analógico } \\ \text { CA } & \text { Corrente alternada } \\ \text { CC } & \text { Corrente contínua } \\ \text { eq./eqs. } & \text { Equação/Equações } \\ \text { fig./figs. } & \text { Figura/Figuras } \\ \text { I/O } & \text { Input/Output } \\ \text { MIT } & \text { Motor de indução trifásico } \\ \text { PC-AT } & \text { Personal computer with AT bus } \\ \text { RELS } & \text { Recursive extended least square } \\ \text { RLS } & \text { Recursive least square }\end{array}$




\section{RESUMO}

O presente trabalho investiga um procedimento de identificação paramétrica de um motor de indução trifásico com rotor em gaiola de esquilo.

O ponto central do trabalho concentra-se na obtenção dos parâmetros elétricos do motor, baseado na análise de um ensaio de excitação tipo degrau aplicado nos enrolamentos de estator.

Através da obtenção analítica do comportamento transitório da corrente do ensaio em degrau, são propostos alguns procedimentos para a obtenção dos parâmetros elétricos, baseado no método dos mínimos quadrados e em métodos numéricos de interpolação de curvas.

O ensaio clássico de desaceleração também é investigado com o objetivo de se obter os parâmetros mecânicos. Neste caso, foram empregadas técnicas de interpolação de curvas.

A validação dos métodos e dos parâmetros obtidos é feita com base em comparações de simulações e dados reais de ensaios do motor, onde discute-se a influência do Efeito Pelicular sobre determinados parâmetros elétricos do mesmo . 


\section{ABSTRACT}

This work deals with a method to identify the parameters of a three-phasesquirrel-cage induction-motor. The identification of the electrical parameters is based on analysis of the motor response to a input voltage step applied to the stator windings.

The least square method and the interpolation methods (Gauss-Newton and Simplex of Nelder-Mead), are applied to obtain the electrical motor parameters. The mechanical parameters values are derived from the deceleration curve coefficients.

The validation of all the methods and parameters is performed by comparing simulated and real data of the free acceleration response. Moreover this thesis discusses the influence of the Skin Effect in some electrical motor parameters. 


\section{Introdução}

Os motores elétricos em geral, constituem os elementos atuadores mais comuns e utilizados em servosistemas. Neste campo em específico, os motores elétricos de corrente contínua conquistaram praticamente, desde seu surgimento, uma posição de destaque e preferência nas aplicações que exijam velocidade variável e controle de posição.

Entretanto, o avanço e progresso da eletrônica de potência com o desenvolvimento de elementos semicondutores eficientes e de baixo custo, tem permitido a construção de conversores de potência CA apresentando eficiência, flexibilidade e facilidade de operação comparáveis ao retificadores controlados e/ou recortadores usados nos servosistemas $\mathrm{CC}$.

Dessa forma, os motores CA vem ganhando também certo destaque como atuadores em servosistemas, dando origem aos chamados servosistemas CA. Os motores de indução, em particular, os de rotor em gaiola, apresentam vantagens adicionais de custo, além de serem bastante robustos. Aliado às modernas técnicas de controle vetorial, os motores de indução passaram a competir plenamente com os motores CC (VAS, 1994)

Técnicas vetoriais vêm se consolidando como uma ferramenta poderosa e universalmente utilizada na modelagem de motores elétricos $\mathrm{CA}$, quando aplicadas em estruturas de controle de velocidade e posição (BLASCHKE, 1972). Através desta técnica, aliada ao desenvolvimento de microprocessadores e microcontroladores de última geração, tornou-se possível a utilização dos motores de CA em uma vasta gama de aplicações, onde tradicionalmente somente os motores de corrente contínua eram empregados. Na técnica de controle de máquinas $\mathrm{CA}$ em campo orientado - obtido através do emprego de técnicas vetoriais - adota-se como referencial de análise, a direção do fluxo de magnetização do rotor (DE DONKER e NOVOTNY, 1994; GARCIA, STEPHAM e WATANABLE, 1994). A escolha deste referencial permite um desacoplamento entre as grandezas de atuação sobre o fluxo e 
aquelas que atuam sobre o conjugado do MIT. Assim, o controle do fluxo é conseguido através de uma atuação sobre a componente da corrente estatórica em fase com o fluxo, enquanto o conjugado é controlado pela componente da corrente estatórica em quadratura com o fluxo. Desse modo, consegue-se, para um motor CA, um controle semelhante ao utilizado em um motor CC através das correntes de campo e armadura.

Para se conseguir um controle eficiente, através da técnica em campo orientado, é necessário um conhecimento preciso dos parâmetros da máquina a ser controlada. Existem diversos métodos que podem ser empregados na identificação dos parâmetros de um motor de indução. Os métodos clássicos utilizando ensaios em vazio e com rotor bloqueado são procedimentos baseados em ensaios complicados, demorados, e que, geralmente utilizam equipamentos sofisticados e caros, dificilmente transportáveis para o campo ou disponíveis nas fábricas e laboratórios de ensino. RUPPERT FILHO e ALMEIDA (1994) propõem um método alternativo, baseado nos métodos clássicos de identificação, onde se determinam os parâmetros do circuito equivalente do motor, através da geração de valores pseudo-aleatórios e solução simultânea das equações de seu circuito equivalente para vários pontos de operação. ATKINSON, ACARNLEY e FINCH (1991) utilizam técnicas de filtro de Kalman para a estimação paramétrica de um motor de indução. MOON e KEYANE (1994), através da análise transitória da corrente de estator, resultante da aplicação de um degrau de tensão CC, utilizam técnicas de filtro de Kalman e o método máximo de likelihood para a identificação paramétrica. Para a validação do modelo utilizado, é realizado um ensaio degrau, um ensaio de resposta em frequência e um ensaio de partida do motor. AGUIAR (1994) excita o motor com um degrau CC somente em uma das fases de estator, utilizando o método dos mínimos quadrados como algoritmo de identificação. Existem também procedimentos gráficos, como o apresentado por HEIDRICH (1991), e métodos de identificação baseados no balanço de potência reativa do sistema, para diferentes valores de regime estacionário (BEIERKE, 1992). GOLDEMBERG (1992), propõe uma metodologia de idenfificação, baseada nas especificações técnicas fornecida pelos fabricantes de motores. 
O objetivo deste trabalho é o de reconhecer e identificar os parâmetros elétricos e mecânicos de um motor de indução trifásico (MIT) comum, através da análise da resposta transitória a uma entrada degrau e da análise da curva de decaimento da velocidade do mesmo. Para isso é então desenvolvida uma metodologia que possibilita estimar os parâmetros rapidamente, utilizando um microcomputador para aquisição dos dados e um programa que contém os algoritmos para o processamento destes dados e identificação dos parâmetros. Como citado, a estimação dos parâmetros é efetuada basicamente a partir de dois ensaios: inicialmente, um degrau de tensão é aplicado nas três fases do enrolamento de estator do motor para a estimação dos parâmetros elétricos do mesmo. Para os parâmetros mecânicos, mede-se a curva de decaimento da velocidade, a partir do desligamento da máquina em regime permanente e estimam-se os parâmetros mecânicos do motor. Apesar de clássico, o procedimento de estimação dos parâmetros mecânicos emprega técnicas digitais para aquisição da velocidade e um algoritmo computacional para a obtenção destes parâmetros.

O trabalho foi organizado iniciando-se com uma discussão sobre a análise vetorial no capítulo 2 e modelagem do MIT. Neste capítulo, destacam-se os principais parâmetros de um motor de indução trifásico, necessários para se efetuar um projeto eficaz de controle e acionamento do mesmo.

No capítulo 3, desenvolve-se a modelagem matemática do motor de indução trifásico para estimação de seus parâmetros elétricos e mecânicos. Assim, para a identificação dos parâmetros elétricos, chega-se ao modelo do MIT e à sua função de transferência discreta, quando excitado por um degrau de tensão CC nas três fases do enrolamento de estator. Para a identificação dos parâmetros mecânicos obtém-se a equação matemática que rege o decaimento da velocidade do motor de indução. No capítulo 4 faz-se uma revisão das metodologias empregadas para a estimação destes parâmetros com a apresentação de alguns algoritmos de estimação. No capítulo 5 são apresentados alguns resultados da etapa de simulação utilizando o pacote gráfico do MATLAB. Para isso, é utilizado um MIT com parâmetros elétricos e mecânicos conhecidos com o objetivo de se investigar a eficiência dos algoritmos de estimação propostos no capítulo 4. No capítulo 6, discutem-se os equipamentos e 
procedimentos utilizados para uma possível implementação e automatização dos ensaios propostos neste trabalho. No capítulo 7 são apresentados os resultados experimentais da estimação paramétrica de um MIT com parâmetros elétricos e mecânicos desconhecidos. Também é efetuada uma análise comparativa entre os resultados experimentais obtidos e os resultados provenientes de simulação utilizando os parâmetros estimados. Neste mesmo capítulo, são apresentadas as curvas real e simulada do ensaio de partida do motor, onde se discute a influência do Efeito Pelicular para a validação completa dos modelos empregados neste estudo, uma vez que, neste tipo de ensaio, todos os parâmetros (elétricos e mecânicos) do motor estão envolvidos.

Finalmente, no apêndice A são fornecidos os resultados dos ensaios clássicos com rotor bloqueado e em vazio do MIT utilizado neste trabalho para efeito comparativo entre os algoritmos de estimação aqui propostos . 


\section{Modelagem Vetorial do Motor de Indução Trifásico}

\subsection{Notação Vetorial}

O motor de indução trifásico é constituído de dois enrolamentos. O primeiro, trifásico, está localizado no estator e é alimentado por tensões trifásicas. O segundo, no caso sob análise, está localizado no rotor e é a "gaiola de esquilo", ao qual não há acesso elétrico. Assim, uma visão espacial do comportamento do mesmo e da contribuição total de cada componente de fase, pode resultar em uma análise extremamente complexa. Desde que o interesse principal no estudo do MIT é a interação entre as correntes e fluxo do motor, responsáveis pela geração de conjugado, é desejável representar estas grandezas em um sistema que permita englobar as contribuições de cada fase.

A notação vetorial permite representar em um único plano complexo, a contribuição de cada fase do motor na geração de seus fluxos, correntes e tensões. Estas grandezas, representadas neste plano complexo, são então descritas pela composição de uma parte real e outra imaginária

Deste modo pode-se, por exemplo, definir a tensão do estator como uma resultante das contribuições das tensões de cada fase (LEONHARD,1990):

$$
\begin{aligned}
\vec{u}_{s}(t) & =u_{s A}+j u_{s B} \\
& =u_{s a}(t)+u_{s b}(t) e^{j \gamma}+u_{s c}(t) e^{j 2 \gamma} \\
& =u_{s}(t) e^{j s(t)}
\end{aligned}
$$

com:

$$
\gamma=\frac{2 \pi}{3}
$$


Na eq. (2.1), a fase "a" do sistema trifásico coincide com o eixo real do sistema complexo e os operadores complexos $\mathrm{e}^{\mathrm{j} \gamma}, \mathrm{e}^{\mathrm{j} 2 \gamma}$ indicam a direção espacial das tensões nas fases "b"e "c" respectivamente.

A fig.(2.1) mostra o vetor tensão complexo resultante $\overrightarrow{\mathrm{u}}_{\mathrm{s}}(\mathrm{t})$ como uma composição dos vetores das fases "a", "b" e "c" do estator, em um instante particular em que $u_{s b}<0$ e $u_{s c}<0$.

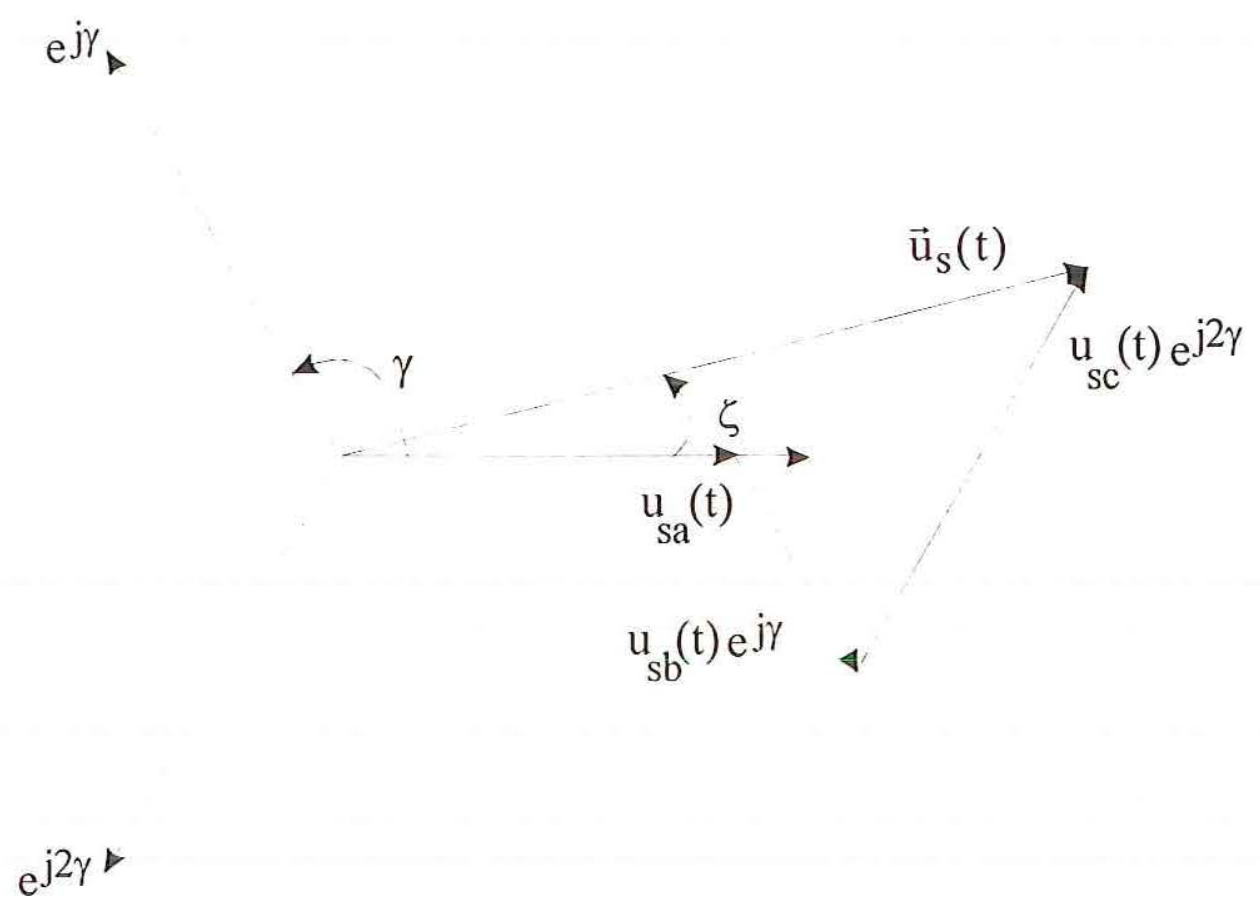

Figura 2.1 - Vetor tensão complexo.

Considerando agora que as tensões são do tipo senoidal com uma frequência angular $\omega_{\mathrm{s}}$ e amplitude $\mathrm{U}$ e que o ponto de neutro não esteja conectado tem-se: 


$$
\begin{aligned}
& u_{s a}(t)=U \cos \left((1)_{s} t\right) \\
& u_{s b}(t)=U \cos \left(\left(\omega_{s} t-\frac{2 \pi}{3}\right)\right. \\
& u_{s c}(t)=U \cos \left(\omega_{s} t-\frac{4 \pi}{3}\right)
\end{aligned}
$$

e introduzindo-se as eqs.(2.2) na definição do vetor tensão complexo, (eq.(2.1)), chega-se ao seguinte resultado:

$$
\vec{u}_{s}(t)=u_{s a}(t)+u_{s b}(t) e^{j \gamma}+u_{s c}(t) e^{j 2 \gamma}=\frac{3}{2} U e^{j \omega} s^{t}
$$

A eq.(2.3) representa que o vetor de espaço tensão gira em torno da origem do plano complexo com velocidade angular e amplitude constantes. O vetor tensão resultante mostrado na fig.(2.1) e representado pela eq.(2.3) está em um referencial fixo no estator. Existem porém, outros referenciais que poderão ser adotados. Esses referenciais serão discutidos posteriormente no decorrer deste capítulo.

Para obter-se as grandezas de fase a partir da notação vetorial basta projetar o vetor de espaço nos eixos do sistema trifásico. Assim tem-se:

$$
\begin{aligned}
& \mathrm{u}_{\mathrm{sa}}(\mathrm{t})=\frac{2}{3} \operatorname{Re}\left\{\overrightarrow{\mathrm{u}}_{\mathrm{s}}\right\}=\frac{2}{3} \mathrm{u}_{\mathrm{sA}}(\mathrm{t}) \\
& \mathrm{u}_{\mathrm{sb}}(\mathrm{t})=\frac{2}{3} \operatorname{Re}\left\{\overrightarrow{\mathrm{u}}_{\mathrm{s}}(\mathrm{t}) \mathrm{e}^{-\mathrm{j} \frac{2 \pi}{3}}\right\}=\frac{2}{3}\left(-\frac{1}{2} \mathrm{u}_{\mathrm{sA}}(\mathrm{t})+\frac{\sqrt{3}}{2} \mathrm{u}_{\mathrm{sB}}(\mathrm{t})\right) \\
& u_{s c}(t)=\frac{2}{3} \operatorname{Re}\left\{\vec{u}_{s}(t) e^{-j \frac{4 \pi}{3}}\right\}=\frac{2}{3}\left(-\frac{1}{2} u_{s A}(t)-\frac{\sqrt{3}}{2} u_{s B}(t)\right)
\end{aligned}
$$


O fator de correção $\frac{2}{3}$ introduzido nas eqs.(2.4) objetiva normalizar o vetor tensão resultante dado pela eq.(2.3), que apresenta uma amplitude $\frac{3}{2}$ vezes maior que as de fase.

Podem-se destacar as seguintes vantagens em se utilizar uma notação vetorial para a análise de um motor de indução trifásico (BLASCHKE,1972 ):

- Devido à representação vetorial, o vetor de corrente e o vetor fluxo proporcionam uma característica fisicamente espacial;

- O conjugado elétrico produzido no motor de indução trifásico tem uma representação visual, uma vez que o mesmo é proporcional à magnitude dos vetores de corrente de estator e rotor e do seno do ângulo entre eles.

- A notação vetorial permite a análise do motor, quando excitado por conversores, uma vez que as grandezas vetoriais podem ser usadas para quaisquer frequências e comportamento temporal das grandezas de fase.

- As variações na amplitude e/ou frequência das grandezas de fase são representadas na notação vetorial respectivamente por variações na amplitude e/ou velocidade angular do vetor de espaço;

- Podem-se representar deslocamentos de fase de diferentes grandezas através de deslocamentos angulares dos correspondentes vetores de espaço.

\subsection{O Motor de Indução Trifásico na Notação Vetorial}

O motor de indução trifásico, com rotor em gaiola, pode ser representado através da fig.(2.2), onde os enrolamentos de estator e de rotor estão defasados de $\frac{2 \pi}{3}$ radianos elétricos entre si: 


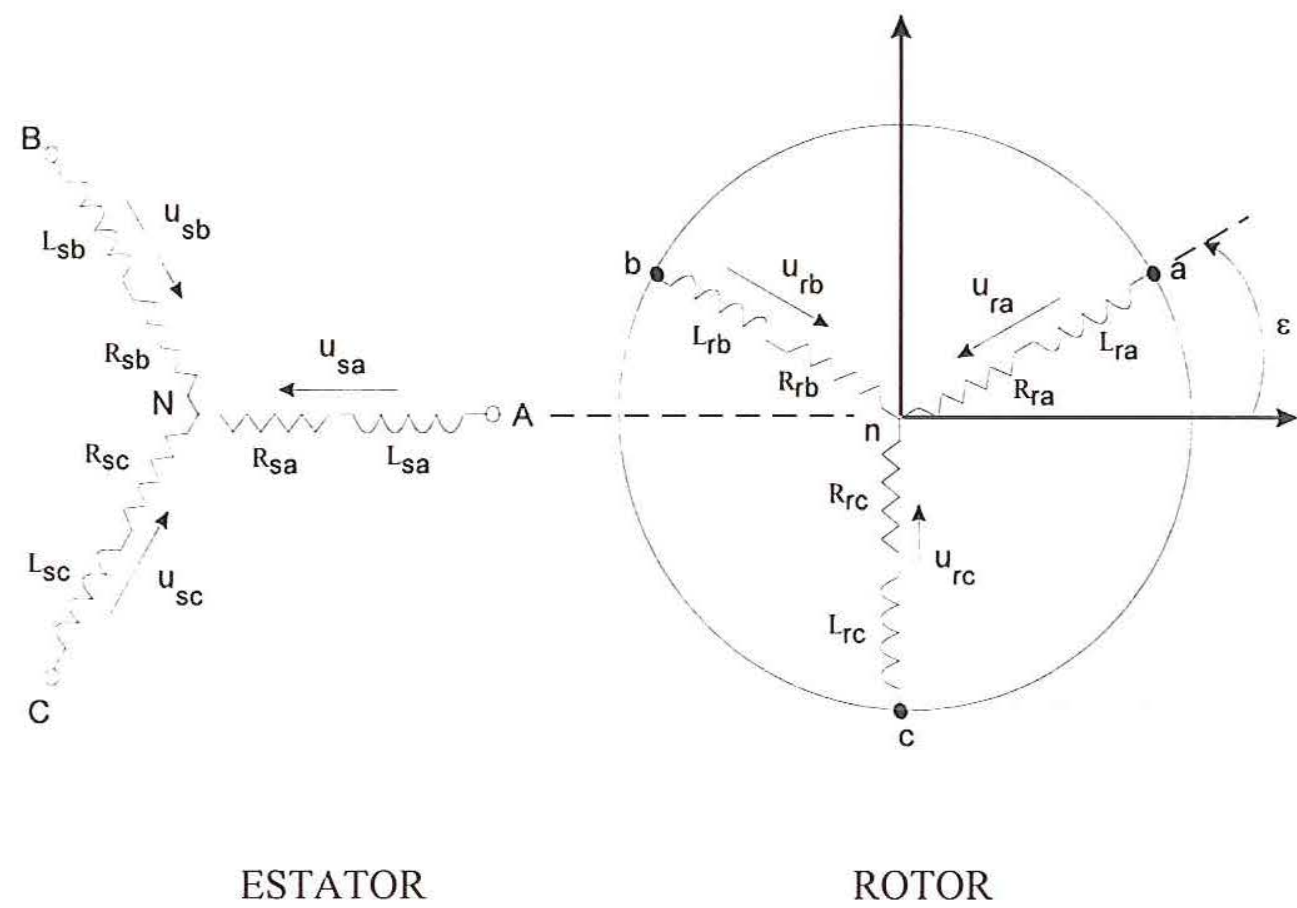

Figura 2.2 - Representação do motor de indução trifásico de dois pólos com rotor em gaiola.

onde:

$\mathrm{R}_{\mathrm{sa}}, \mathrm{R}_{\mathrm{sb}}, \mathrm{R}_{\mathrm{sc}}=$ Resistência dos enrolamentos de estator das fases $\mathrm{A}$, $\mathrm{B}$ e $\mathrm{C}$ respectivamente;

$R_{r a}, R_{r b}, R_{r c}=$ Resistência dos enrolamentos de rotor das fases $a, b$ e c respectivamente;

$\mathrm{L}_{\mathrm{sa}}, \mathrm{L}_{\mathrm{sb}}, \mathrm{L}_{\mathrm{sc}}=$ Indutância total de estator das fases $\mathrm{a}, \mathrm{b}$ e c respectivamente;

$$
\mathrm{L}_{\mathrm{ra}}, \mathrm{L}_{\mathrm{rb}}, \mathrm{L}_{\mathrm{rc}}=\text { Indutância total de rotor das fases } \mathrm{a}, \mathrm{b} \text { e c }
$$
respectivamente;

Nesta figura, assim como na literatura clássica de máquinas elétricas de CA, são adotadas certas considerações de simetria com relação ao aspecto construtivo do motor. A fase "a" do rotor possui um deslocamento angular $\varepsilon$ em relação ao enrolamento " $\mathrm{A}$ " do estator. As indutâncias e as resistências dos enrolamentos do 
rotor e estator são consideradas iguais. O motor é considerado magneticamente linear, não é considerado a influência do Efeito Pelicular e as perdas no ferro são desprezíveis. As fases de estator e rotor são conectados em Y de modo que a soma das correntes instantâneas de estator e rotor é nula para qualquer instante de tempo, ou seja:

$$
\begin{aligned}
& i_{s a}(t)+i_{s b}(t)+i_{s c}(t)=0 \\
& i_{r a}(t)+i_{r b}(t)+i_{r c}(t)=0
\end{aligned}
$$

Tomando as considerações de simetria descritas no parágrafo anterior, definese conforme fig.(2.2) que:

$$
\begin{aligned}
& \mathrm{R}_{\mathrm{sa}}=\mathrm{R}_{\mathrm{sb}}=\mathrm{R}_{\mathrm{sc}}=\mathrm{R}_{\mathrm{s}} \\
& \mathrm{R}_{\mathrm{ra}}=\mathrm{R}_{\mathrm{rb}}=\mathrm{R}_{\mathrm{rc}}=\mathrm{R}_{\mathrm{r}} \\
& \mathrm{L}_{\mathrm{sa}}=\mathrm{L}_{\mathrm{sb}}=\mathrm{L}_{\mathrm{sc}}=\left(\mathrm{l}_{\mathrm{s}}+\mathrm{l}_{\sigma \mathrm{s}}\right) \\
& \mathrm{L}_{\mathrm{ra}}=\mathrm{L}_{\mathrm{rb}}=\mathrm{L}_{\mathrm{rc}}=\left(\mathrm{l}_{\mathrm{r}}+\mathrm{l}_{\sigma \mathrm{r}}\right)
\end{aligned}
$$

com:

$$
\begin{aligned}
& 1_{S}, 1_{r}=\text { Indutância própria de estator e rotor respectivamente; } \\
& 1_{\sigma s}, l_{\sigma r}=\text { Indutância de dispersão de estator e rotor respectivamente; }
\end{aligned}
$$

Estendendo a definição de vetor de espaço (eq.(2.1)) para o fluxo concatenado total de estator tem-se:

$$
\vec{\psi}_{s}(t)=\psi_{s a}(t)+\psi_{s b}(t) e^{j \gamma}+\psi_{s c}(t) e^{j 2 \gamma}
$$

onde:

$$
\psi_{\mathrm{sa}}, \psi_{\mathrm{sb}}, \psi_{\mathrm{sc}}=\text { Fluxos nas fases } \mathrm{A}, \mathrm{B} \text { e C de estator respectivamente }
$$


O fluxo concatenado resultante por fase de estator é o resultado das contribuições dos fluxos das fases de estator e das mútuas entre estator e rotor. Desse modo, pode-se escrever, baseado na fig.(2.2), que:

$$
\begin{aligned}
\psi_{s a}(t)= & \left(l_{s}+1_{\sigma s}\right) i_{s a}(t)+1_{s} \cos \left(\frac{2 \pi}{3}\right) i_{s b}(t)+1_{s} \cos \left(-\frac{2 \pi}{3}\right) i_{s c}(t)+m i_{r a}(t) \cos (\varepsilon(t))+ \\
& m \cos \left(\frac{2 \pi}{3}+\varepsilon(t)\right) i_{r b}(t)+m \cos \left(-\frac{2 \pi}{3}+\varepsilon(t)\right) i_{r c}(t)
\end{aligned}
$$

com $\mathrm{m}$ = indutância mútua entre estator e rotor

Do mesmo modo, podem-se conseguir expressões análogas a eq.(2.8) para as fases "B" e "C" de estator. Substituindo a eq.(2.8), e as expressões obtidas de forma análoga para as fases "B" e "C", na eq.(2.7), chega-se após algumas passagens matemáticas ao seguinte resultado:

$$
\vec{\psi}_{s}(t)=\left(\frac{3}{2} \mathrm{l}_{s}+\mathrm{l}_{\sigma s}\right) \overrightarrow{\mathrm{i}}_{\mathrm{s}}(\mathrm{t})+\left(\frac{3}{2} \mathrm{~m}\right) \overrightarrow{\mathrm{i}}_{\mathrm{r}}(\mathrm{t}) \mathrm{e}^{\mathrm{j} \varepsilon(\mathrm{t})}
$$

onde :

$$
\vec{i}_{s}(t)=i_{s a}(t)+i_{s b}(t) e^{j \gamma}+i_{s c}(t) e^{j 2 \gamma}
$$

e

$$
\overrightarrow{\mathrm{i}}_{\mathrm{r}}(\mathrm{t})=\mathrm{i}_{\mathrm{ra}}(\mathrm{t})+\mathrm{i}_{r b}(\mathrm{t}) \mathrm{e}^{\mathrm{j} \gamma}+\mathrm{i}_{r c}(\mathrm{t}) \mathrm{e}^{\mathrm{j} 2 \gamma}
$$

são os vetores de espaço corrente de estator e rotor respectivamente. Procedendo de maneira análoga para o rotor tem-se:

$$
\vec{\psi}_{\mathrm{r}}(\mathrm{t})=\left(\frac{3}{2} 1_{s}+1_{\sigma s}\right) \overrightarrow{\mathrm{i}}_{\mathrm{r}}(\mathrm{t})+\left(\frac{3}{2} \mathrm{~m}\right) \overrightarrow{\mathrm{i}}_{\mathrm{s}}(\mathrm{t}) \mathrm{e}^{-\mathrm{j} \varepsilon(\mathrm{t})}
$$


O termo $\mathrm{e}^{\mathrm{j} \varepsilon(1)}$ da eq.(2.9) e $\mathrm{e}^{-\mathrm{j} \varepsilon(t)}$ da eq.(2.11) indicam que as grandezas estão em referenciais distintos, respectivamente ao estator e ao rotor. A partir das eq.(2.9) e (2.11), define-se: (LEONHARD, 1990):

$$
\mathrm{L}_{\mathrm{s}}=\left(\mathrm{L}_{0}+\mathrm{l}_{\sigma \mathrm{s}}\right)=\mathrm{L}_{0}\left(1+\sigma_{\mathrm{s}}\right)=\text { Indutância de estator no sistema }
$$

ortogonal;

$$
\mathrm{L}_{\mathrm{r}}=\left(\mathrm{L}_{0}+\mathrm{l}_{\sigma \mathrm{r}}\right)=\mathrm{L}_{0}\left(1+\sigma_{\mathrm{r}}\right)=\text { Indutância de rotor no sistema }
$$

ortogonal;

$$
\begin{aligned}
& \sigma_{\mathrm{S}}, \sigma_{\mathrm{r}}=\text { Fator de dispersão de estator e rotor respectivamente; } \\
& \mathrm{L}_{0}=\frac{3}{2} \mathrm{~m}=\frac{3}{2} \mathrm{l}_{\mathrm{s}}=\frac{3}{2} \mathrm{l}_{\mathrm{r}}=\text { Indutância mútua entre enrolamentos de }
\end{aligned}
$$

estator e rotor no sistema ortogonal;

Reescrevendo as eqs.(2.9) e (2.11) em termos das definições acima tem-se:

$$
\begin{aligned}
& \vec{\psi}_{s}(t)=L_{s} \vec{i}_{s}(t)+L_{0} \vec{i}_{r}(t) e^{j \varepsilon(t)} \\
& \vec{\psi}_{r}(t)=L_{r} \vec{i}_{r}(t)+L_{0} \vec{i}_{s}(t) e^{-j \varepsilon(t)}
\end{aligned}
$$

Através da fig.(2.2), podem-se relacionar as tensões de cada fase de estator da seguinte forma:

$$
\begin{aligned}
& \mathrm{R}_{\mathrm{s}} \mathrm{i}_{\mathrm{sa}}(\mathrm{t})+\frac{\mathrm{d}}{\mathrm{dt}} \psi_{s a}(\mathrm{t})=\mathrm{u}_{\mathrm{sa}}(\mathrm{t}) \\
& \mathrm{R}_{\mathrm{s}} \mathrm{i}_{\mathrm{sb}}(\mathrm{t})+\frac{\mathrm{d}}{\mathrm{dt}} \psi_{s b}(\mathrm{t})=\mathrm{u}_{\mathrm{sb}}(\mathrm{t}) \\
& \mathrm{R}_{\mathrm{s}} \mathrm{i}_{\mathrm{sc}}(\mathrm{t})+\frac{\mathrm{d}}{\mathrm{dt}} \psi_{s c}(\mathrm{t})=\mathrm{u}_{\mathrm{sc}}(\mathrm{t})
\end{aligned}
$$


Substituindo as eq.(2.14a), (2.14b) e (2.14c) na eq.(2.1), e fazendo uso da eq.(2.7) e da eq.(2.10a) tem-se:

$$
R_{s} \vec{i}_{s}(t)+\frac{d}{d t} \vec{\psi}_{s}(t)=\vec{u}_{s}(t)
$$

Procedendo de maneira análoga para o rotor, considerando as tensões de fase nulas, devido à estrutura em gaiola, chega-se a seguinte expressão:

$$
R_{r} \vec{i}_{r}(t)+\frac{d}{d t} \vec{\psi}_{r}(t)=0
$$

As equações (2.15) e (2.16) descrevem o comportamento eletromagnético do motor de indução em condições de regime permanente bem como de transitório. $\mathrm{O}$ comportamento da máquina é completado pelas equações mecânicas, ou seja, do conjugado elétrico e transientes mecânicos. O conjugado elétrico é definido como a força tangente exercida no enrolamento do rotor devido ao campo magnético produzido pela força contra-eletromotriz do estator.

Pode-se escrever o conjugado elétrico através da equação abaixo (LEONHARD, 1990):

$$
m_{d}(t)=\frac{2}{3} L_{0} \operatorname{Im}\left[\vec{i}_{s}(t)\left(\vec{i}_{r}(t) e^{j \varepsilon(t)}\right)^{*}\right]
$$

Substituindo as eqs.(2.12) e (2.13) nas eqs(2.15) e (2.16) respectivamente, chega-se ao modelo completo do motor de indução como sendo:

$$
\begin{aligned}
& R_{s} \vec{i}_{s}(t)+L_{s} \frac{d}{d t} \vec{i}_{s}(t)+L_{0} \frac{d}{d t}\left(\vec{i}_{r}(t) e^{j \varepsilon(t)}\right)=\vec{u}_{s}(t) \\
& R_{r} \vec{i}_{r}(t)+L_{r} \frac{d}{d t} \vec{i}_{r}(t)+L_{0} \frac{d}{d t}\left(\vec{i}_{s}(t) e^{-j \varepsilon(t)}\right)=0
\end{aligned}
$$




$$
\begin{aligned}
& J \frac{d}{d t} \omega(t)=\frac{2}{3} L_{0} \operatorname{Im}\left[\vec{i}_{s}(t)\left(\vec{i}_{r}(t) e^{j \varepsilon(t)}\right)^{*}\right]-M_{1}(t)-K_{D} \omega(t)-M_{f} \\
& \frac{d}{d t} \varepsilon(t)=\omega(t)
\end{aligned}
$$

com:

$$
\begin{aligned}
& \mathrm{M}_{\mathrm{l}}=\text { Conjugado de carga } \\
& \mathrm{K}_{\mathrm{D}}=\text { Coeficiente de atrito dinâmico do motor } \\
& \mathrm{M}_{\mathrm{f}}=\text { Coeficiente de atrito estático do motor }
\end{aligned}
$$

As eqs.(2.15) e (2.16) podem ser desdobradas em parte real e parte imaginária. Portanto, o MIT é representado por um total de seis equações diferenciais não lineares.

A equação do conjugado, representado por (2.17), descreve a interação entre as correntes do rotor e o fluxo resultante das correntes do estator. Desde que a corrente do rotor em gaiola não pode ser medida, é apropriado substituir o termo $\vec{i}_{r}(t) e^{j \varepsilon(t)}$ por uma outra variável que possa ser obtida através de medições das grandezas do estator.

Assim, define-se uma grandeza auxiliar chamada de vetor corrente de magnetização do rotor, $\overrightarrow{\mathrm{i}}_{\mathrm{mr}}(\mathrm{t})$ (BLASCHKE, 1972). Esta grandeza representa a relação entre o fluxo de magnetização do rotor e a indutância de magnetização (GARCIA e WATANABE,1994) :

$$
\vec{\psi}_{r}(t)=L_{0} \vec{i}_{m r}(t)
$$

onde define-se (LEONHARD,1990):

$$
\overrightarrow{\mathrm{i}}_{m r}(t)=\overrightarrow{\mathrm{i}}_{\mathrm{s}}(\mathrm{t})+\left(1+\sigma_{\mathrm{r}}\right) \overrightarrow{\mathrm{i}}_{\mathrm{r}}(\mathrm{t}) \mathrm{e}^{\mathrm{j \varepsilon (t)}}=\mathrm{i}_{m r}(\mathrm{t}) \mathrm{e}^{\mathrm{j} \rho(\mathrm{t})}
$$


Reescrevendo a eq.(2.17) em termos da definição acima tem-se:

$$
J \frac{d}{d t} \omega(t)=K_{w} \operatorname{Im}\left[\vec{i}_{s}(t) \vec{i}_{m r}^{*}(t)\right]=m_{d}(t)-K_{D} \omega(t)-M_{f}-M_{l}(t)
$$

onde:

$$
\mathrm{K}_{\mathrm{w}}=\frac{2}{3} \frac{\mathrm{L}_{0}}{1+\sigma_{\mathrm{r}}}
$$

As equações relacionadas em (2.18) e (2.19) estão referidas a diferentes referenciais, parte ao referencial de estator e parte ao de rotor. Para uma melhor análise destas equações torna-se necessário projetá-las em um referencial único e comum para as grandezas de estator e rotor. Existem entretanto vários referenciais (LEONHARD, 1990), que poderão ser adotados tais como os indicados na fig.(2.3) e esclarecidos na sequência:

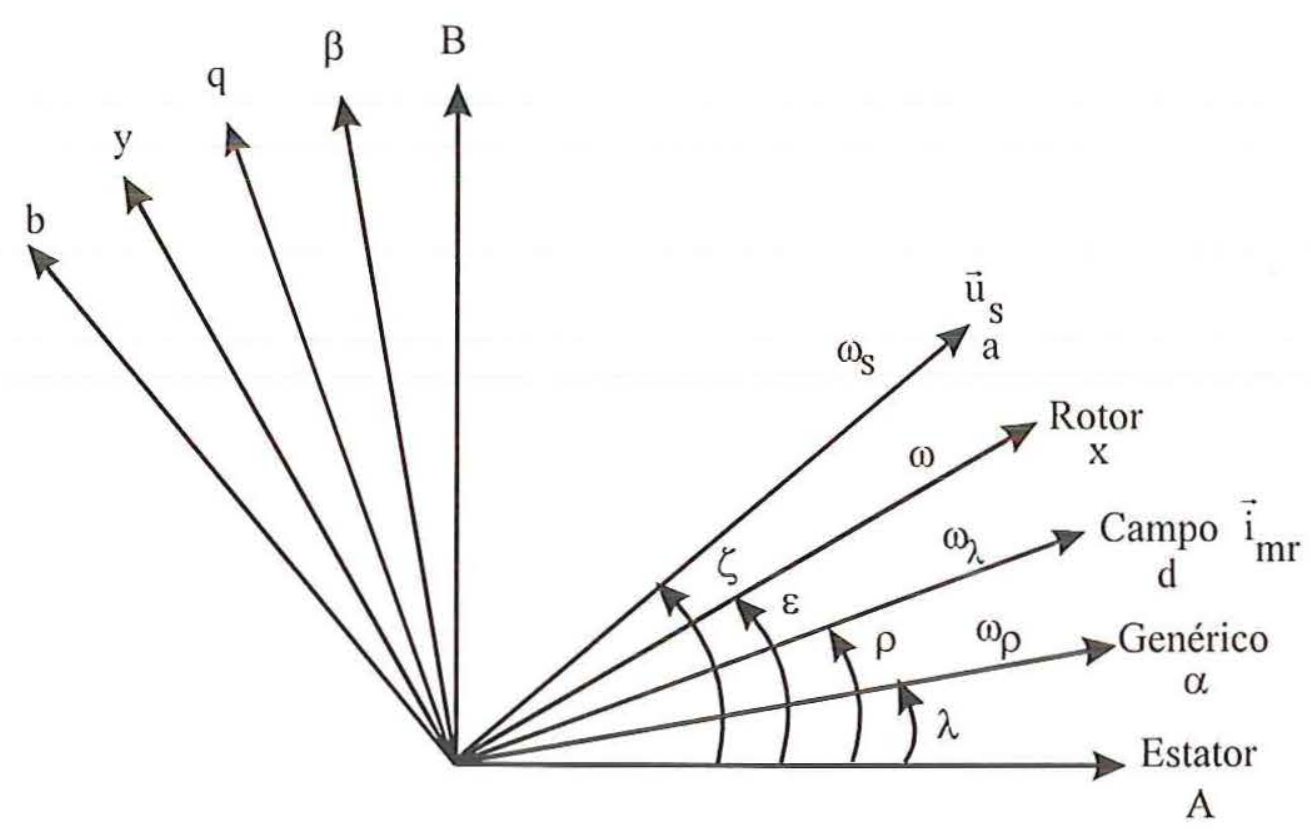

Figura 2.3 - Plano Complexo e referenciais arbitrários. 
O sistema de coordenadas A-B, é um referencial fixo no estator o qual é tomado como base para a análise e definição dos demais. O referencial vetor tensão do estator $\overrightarrow{\mathrm{u}}_{\mathrm{s}}(\mathrm{t})$ ( com sistema de coordenadas $\mathrm{a}-\mathrm{b}$ ) gira com a velocidade angular $\frac{d}{d t} \zeta(t)=\omega_{s}(t)$ em relação ao sistema de coordenadas A-B. O referencial adotado no rotor, com sistema de coordenadas $x-y$, gira com a velocidade angular $\frac{d}{d t} \varepsilon(t)=\omega(t)$. O referencial de campo, com o eixo real adotado sobre o vetor corrente de magnetização do rotor (com sistema de coordenadas $d$-q), gira com velocidade angular $\frac{\mathrm{d}}{\mathrm{dt}} \rho(\mathrm{t})=\omega_{\mathrm{mr}}(\mathrm{t})$ em relação ao sistema A-B. O referencial genérico é considerado um referencial qualquer, com deslocamento angular $\lambda$ em relação ao estator e velocidade angular $\omega_{\lambda}(t)$. Pode ser qualquer um dos demais referenciais mostrados bastando para isso igualar o ângulo $\lambda$ ao ângulo do referencial desejado.

De uma maneira geral, ao se mudar para um determinado referencial, basta projetar as grandezas envolvidas no estator e no rotor para esse referencial multiplicando-as pelo fator $\mathrm{e}^{-\mathrm{j}(\text { ângulo referencial desejado) }}$.

\subsection{Modelagem do MIT em um Referencial Genérico}

Conforme descrito anteriormente, para se representar as grandezas do MIT no referencial genérico é necessário multiplicá-las por $\mathrm{e}^{-\mathrm{j} \lambda(\mathrm{t})}$ :

$$
\begin{aligned}
& \vec{i}_{s}(t) e^{-j \lambda(t)}=i_{s \alpha}(t)+j i_{s \beta}(t) \\
& \vec{u}_{s}(t) e^{-j \lambda(t)}=u_{s \alpha}(t)+j u_{s \beta}(t) \\
& \vec{i}_{m r}(t) e^{-j \lambda(t)}=i_{m r \alpha}(t)+j i_{m r \beta}(t)
\end{aligned}
$$

Substituindo a eq.(2.23), que relaciona $\overrightarrow{\mathrm{i}}_{\mathrm{r}}(\mathrm{t})$ com $\overrightarrow{\mathrm{i}}_{\mathrm{mr}}(\mathrm{t})$ na eq.(2.18), dividindo os seus termos por $R_{s}$ e multiplicando o resultado por $\mathrm{e}^{-\mathrm{j} \lambda(t)}$ para mudança de referencial, após algumas operações matemáticas, chega-se à seguinte expressão: 
$\frac{\vec{u}_{s}(t)}{R_{s}} e^{-j \lambda(t)}=\vec{i}_{s}(t) e^{-j \lambda(t)}+T_{s} \sigma \frac{d}{d t} \vec{i}_{s}(t) e^{-j \lambda(t)}+T_{s}(1-\sigma) \frac{d}{d t}\left(\vec{i}_{m r}(t)\right) e^{-j \lambda(t)}$

onde :

$$
\begin{aligned}
& T_{S}=\frac{L_{s}}{R_{S}}=\text { Constante de tempo do estator; } \\
& \sigma=1-\frac{1}{\left(1+\sigma_{s}\right)\left(1+\sigma_{r}\right)}=\text { Fator de dispersão global do motor }
\end{aligned}
$$

Dividindo a eq.(2.28) em parte real e parte imaginária e utilizando as eq.(2.25) à eq.(2.27) tem-se:

$$
\begin{gathered}
\frac{d}{d t} i_{s \alpha}(t)=\frac{1}{L_{s} \sigma} u_{s \alpha}(t)-\frac{i_{s \alpha}(t)}{T_{s} \sigma}-\frac{(1-\sigma)}{\sigma} \frac{d}{d t} i_{m r \alpha}(t)+ \\
\omega_{\lambda}(t)\left(i_{s \beta}(t)+\frac{(1-\sigma)}{\sigma} i_{m r \beta}(t)\right) \\
\frac{d}{d t} i_{s \beta}(t)=\frac{1}{L_{s} \sigma} u_{s \beta}(t)-\frac{i_{s \beta}(t)}{T_{s} \sigma}-\frac{(1-\sigma)}{\sigma} \frac{d}{d t} i_{m r \beta}(t)- \\
\omega_{\lambda}(t)\left(i_{s \alpha}(t)+\frac{(1-\sigma)}{\sigma} i_{m r \alpha}(t)\right)
\end{gathered}
$$

onde:

$\omega_{\lambda}=$ Velocidade angular do referencial genérico

Procedendo de maneira análoga para o rotor utilizando a eq.(2.19) tem-se: 


$$
T_{r} \frac{d}{d t} \vec{i}_{m r}(t) e^{-j \lambda(t)}+\left(1-j \omega(t) T_{r}\right) \vec{i}_{m r}(t) e^{-j \lambda(t)}=\vec{i}_{s}(t) e^{-j \lambda(t)}
$$

onde: $T_{r}=\frac{L_{r}}{R_{r}}=$ Constante de Tempo do rotor.

Dividindo a eq.(2.31) em parte real e parte imaginária e utilizando novamente as eq.(2.25) à eq.(2.27) chega-se às seguintes expressões:

$$
\begin{aligned}
& \frac{d}{d t} i_{m r \alpha}(t)=\frac{i_{s \alpha}(t)}{T_{r}}-\frac{i_{m r \alpha}(t)}{T_{r}}+i_{m r \beta}(t)\left(\omega_{\lambda}(t)-\omega(t)\right) \\
& \frac{d}{d t} i_{m r \beta}(t)=\frac{i_{s \beta}(t)}{T_{r}}-\frac{i_{m r \beta}(t)}{T_{r}}-i_{m r \alpha}(t)\left(\omega_{\lambda}(t)-\omega(t)\right)
\end{aligned}
$$

Retomando a eq.(2.24) que representa o conjugado elétrico do MIT e desenvolvendo o termo imaginário chega-se à seguinte expressão:

$$
\begin{aligned}
& m_{d}(t)=K_{w}\left[i_{s \alpha}(t) i_{m r \beta}(t)-i_{s \beta}(t) i_{m r \alpha}(t)\right] \\
& J \frac{d}{d t} \omega(t)=m_{d}(t)-K_{D}(1)(t)-M_{l}(t)-M_{f}
\end{aligned}
$$

Resumindo, pode-se representar o modelo completo do motor de indução no sistema de coordenadas genérico através do seguinte conjunto de equações diferenciais: 


$$
\begin{aligned}
& \frac{d}{d t} i_{s \alpha}(t)=\frac{1}{L_{s} \sigma} u_{s \alpha}(t)-\frac{i_{s \alpha}(t)}{T_{s} \sigma}-\frac{(1-\sigma)}{\sigma} \frac{d}{d t} i_{m r \alpha}(t)+ \\
& \omega_{\lambda}(t)\left(i_{s \beta}(t)+\frac{(1-\sigma)}{\sigma} i_{m r \beta}(t)\right) \\
& \frac{d}{d t} i_{s \beta}(t)=\frac{1}{L_{s} \sigma} u_{s \beta}(t)-\frac{i_{s \beta}(t)}{T_{s} \sigma}-\frac{(1-\sigma)}{\sigma} \frac{d}{d t} i_{m r \beta}(t)- \\
& \omega)_{\lambda}(t)\left(i_{s \alpha}(t)+\frac{(1-\sigma)}{\sigma} i_{m r \alpha}(t)\right) \\
& \frac{d}{d t} i_{m r \alpha}(t)=\frac{i_{s \alpha}(t)}{T_{r}}-\frac{i_{m r \alpha}(t)}{T_{r}}+i_{m r \beta}(t)\left[\omega \lambda_{\lambda}(t)-\omega(t)\right] \\
& \frac{d}{d t} i_{m r \beta}(t)=\frac{i_{s \beta}(t)}{T_{r}}-\frac{i_{m r \beta}(t)}{T_{r}}-i_{m r \alpha}(t)[\omega \lambda(t)-\omega(t)] \\
& m_{w}\left[i_{s \alpha}(t) i_{m r \beta}(t)-i_{s \beta}(t) i_{m r \alpha}(t)\right]
\end{aligned}
$$

As eqs.(2.36) à eq.(2.41) descrevem um sistema não linear de $6^{\underline{a}}$ ordem para representação completa do MIT. Dependendo da escolha do referencial $\lambda$, pode-se reduzir a ordem do sistema, simplificando a análise do MIT. Com a escolha do referencial de campo (sistema de coordenadas d-q), consegue-se um modelo mais linear para o MIT e um desacoplamento entre as grandezas de atuação sobre o fluxo e conjugado do mesmo. 


\subsection{Modelagem do MIT no Referencial de Campo}

Uma das estratégias de controle muito utilizada atualmente, é a que emprega o referencial de campo (sistema de coordenadas d-q) (LEONHARD, 1990). Neste sistema de coordenadas complexo, os eixos são escolhidos, de forma que o eixo real tenha a mesma direção do vetor de espaço da corrente de magnetização do rotor $\overrightarrow{\mathrm{i}}_{\mathrm{mr}}(\mathrm{t})$, ou seja, o termo imaginário que envolve esta corrente é nulo. Portanto, neste referencial, omite-se os índices d-q das componentes real e imaginária do vetor $\vec{i}_{m r}(t)$, passando a representá-lo apenas por $i_{m r}(t)$. Como será evidenciado a seguir, com a escolha deste referencial, cơnsegue-se simplificações nas equações que descrevem o modelo do MIT. Para se obter as equações do MIT no referencial de campo basta substituir o ângulo $\lambda$ pelo ângulo $\rho$ fazendo as seguintes considerações nas eqs.(2.36)-(2.40):

$$
\begin{aligned}
& i_{s \alpha}(t)=i_{s d}(t) \\
& i_{s \beta}(t)=i_{s q}(t) \\
& i_{m r \alpha}(t)=i_{m r}(t) \\
& i_{m r \beta}(t)=0 \\
& \omega_{\lambda}(t)=\omega_{m r}(t)
\end{aligned}
$$

O modelo completo do MIT no referencial de campo fica então representado pelo seguinte conjunto de equações diferenciais:

$$
\frac{d}{d t} i_{s d}(t)=\frac{1}{L_{s} \sigma} u_{s d}(t)-\frac{i_{s d}(t)}{T_{s} \sigma}-\frac{(1-\sigma)}{\sigma} \frac{d}{d t} i_{m r}(t)+\omega_{m r}(t) i_{s q}(t)
$$




$$
\begin{aligned}
& \frac{d}{d t} i_{s q}(t)=\frac{1}{L_{s} \sigma} u_{s q}(t)-\frac{i_{s q}(t)}{T_{s} \sigma}-\frac{(1-\sigma)}{\sigma} \omega_{m r}(t) i_{m r}(t) \\
& \quad-(1)_{m r}(t) i_{s d}(t) \\
& \frac{d}{d t} i_{m r}(t)=\frac{i_{s d}(t)}{T_{r}}-\frac{i_{m r}(t)}{T_{r}} \\
& \left.i_{s q}(t)=T_{r} i_{m r \alpha}(t)(\omega)_{m r}(t)-\omega(t)\right) \\
& m_{d}(t)=K_{w}\left[i_{m r}(t) i_{s q}(t)\right] \\
& J \frac{d}{d t} \omega(t)=m_{d}(t)-K_{D} \omega(t)-M_{l}(t)-M_{f}
\end{aligned}
$$

Baseados nas equações acima, podem-se destacar as seguintes vantagens em se utilizar o referencial de campo:

- Simplificação do modelo: a parte elétrica do MIT passa a ser descrita por apenas três equações diferenciais ao invés de quatro ( eqs.(2.36) à (2.39) no sistema de coordenadas genérico);

- A equação do conjugado torna-se mais linear uma vez que passa a ser representada por um único produto de grandezas de estado;

- A partir da eq.(2.51), empregando-se estratégias adequadas de controle, pode-se manter o fluxo de rotor constante através de uma atuação sob $\vec{i}_{m r}(t)$. Assim, o conjugado resultante será proporcional somente ao termo $\mathrm{i}_{\mathrm{sq}}(\mathrm{t})$.

As equações (2.47) à eq.(2.52) representam o modelo completo do MIT em campo orientado e evidenciam os principais parâmetros elétricos e mecânicos de um motor de indução trifásico. São eles: 
- $R_{S}=$ Resistência do enrolamento do estator;

- $\mathrm{T}_{\mathrm{S}}=$ Constante de tempo do estator;

- $\mathrm{L}_{\mathrm{s}}=$ Indutância do enrolamento do estator;

$-\mathrm{T}_{\mathrm{r}}=$ Constante de tempo do rotor;

- $\sigma=$ Fator de dispersão global do motor.

- $\mathrm{J}$ = Momento de Inércia do motor

$-K_{D}=$ Coeficiente de atrito dinâmico do motor

$-\mathrm{M}_{\mathrm{f}}=$ Coeficiente de atrito estático do motor

O conhecimento destes parâmetros é de fundamental importância para se fazer o controle ou acionamento de um motor de indução trifásico. Portanto é desejável que o método empregado na determinação destes parâmetros seja eficaz e confiável para que se garanta um comportamento eficiente nos projetos envolvendo esses motores. 


\section{Metodologia de Estimação}

Os parâmetros elétricos e mecânicos a serem identificados são aqueles das eqs.(2.47) à (2.52) discutidas no capítulo 2 .

A metodologia empregada para a estimação dos parâmetros elétricos do motor de indução consiste na aplicação de um degrau de tensão nos enrolamentos de estator da máquina com rotor bloqueado. Em seguida é analisado o comportamento transitório da corrente. Basicamente, através de uma placa de aquisição de dados, os valores de tensão e transitório da corrente são amostrados, para depois serem processados em um programa contendo o algoritmo de estimação apropriado (discutidos no capítulo 4), que fornecerá os valores dos parâmetros elétricos desejados.

Assim sendo, deve ser obtido o modelo matemático para excitação CC do motor de indução trifásico.

Neste capítulo serão apresentados o modelo matemático do motor de indução trifásico alimentado por um degrau de tensão CC nos enrolamentos de estator, as principais equações para se atingir tal modelo e a função de transferência correspondente. O modelo obtido neste capítulo é o utilizado nas simulações e nos testes de laboratório para a estimação dos parâmetros elétricos do motor de indução.

Para a estimação dos parâmetros mecânicos analisa-se a curva de decaimento da velocidade do motor a partir de um determinado estado de regime. Como no caso anterior são amostradas a velocidade e a tensão de ensaio em um placa de aquisição para posterior processamento em um algoritmo de estimação adequado (capítulo 4).

Portando, é apresentado também neste capítulo, o equacionamento matemático da curva que descreve a desaceleração do motor de indução. 


\subsection{Modelagem do Motor de Indução para Excitação CC}

O motor de indução trifásico com rotor em gaiola é representado conforme fig.(2.2) do capítulo 2. Para o ensaio degrau, adotou-se a seguinte configuração:
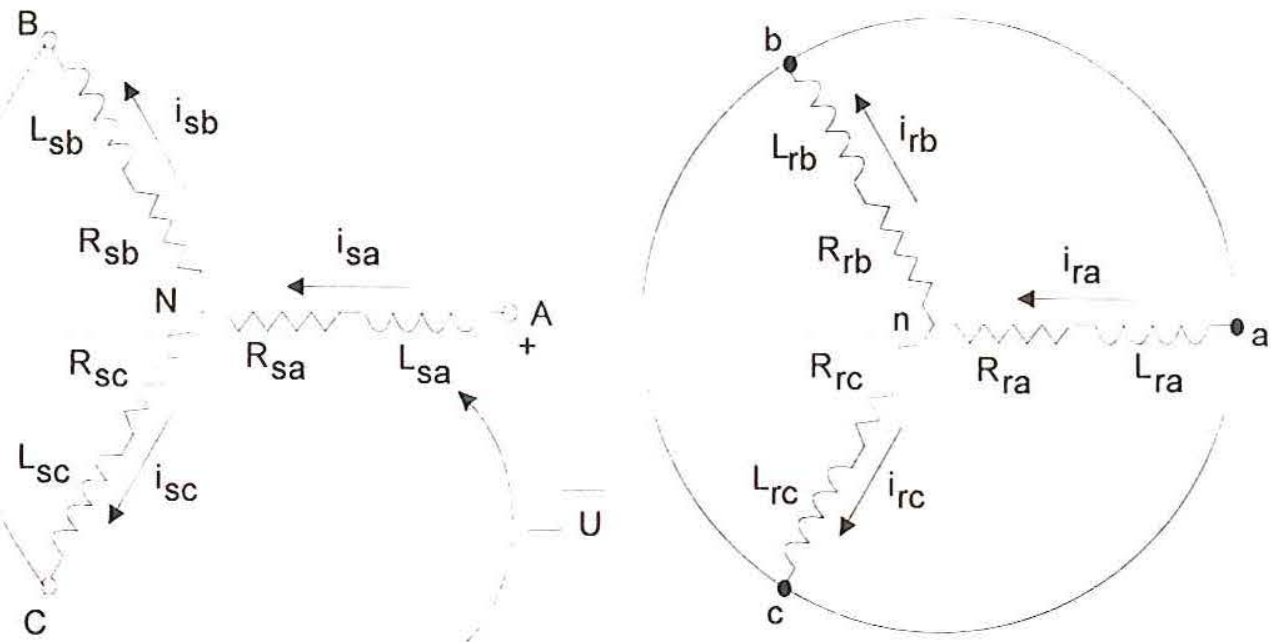

Figura 3.1 - Representação do ensaio em degrau do motor de indução trifásico com rotor em gaiola.

onde:

$$
\begin{array}{ll}
R_{s a}=R_{s b}=R_{s c}=R_{s} & \Rightarrow \text { Resistências das fases de estator } \\
R_{r a}=R_{r b}=R_{r c}=R_{r} & \Rightarrow \text { Resistências das fases de rotor } \\
1_{s a}=1_{s b}=1_{s c}=1_{s} & \Rightarrow \text { Indutância própria das fases de }
\end{array}
$$

estator;

$$
\begin{array}{ll}
1_{\mathrm{ra}}=1_{\mathrm{rb}}=1_{\mathrm{rc}}=1_{\mathrm{r}} & \Rightarrow \text { Indutância própria das fases de rotor; } \\
1_{\sigma s \mathrm{a}}=1_{\sigma s b}=1_{\sigma s c}=1_{\sigma s} \quad \Rightarrow \text { Indutância de dispersão das fases de }
\end{array}
$$

estator; 


$$
1_{\sigma r a}=1_{\sigma r b}=1_{\sigma r c}=1_{\sigma r} \quad \Rightarrow \text { Indutância de dispersão das fases de }
$$

rotor;

$$
\mathrm{m}_{\mathrm{r}}=\mathrm{m}_{\mathrm{s}}=\mathrm{m} \quad \Rightarrow \text { Indutância Mútua entre rotor-estator }
$$

e estator-rotor;

$$
\begin{aligned}
& \mathrm{L}_{\mathrm{sa}}=\mathrm{L}_{\mathrm{sb}}=\mathrm{L}_{\mathrm{sc}}=\left(\mathrm{l}_{\mathrm{s}}+\mathrm{l}_{\sigma \mathrm{s}}\right) \Rightarrow \text { Indutância total das fases de estator; } \\
& \mathrm{L}_{\mathrm{ra}}=\mathrm{L}_{\mathrm{rb}}=\mathrm{L}_{\mathrm{rc}}=\left(1_{\mathrm{r}}+\mathrm{l}_{\sigma \mathrm{r}}\right) \Rightarrow \text { Indutância total das fases de rotor; }
\end{aligned}
$$

Devido ao motor não sofrer movimento quando excitado por uma tensão CC, pode-se escolher um ângulo de rotação $\varepsilon$ arbitrário para o rotor. Assim, as fases "A e "a" de estator e rotor respectivamente, são coincidentes para se simplificar a análise e equacionamento do MIT. O degrau é aplicado na fase "A " do estator com os terminais "B" e "C" curto circuitados. Devido as condições de simetria do MIT, as resistências e indutâncias de fase são consideradas iguais entre si. Por conveniência, é omitida neste item, a grandeza (t) (grandeza variável tempo), ou seja, subtende-se que as correntes, tensões e fluxos envolvidos nas demonstrações que se sucedem sejam variáveis dependentes do tempo. Assim, as correntes da fase "A" e "a" de estator e rotor respectivamente, dividem-se igualmente entre as demais fases, ou seja:

$$
\begin{aligned}
& i_{s a}=i_{s} \\
& i_{s b}=i_{s c}=-\frac{i_{s}}{2} \\
& i_{r a}=i_{r} \\
& i_{r b}=i_{r c}=-\frac{i_{r}}{2}
\end{aligned}
$$


O fluxo resultante na direção da fase "a" do estator é o resultado da contribuição dos fluxos desta fase, das demais fases de estator e das mútuas entre estator e rotor. Assim tem-se:

$$
\begin{aligned}
\psi_{\mathrm{sa}}= & \mathrm{L}_{\mathrm{sa}} \mathrm{i}_{\mathrm{sa}}+\mathrm{l}_{\mathrm{s}} \cos \left(\frac{2 \pi}{3}\right) \mathrm{i}_{\mathrm{sb}}+\mathrm{l}_{\mathrm{s}} \cos \left(-\frac{2 \pi}{3}\right) \mathrm{i}_{\mathrm{sc}}+\mathrm{mi}_{\mathrm{ra}}+ \\
& m \cos \left(\frac{2 \pi}{3}\right) \mathrm{i}_{\mathrm{rb}}+m \cos \left(-\frac{2 \pi}{3}\right) \mathrm{i}_{\mathrm{rc}}
\end{aligned}
$$

Substituindo as eqs.(3.2a)-(3.2d) e a eq.(3.1a) na eq.(3.3) chega-se, após algumas operações matemáticas, à seguinte expressão para o fluxo resultante na fase "a" do estator:

$$
\psi_{s a}=\left(\frac{3}{2} 1_{s}+1_{\sigma s}\right) i_{s}+\frac{3}{2} m i_{r}
$$

Analogamente, para os fluxos nas fases "B" e "C" do estator tem-se:

$$
\begin{aligned}
& \psi_{s b}=-\frac{1}{2}\left(\frac{3}{2} 1_{s}+1_{\sigma s}\right) i_{s}-\frac{1}{2}\left(\frac{3}{2} m\right) i_{r} \\
& \psi_{s c}=-\frac{1}{2}\left(\frac{3}{2} 1_{s}+1_{\sigma s}\right) i_{s}-\frac{1}{2}\left(\frac{3}{2} m\right) i_{r}
\end{aligned}
$$

Procedendo de maneira semelhante para o rotor tem-se que o fluxo resultante na direção da fase "a" será dado por: 


$$
\begin{aligned}
\psi_{r a}= & L_{r a} i_{r a}+l_{r} \cos \left(\frac{2 \pi}{3}\right) i_{r b}+l_{r} \cos \left(-\frac{2 \pi}{3}\right) i_{r c}+m i_{s a}+ \\
& m \cos \left(\frac{2 \pi}{3}\right) i_{s b}+m \cos \left(-\frac{2 \pi}{3}\right) i_{s c}
\end{aligned}
$$

Substituindo na eq.(3.7) as expressões definidas pelas eqs.(3.2a)-(3.2d) e a eq. (3.1b), após algumas operações matemáticas, obtém-se para o fluxo na fase "a" do rotor:

$$
\psi_{\mathrm{ra}}=\left(\frac{3}{2} 1_{\mathrm{r}}+1_{\sigma r}\right) i_{r}+\left(\frac{3}{2} m\right) i_{S}
$$

Para as fases "b" e "c" do rotor tem-se:

$$
\begin{aligned}
& \psi_{r b}=-\frac{1}{2}\left(\frac{3}{2} l_{s}+l_{\sigma s}\right) i_{s}-\frac{1}{2}\left(\frac{3}{2} m\right) i_{r} \\
& \psi_{r c}=-\frac{1}{2}\left(\frac{3}{2} 1_{s}+1_{\sigma s}\right) i_{s}-\frac{1}{2}\left(\frac{3}{2} m\right) i_{r}
\end{aligned}
$$

Aplicando o lei das tensões de Kirchhoff na malha A-N-B da fig.(3.1) temse:

$$
\mathrm{U}=\mathrm{V}_{\mathrm{AN}}+\mathrm{V}_{\mathrm{NB}}
$$

onde:

$$
\begin{aligned}
& \mathrm{V}_{\mathrm{AN}}=\mathrm{R}_{\mathrm{s}} \mathrm{i}_{\mathrm{s}}+\frac{\mathrm{d}}{\mathrm{dt}} \psi_{\mathrm{sa}} \\
& \mathrm{V}_{\mathrm{BN}}=-\frac{1}{2} \mathrm{R}_{\mathrm{s}} \mathrm{i}_{\mathrm{s}}+\frac{\mathrm{d}}{\mathrm{dt}} \psi_{\mathrm{sb}}
\end{aligned}
$$


Substituindo as eqs.(3.4) e (3.5) nas eqs. (3.12) e o resultado desta operação na eq. (3.11) tem-se:

$$
V_{A B}=U=\frac{3}{2}\left(R_{s} i_{s}+\left(\frac{3}{2} l_{s}+l_{\sigma s}\right) \frac{d}{d t} i_{s}+\left(\frac{3}{2} m\right) \frac{d}{d t} i_{r}\right)
$$

Para o rotor pode-se escrever:

$$
\mathrm{V}_{\mathrm{an}}+\mathrm{V}_{\mathrm{nb}}=0
$$

onde:

$$
\begin{aligned}
& V_{a n}=R_{r} i_{r}+\frac{d}{d t} \psi_{r a} \\
& V_{b n}=-\frac{1}{2} R_{r} i_{r}+\frac{d}{d t} \psi_{r b}
\end{aligned}
$$

Substituindo as eqs.(3.8) e (3.9) nas eqs. (3.15) e o resultado desta operação na eq. (3.14) chega-se à seguinte expressão matemática para o rotor:

$$
V_{a b}=\frac{3}{2}\left(R_{r} i_{r}+\left(\frac{3}{2} 1_{r}+l_{\sigma r}\right) \frac{d}{d t} i_{r}+\left(\frac{3}{2} m\right) \frac{d}{d t} i_{s}\right)=0
$$

Através das definições do capítulo 2, repetidas aqui por conveniência, tem-se que:

$$
\begin{aligned}
& \mathrm{L}_{\mathrm{s}}=\frac{3}{2} 1_{\mathrm{s}}+1_{\sigma \mathrm{s}} \\
& \mathrm{L}_{\mathrm{r}}=\frac{3}{2} 1_{\mathrm{r}}+\mathrm{l}_{\sigma \mathrm{r}}
\end{aligned}
$$




$$
\begin{aligned}
& \mathrm{L}_{0}=\frac{3}{2} \mathrm{~m}=\frac{3}{2} \mathrm{l}_{\mathrm{r}}=\frac{3}{2} \mathrm{l}_{\mathrm{s}} \\
& \mathrm{L}_{\mathrm{s}}=\mathrm{L}_{0}\left(1+\sigma_{\mathrm{s}}\right) \\
& \mathrm{L}_{\mathrm{r}}=\mathrm{L}_{0}\left(1+\sigma_{\mathrm{r}}\right) \\
& \mathrm{T}_{\mathrm{s}}=\frac{\mathrm{L}_{\mathrm{s}}}{\mathrm{R}_{\mathrm{s}}} \\
& \mathrm{T}_{\mathrm{r}}=\frac{\mathrm{L}_{\mathrm{r}}}{\mathrm{R}_{\mathrm{r}}}
\end{aligned}
$$

Fazendo uso da eq. (3.19) nas eqs. (3.13) e (3.16), chega-se ao seguinte conjunto de equações para o motor de indução:

$$
\begin{aligned}
& U=R_{s} \frac{3}{2} i_{s}+l_{\sigma s} \frac{d}{d t}\left(\frac{3}{2} i_{s}\right)+L_{0}\left(\frac{d}{d t}\left(\frac{3}{2} i_{r}\right)+\frac{d}{d t}\left(\frac{3}{2} i_{s}\right)\right) \\
& 0=R_{r} \frac{3}{2} i_{r}+l_{\sigma r} \frac{d}{d t}\left(\frac{3}{2} i_{r}\right)+L_{0}\left(\frac{d}{d t}\left(\frac{3}{2} i_{r}\right)+\frac{d}{d t}\left(\frac{3}{2} i_{s}\right)\right)
\end{aligned}
$$

Através das eqs.(3.24) e (3.25) pode-se chegar ao modelo do MIT com excitação CC, conforme mostra a fig.(3.2)

O objetivo agora é determinar o comportamento da corrente de estator em função do degrau CC de tensão de entrada. Para isso, é necessário obter a função de transferência do modelo. 


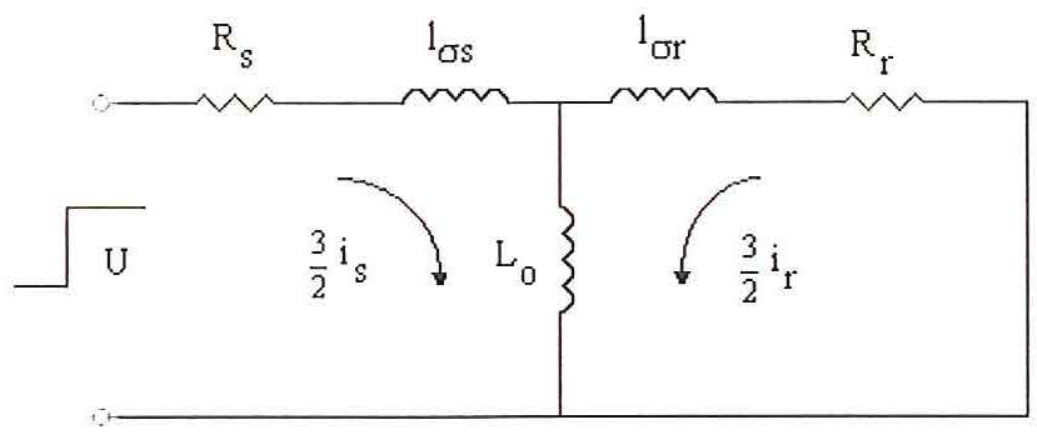

Figura 3.2 - Modelo do MIT com rotor em gaiola para excitação CC.

Aplicando a Transformada de Laplace nas eqs. (3.24) e (3.25) e fazendo as substituições necessárias tomando uso das definições mostradas nas eqs. (3.17)(3.23) obtém-se a função de transferência do modelo CC do MIT :

$$
G(s)=\frac{I_{s}(s)}{U(s)}=\frac{2}{3} \frac{1}{R_{s}} \frac{1+T_{r} s}{1+\left(T_{r}+T_{s}\right) s+\left(T_{r} T_{s} \sigma\right) s^{2}}
$$

Assim, os parâmetros elétricos resultantes do modelo CC do MIT sujeito a um degrau de tensão são os mesmos do capítulo 2 para o sistema de coordenadas de campo. A equação acima pode ainda ser reescrita da seguinte forma:

$$
G(s)=K \frac{1+T_{d} s}{1+\left(T_{2}+T_{1}\right) s+\left(T_{1} T_{2}\right) s^{2}}
$$

onde:

$$
\begin{aligned}
& T_{d}=T_{r} \\
& T_{2}+T_{1}=T_{r}+T_{s} \\
& T_{1} T_{2}=T_{r} T_{s} \sigma \\
& K=\frac{2}{3} \frac{1}{R_{s}}
\end{aligned}
$$


A eq.(3.26) descreve um sistema de $2^{\underline{a}}$ ordem com dois pares de pólos reais e distintos, como será mostrado posteriormente através dos ensaios reais. A função que descreve a corrente de estator é então caracterizada por uma constante de tempo rápida e outra lenta em seu transitório.

O comportamento do transitório de corrente de estator no domínio do tempo para um degrau $C C$ de tensão pode ser obtido a partir da eq.(3.26) isolando-se $I_{S}$ e aplicando a Transformada Inversa de Laplace:

$$
i_{S}(t)=\left(A_{0}+A_{1} e^{-\frac{t}{T_{1}}}+A_{2} e^{-\frac{t}{T_{2}}}\right)
$$

com:

$$
\begin{aligned}
& A_{0}=\frac{2}{3} \frac{U}{R_{s}} \\
& A_{1}=\frac{T_{r}-T_{1}}{T_{1}-T_{2}} \\
& A_{2}=\frac{T_{2}-T_{r}}{T_{1}-T_{2}}
\end{aligned}
$$

No processamento de dados que utilizam computadores para aquisição, os sinais são amostrados e digitalizados, resultando em sinais discretos que são quantizados em amplitude e tempo. Desse modo, ao contrário dos sinais contínuos, estes sinais possuem valores de amplitudes discretas tomadas em instantes de tempo também discretos. Daí a necessidade de se trabalhar com a forma discreta da eq.(3.26) ou eq.(3.27). Fazendo o uso de uma tabela de transformada $\mathrm{z}$ (ISERMANN,1989), obtém-se a forma discretizada da eq. (3.27) como sendo: 


$$
G(z)=\frac{b_{1} z^{-1}+b_{2} z^{-2}}{1+a_{1} z^{-1}+a_{2} z^{-2}}
$$

onde:

$$
\begin{aligned}
& z_{1}=e^{-\frac{T_{0}}{T_{1}}} \\
& z_{2}=e^{-\frac{T_{0}}{T_{2}}} \\
& b_{1}=\frac{K}{\left(T_{1}-T_{2}\right)}\left[z_{1}\left(T_{d}-T_{1}\right)-z_{2}\left(T_{d}-T_{2}\right)+\left(T_{1}-T_{2}\right)\right]
\end{aligned}
$$

$$
\mathrm{b}_{2}=\frac{\mathrm{K}}{\left(\mathrm{T}_{1}-\mathrm{T}_{2}\right)}\left[\mathrm{z}_{1}\left(\mathrm{~T}_{1} \mathrm{z}_{2}+\mathrm{T}_{2}-\mathrm{T}_{\mathrm{d}}\right)-\mathrm{z}_{2}\left(\mathrm{~T}_{2} \mathrm{z}_{1}+\mathrm{T}_{1}-\mathrm{T}_{\mathrm{d}}\right)\right]
$$

$$
\begin{aligned}
& \mathrm{a}_{1}=-\left(\mathrm{z}_{1}+\mathrm{z}_{2}\right) \\
& \mathrm{a}_{2}=\left(\mathrm{z}_{1} \mathrm{z}_{2}\right) \\
& \mathrm{T}_{1}=\frac{\mathrm{T}_{0}}{\ln \chi} \\
& \mathrm{T}_{2}=-\frac{\mathrm{T}_{0}}{\ln \mathrm{a}_{2} \chi} \\
& \chi=\frac{-\mathrm{a}_{1} \pm \sqrt{\mathrm{a}_{1}^{2}-4 \mathrm{a}_{2}}}{2 \mathrm{a}_{2}}
\end{aligned}
$$


e $\mathrm{T}_{0}$ é o tempo de amostragem a ser utilizado no processo.

Assim, para a estimação dos parâmetros elétricos, deve-se inicialmente fazer a leitura, dos valores da entrada "y" (degrau de tensão) e saída "u" (corrente do estator). Estes vetores são processados em um programa contendo um dos algoritmos de estimação discutidos no capítulo 4.

\subsection{Modelagem Mecânica do Motor de Indução}

O movimento do motor de indução trifásico é descrito pela eq.(2.24) apresentada no capítulo 2 e repetida aqui por conveniência :

$$
J \frac{d}{d t} \omega(t)+K_{D} \omega(t)+M_{f}=m_{d}(t)
$$

Nesta equação é considerado que o motor gira livremente, assim, o conjugado de carga $\mathrm{M}_{\mathrm{l}}$ é nulo.

No instante em que o motor é desligado tem-se $\mathrm{m}_{\mathrm{d}}(\mathrm{t})=0$.

Considerando que no instante do desligamento o motor gira com velocidade de regime $\omega_{0}$ e aplicando a Transformada de Laplace na eq.(3.44) com $\mathrm{m}_{\mathrm{d}}(\mathrm{t})=0$ temse:

$$
J\left(s \omega(s)-\omega_{0}\right)+K_{D} \omega(s)+\frac{M_{f}}{s}=0
$$

Desenvolvendo a eq.(3.45) em função de " $\omega$ " e aplicando a Transformada Inversa de Laplace chega-se à equação que descreve a curva de decaimento velocidade do MIT:

$$
\left.\omega(t)=\frac{1}{K_{D}}\left[-M_{f}+\left(M_{f}+\omega_{0} K_{D}\right)\right] e^{-\frac{K_{D}}{J} t}\right]
$$


Assim, $M_{f}, K_{D}$ e $J$ são os parâmetros mecânicos a serem identificados. Reescrevendo a eq.(3.46) tem-se:

$$
\omega(\mathrm{t})=\theta_{1}+\theta_{2} \mathrm{e}^{-\theta_{3} \mathrm{t}}
$$

onde:

$$
\begin{aligned}
& \theta_{1}=-\frac{M_{f}}{K_{D}} \\
& \theta_{2}=\frac{M_{f}}{K_{D}}+\omega_{0} \\
& \theta_{3}=\frac{-K_{D}}{J}
\end{aligned}
$$

Através de um algoritmo de identificação conveniente (discutido no capítulo 4), determinam-se os valores de $\theta_{1}, \theta_{2}$ e $\theta_{3}$. Analisando as eqs.(3.48), verifica-se a necessidade de se encontrar uma outra equação que relacione $\mathrm{M}_{\mathrm{f}}$ com $\mathrm{K}_{\mathrm{D}}$ pois as eq.(3.48a) e (3.48b) são linearmente dependentes. Esta nova equação é obtida considerando-se o MIT girando em regime com velocidade $\omega_{0}$. Utilizando a eq.(2.24) no capítulo 2 e desprezando o conjugado de carga $M_{l}$, obtém-se a equação que representa o conjugado de regime permanente do MIT:

$$
\mathrm{m}_{\mathrm{d} 0}=-\mathrm{K}_{\mathrm{D}}{ }^{\omega_{0}}-\mathrm{M}_{\mathrm{f}}
$$

ou,

$$
\omega_{0}=-\left(\frac{m_{d 0}-M_{f}}{K_{D}}\right)
$$


Para uma alimentação trifásica senoidal com amplitude $U_{s}$ e frequência angular $\omega_{\mathrm{s}}$, pode-se representar o conjugado de regime do motor de indução trifásico em função da tensão eficaz do estator e do seu escorregamento (LEONHARD,1990):

$$
\mathrm{m}_{\mathrm{d} 0}=\frac{3}{2} \frac{1-\sigma}{\sigma} \frac{\mathrm{U}_{\mathrm{s}}^{2}}{\omega_{\mathrm{s}}^{2} \mathrm{~L}_{\mathrm{s}}} \frac{2}{\mathrm{~S} / \mathrm{S}_{\mathrm{p}}+\mathrm{S}_{\mathrm{p}} / \mathrm{S}}
$$

onde:

$$
\begin{aligned}
& \mathrm{S}=\frac{\omega_{\mathrm{S}}-\omega}{\omega_{\mathrm{S}}}=\text { Escorregamento do motor } \\
& \mathrm{S}_{\mathrm{p}}=\frac{1}{\sigma \omega_{\mathrm{S}} \mathrm{T}_{\mathrm{r}}}=\text { Frequência de escorregamento onde o conjugado é }
\end{aligned}
$$

máximo

Em termos de corrente eficaz de estator tem-se:

$$
m_{d 0}=\frac{3 L_{s} I_{s}^{2} \omega_{s} T_{r} S(1-\sigma)}{1+\omega_{s}^{2} T_{r}^{2} S^{2}}
$$

Portanto, conhecendo-se o valor do conjugado $\mathrm{m}_{\mathrm{d} 0}$ de regime permanente (eq.(3.51) ou eq.(3.53)) e a velocidade de regime $\omega_{0}$ (eq.(3.50)), pode-se determinar todos os parâmetros mecânicos do motor de indução trifásico. 


\section{Algoritmos de Identificação Paramétrica}

A identificação paramétrica consiste na determinação experimental dos parâmetros de um determinado processo, baseado no comportamento dinâmico (entrada e/ou saída) do mesmo, a partir do qual, determinam-se modelos matemáticos apropriados que se aproximem ao máximo do processo real.

Segundo DAVIS \& VINTER (1985), a identificação paramétrica é constituída de diversas etapas assim descritas :

- Seleção de uma classe de modelos;

- Projeto experimental com a escolha das entradas a serem aplicadas no processo de identificação, bem como na escolha das saídas a serem observadas no mesmo;

- Seleção do modelo adequado baseado em dados experimentais;

- Verificação da validade do modelo, ou seja, da concordância do modelo escolhido em relação a algumas atribuições específicas. O modelo mais adequado será aquele que se ajustar melhor aos dados experimentais de acordo com uma função critério ou índice de desempenho dado.

Existem diversas técnicas para a identificação de parâmetros de um processo. Neste trabalho são apresentados alguns destes algoritmos de identificação tais como: Método dos Mínimos Quadrados Recursivo (RLS), Método dos Mínimos Quadrados Recursivo Estendido (RELS) e o Método de Gauss-Newton. Também é apresentado um algoritmo de identificação baseado no Método Simplex de Nelder-Mead disponível no software do MATLAB (MATHWORKS Inc., 1993).

\subsection{Método dos Mínimos Quadrados}

O Método dos Mínimos Quadrados é utilizado em processos variantes e invariantes no tempo, algumas classes de processos lineares e não lineares bem como 
em algumas classes de processos estacionários e não estacionários. Existem diversos algoritmos baseados neste método. O utilizado neste trabalho é conhecido como Método dos Mínimos Quadrados Recursivo (RLS) e Método dos Mínimos Quadrados Recursivo Estendido (RELS).

Um processo estável, invariante no tempo e linearizável pode ser representado por uma equação de diferenças linear do tipo (ISERMANN,1989):

$$
\begin{aligned}
& y_{u}(k)+a_{1} y_{u}(k-1)+\ldots+a_{m} y_{u}(k-m) \\
& =b_{1} u(k-1)+\ldots+b_{m} u(k-m)
\end{aligned}
$$

onde:

$$
\begin{aligned}
& m=\text { ordem do sistema } \\
& u(k)=\text { sinal de entrada } \\
& y(k)=\text { sinal de saída }
\end{aligned}
$$

Nota-se que se necessita de no mínimo "m" medidas para se iniciar o processo de identificação uma vez que se tem "m" parâmetros a serem identificados. Assim sendo, deve-se conhecer "a priori", a ordem do sistema de identificação.

A função de transferência no domínio $Z$, do processo representado pela eq. (4.1) é dada por:

$$
G_{p}(z)=\frac{y_{u}(z)}{u(z)}=\frac{B\left(z^{-1}\right)}{A\left(z^{-1}\right)}=\frac{b_{1} z^{-1}+\ldots+b_{m} z^{-m}}{1+a_{1} z^{-1}+\ldots+a_{m} z^{-m}}
$$

Considerando-se agora um sistema genérico submetido a um ruído externo $\mathrm{n}$, pode-se representá-lo conforme fig. (4.1) abaixo: 


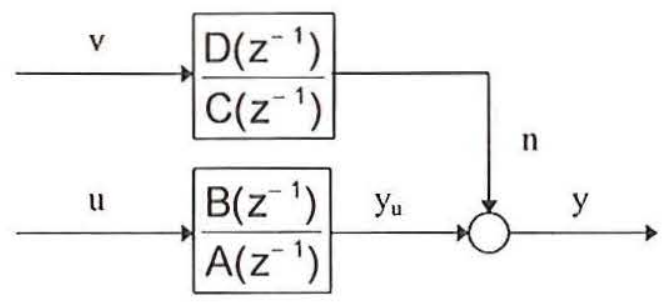

Figura 4.1 - Diagrama de um Sistema Genérico com ruído.

Este sinal é assumido estacionário e pode ser representado similarmente à eq.(4.1):

$$
n(k)+c_{1} n(k-1)+\ldots+c_{p} n(k-p)=v(k)+d_{1} v(k-1)+\ldots+d_{p} v(k-p)
$$

Através da eq.(4.3), pode-se obter a função de transferência no domínio $Z$ do sistema representado pela fig. (4.1):

$$
G_{v}(z)=\frac{n(z)}{v(z)}=\frac{D\left(z^{-1}\right)}{C\left(z^{-1}\right)}=\frac{1+d_{1} z^{-1}+\ldots+d_{p} z^{-p}}{1+c_{1} z^{-1}+\ldots+c_{p} z^{-p}}
$$

Pela fig. (4.1) temos que:

$$
y(k)=y_{u}(k)+n(k)
$$

Substituindo as eqs (4.1) e (4.3) na eq. (4.5) e aplicando a Transformada Z neste resultado obtém-se o modelo geral de um sistema qualquer sujeito a um ruído externo $n(k)$ :

$$
y(z)=\frac{B\left(z^{-1}\right)}{A\left(z^{-1}\right)} u(z)+\frac{D\left(z^{-1}\right)}{C\left(z^{-1}\right)} v(z)
$$


Os termos $a_{1} \ldots a_{m}, b_{1} \ldots b_{m}, c_{1} \ldots c_{p}, d_{1} \ldots d_{p}$ são os parâmetros a serem identificados no processo. Nota-se mais uma vez, que se deve conhecer as ordens do modelo "m" e " $p$ " ou determiná-las através de métodos apropriados.

\subsection{Método dos Mínimos Quadrados Recursivo}

Considere os sinais de entrada e saída $\mathrm{u}(\mathrm{k})$ e $\mathrm{y}(\mathrm{k})$ medidos até o instante $\mathrm{k}$ e os parâmetros do sistema estimados até o instante k-1. Através da eq.(4.1) pode-se escrever:

$$
\begin{aligned}
& y(k)+\hat{a}_{1}(k-1) y(k-1)+\ldots+\hat{a}_{m}(k-1) y(k-m) \\
& -\hat{b}_{1}(k-1) u(k-1)-\ldots-\hat{b}_{m} u(k-m)=e(k)
\end{aligned}
$$

onde e(k) é o erro devido a estimação dos parâmetros do processo e o sinal de circunflexo indica uma variável estimada. Este erro é considerado zero na eq.(4.1) pois nesta seus termos são considerados reais e não estimados como na eq. (4.7).

Assim, o valor estimado de $\mathrm{y}(\mathrm{k})$ no instante $(\mathrm{k}-1)$ com os parâmetros estimados no mesmo instante será dado por:

$$
\begin{aligned}
\hat{y}(k \mid k-1)= & -\hat{a}_{1}(k-1) y(k-1)-\ldots-\hat{a}_{m}(k-1) y(k-m) \\
& +\hat{b}_{1}(k-1) u(k-1)+\ldots+\hat{b}_{m}(k-1) u(k-m)
\end{aligned}
$$

Introduzindo a notação vetorial tem-se:

$$
\hat{y}(\mathrm{k} \mid \mathrm{k}-1)=\psi^{\mathrm{T}}(\mathrm{k}) \hat{\theta}(\mathrm{k}-1)
$$


onde:

$\psi^{\mathrm{T}}(\mathrm{k})=[-\mathrm{y}(\mathrm{k}-1) \ldots-\mathrm{y}(\mathrm{k}-\mathrm{m}) \vdots \mathrm{u}(\mathrm{k}-1) \ldots \mathrm{u}(\mathrm{k}-\mathrm{m})]-$ Vetor de dados

$\hat{\theta}(\mathrm{k}-1)=\left[\hat{\mathrm{a}}_{1} \ldots \hat{\mathrm{a}}_{\mathrm{m}} \vdots \hat{\mathrm{b}}_{1} \ldots \hat{\mathrm{b}}_{\mathrm{m}}\right]-$ Vetor de parâmetros ;

Assim, o erro entre o valor real e o valor estimado será dado por:

$$
\mathrm{e}(\mathrm{k})=\mathrm{y}(\mathrm{k})-\hat{\mathrm{y}}(\mathrm{k} \mid \mathrm{k}-1)
$$

Substituindo a eq.(4.9) na eq.(4.10) tem-se:

$$
y(k)=\psi^{T}(k) \hat{\theta}(k-1)+e(k)
$$

Considere agora os sinais de entrada e saída medidos para $\mathrm{k}=1,2 \ldots, \mathrm{m}+\mathrm{N}$. Pode-se agrupar este conjunto de medidas em uma matriz. Assim a eq. (4.11) pode ser reescrita na forma matricial:

$$
\mathbf{y}(m+N)=\psi^{T}(m+N) \hat{\theta}(m+N-1)+e(m+N)
$$

onde :

Vetor de saída:

$$
\mathbf{y}^{T}(m+N)=[y(m) y(m+1) \ldots y(m+N)]
$$


Matriz dados:

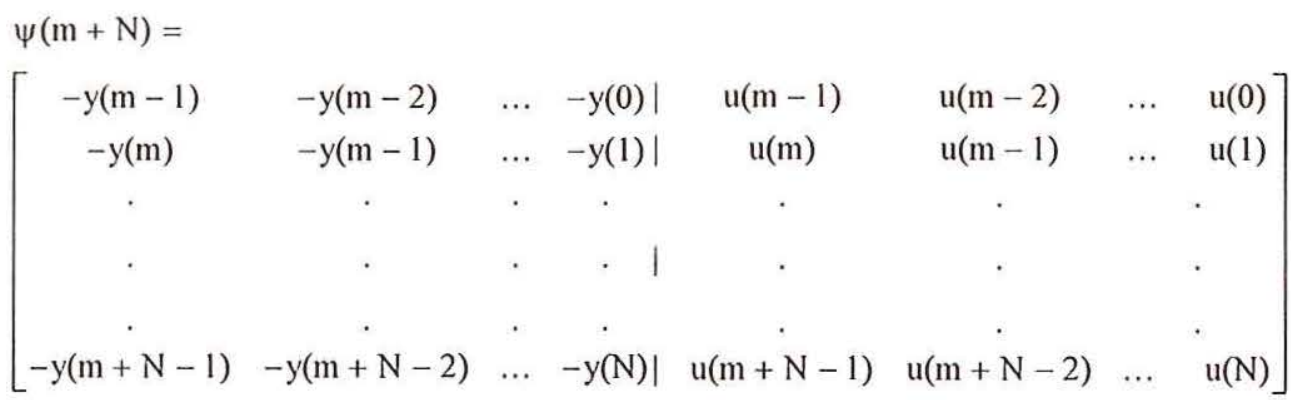

Vetor erro:

$$
\mathrm{e}^{\mathrm{T}}(\mathrm{m}+\mathrm{N})=[\mathrm{e}(\mathrm{m}) \mathrm{e}(\mathrm{m}+1) \ldots e(m+N)]
$$

Os valores do vetor erro devem ser o menor possível para que os valores estimados se aproximem dos valores reais. Definindo a função de perdas como:

$$
V=\mathbf{e}^{T}(m+N) \mathbf{e}(m+N)=\sum_{k=m}^{m+N} e^{2}(k)
$$

ela será mínima quando:

$$
\left.\frac{\mathrm{dV}}{\mathrm{d} \theta}\right|_{\theta=\hat{\theta}}=0
$$

Define-se a matriz $\mathbf{P}$ como:

$$
P(m+N)=\left[\psi^{T}(m+N) \psi^{T}(m+N)\right]^{-1}
$$

Desenvolvendo a derivada na eq.(4.17) e utilizando as eqs. (4.12) e (4.18), chega-se, após algumas passagens matemáticas, a seguinte expressão: 


$$
\hat{\theta}(m+N-1)=P(m+N) \psi^{T}(m+N) \mathbf{y}(m+N)
$$

O desenvolvimento acima representa o método não recursivo de estimação de parâmetros uma vez que deve-se armazenar todas as medidas em uma matriz para depois estimar os parâmetros. A cada nova medida retira-se a primeira linha da matriz de dados e acrescenta-se esta nova medida à última linha dessa matriz. Em seguida calcular-se a matriz $\mathbf{P}$ conforme a eq.(4.18) para depois estimar a nova matriz de parâmetros. Se ao invés disso, o vetor parâmetros estimado no instante k , $(\theta(\mathrm{k}))$, for subtraído do valor estimado no instante posterior $\mathrm{k}+1,(\theta(\mathrm{k}+1))$ obtém-se o algoritmo de estimação de parâmetros na forma recursiva:

$$
\hat{\theta}(\mathrm{k}+1)=\hat{\theta}(\mathrm{k})+\gamma(\mathrm{k})\left[\mathrm{y}(\mathrm{k}+1)-\psi^{\mathrm{T}}(\mathrm{k}+1) \hat{\theta}(\mathrm{k})\right]
$$

onde:

$$
\gamma(\mathrm{k})=\mathbf{P}(\mathrm{k}+1) \psi(\mathrm{k}+1)=\frac{1}{\psi^{\mathrm{T}}(\mathrm{k}+1) \mathbf{P}(\mathrm{k}) \psi(\mathrm{k}+1)+1} \mathbf{P}(\mathrm{k}) \psi(\mathrm{k}+1)
$$

é o vetor de correção

$\mathrm{e}$

$$
\mathbf{P}(\mathrm{k}+1)=\left[\mathbf{I}-\gamma(\mathrm{k}) \psi^{\mathrm{T}}(\mathrm{k}+1)\right] \mathbf{P}(\mathrm{k})
$$

O método é iniciado fazendo:

$$
\begin{aligned}
& \hat{\theta}(0)=0 \\
& \mathbf{P}(0)=\alpha \mathbf{I}
\end{aligned}
$$

com I igual a matriz identidade e $\alpha$ grande $\left(\approx 10^{6}\right)$. 
A eq. (4.21) pode ser reescrita na forma :

$$
\hat{\theta}(\mathrm{k}+1)=\hat{\theta}(\mathrm{k})+\gamma(\mathrm{k}) \mathrm{e}(\mathrm{k}+1)
$$

O Método dos Mínimos Quadrados Recursivo possui boas propriedades quando os parâmetros são invariantes no tempo, o mesmo não ocorrendo para parâmetros variantes no tempo uma vez que o ganho do algoritmo converge para zero interrompendo a estimação ( LOURO, 1995 ).

\subsubsection{Método dos Mínimos Quadrados Recursivo Estendido (RELS)}

Muitos sistemas apresentam-se, na prática, ruidosos. Desse modo a estimação dos parâmetros do mesmo fica comprometida caso se utilize o método RLS . Para tais sistemas obtém-se um melhor resultado prático utilizando-se uma forma variante do Método dos Mínimos Quadrados Recursivo:- o Método dos Mínimos Quadrados Recursivo Estendido (RELS). O método RELS permite tratar sinais correlacionados e é um dos mais atrativos para identificação de sistemas em tempo real. Este tipo de método é baseado na eq. (4.6) tomando $\mathrm{C}\left(\mathrm{z}^{-1}\right)=1 \mathrm{e} \mathrm{v}(\mathrm{z})=\mathrm{e}(\mathrm{z})$ ( modelo ARMAXAutoregressive Moving Average with Exogeneous variable). Fazendo essas considerações pode-se reescrever a eq.(4.6) como:

$$
A\left(z^{-1}\right) y(z)-B\left(z^{-1}\right) u(z)=D\left(z^{-1}\right) \varepsilon(z)
$$

onde $\varepsilon=\mathrm{D}\left(\mathrm{z}^{-1}\right) \frac{1}{\mathrm{~A}\left(\mathrm{z}^{-1}\right)} \mathrm{v}(\mathrm{z})$

Desse modo, basta introduzir-se os seguintes termos no vetor de dados e no vetor de parâmetros : 


$$
\begin{aligned}
& \psi^{\mathrm{T}}(\mathrm{k})=[-\mathrm{y}(\mathrm{k}-1) \ldots-\mathrm{y}(\mathrm{k}-\mathrm{m}) \vdots \mathrm{u}(\mathrm{k}-1) \ldots \mathrm{u}(\mathrm{k}-\mathrm{m}) \\
& \hat{\mathrm{v}}(\mathrm{k}-1) \ldots \hat{\mathrm{v}}(\mathrm{k}-\mathrm{p})] \\
& \hat{\theta}^{\mathrm{T}}=\left[\hat{\mathrm{a}}_{1} \ldots \hat{\mathrm{a}}_{\mathrm{m}} \vdots \hat{\mathrm{b}}_{1} \ldots \hat{\mathrm{b}}_{\mathrm{m}} \vdots \hat{\mathrm{d}}_{1} \ldots \hat{\mathrm{d}}_{\mathrm{p}}\right]
\end{aligned}
$$

Os parâmetros serão estimados substituindo as equações acima na eq. (4.20):

$$
\hat{\theta}(\mathrm{k}+1)=\hat{\theta}(\mathrm{k})+\gamma(\mathrm{k})\left[\mathrm{y}(\mathrm{k}+1)-\hat{\psi}^{\mathrm{T}}(\mathrm{k}+1) \hat{\theta}(\mathrm{k})\right]
$$

$\operatorname{com} \hat{\mathrm{v}}(\mathrm{k})=\mathrm{e}(\mathrm{k})$.

Até agora foi considerado que os parâmetros do processo a serem estimados são invariantes no tempo e portanto que os sinais $u(k), y(k)$ e a equação de erro $e(k)$ possuem o mesmo peso sobre as medidas de tempo de $k=0, \ldots \ldots . . N$. Quando o processo possui estas características os algoritmos de estimação apresentados convergem normalmente para os valores esperados. Quando os parâmetros são variantes no tempo, o estimador sozinho não é capaz de detectar esta variação devido à convergência da matriz $\mathbf{P}$ para zero. Se o algoritmo de estimação tiver que acompanhar essas variações dos parâmetros com o tempo, as medidas mais recentes deverão ter um peso maior sobre as medidas anteriores. Desse modo deve-se acrescentar no algoritmo o que é conhecido como fading memory (fator de esquecimento). Este fator pondera os valores mais recentes com maior peso e evita que os elementos da matriz $\mathbf{P}$ se tornem pequenos mantendo a sensibilidade do algoritmo e permitindo que os dados novos continuem a influir nas estimativas mais recentes dos parâmetros. Para isso incorpora-se à eq. (4.21) uma constante $\lambda$ (fator de esquecimento) que deverá ser escolhida na faixa de 0.95 (para variações rápidas) e 0.999 (para variações lentas). Para $\lambda=1$ os pesos das medidas mais recentes é o mesmo que o das anteriores. Assim tem-se: 


$$
\gamma(\mathrm{k})=\mathbf{P}(\mathrm{k}+1) \psi(\mathrm{k}+1)=\frac{1}{\psi^{\mathrm{T}}(\mathrm{k}+1) \mathbf{P}(\mathrm{k}) \psi(\mathrm{k}+1)+\lambda} \mathbf{P}(\mathrm{k}) \psi(\mathrm{k}+1)
$$

Um dos problemas existentes na escolha de um fator de esquecimento fixo é que, como ele tem a mesma influência em todas as amostras, poderão ocorrer problemas de convergência no caso não estacionário (caso o valor fixado seja muito alto) ou problemas de oscilação no caso estacionário (caso o valor fixado seja pequeno).

Para se utilizar o Método dos Mínimos Quadrados ou uma de suas variações na identificação dos parâmetros elétricos do MIT é fundamental conhecer os vetores de entrada "u" e de saída "y". Conforme descrito no capítulo 3 eq.(3.26), para o ensaio degrau de tensão, esses vetores representam a tensão $U$ aplicada no enrolamento de estator e sua corrente $\mathrm{I}_{\mathrm{S}}$ respectivamente. Esta mesma equação fornece o grau do sistema ( $2^{\underline{a}}$ ordem) que também é necessário para o processo de identificação quando se utiliza um dos métodos descritos acima. Embora o ensaio degrau não permita, o Método dos Mínimo Quadrados Recursivo pode ser utilizado na identificação dos parâmetros em tempo real

\subsection{Método de Gauss-Newton}

O método de Gauss-Newton é uma modificação do método de Newton e foi apresentado por Gauss em 1809 (SEBER \& WILD, 1989). Pode ser entendido como uma aproximação linear de uma função qualquer com comportamento previamente conhecido, a partir do ajuste iterativo dos parâmetros desta função. A iteração é efetuada com base nos valores amostrados das grandezas envolvidas no processo a partir de valores iniciais para os parâmetros da função.

Esses valores iniciais para os parâmetros da função podem ser descobertos de acordo com as características do sistema em questão, ou preliminarmente estimados 
baseados em alguma informação disponível. O método então melhora estas aproximações iniciais de maneira iterativa até que se atinjam valores satisfatórios para os parâmetros da função.

O Método de Gauss-Newton propõe que uma função não-linear $f\left(t_{n}, \theta\right)$ qualquer pode ser expandida em uma série de Taylor de $1^{\underline{a}}$ ordem em torno de um valor inicial $\theta_{0}$ para os parâmetros desta função. Desse modo, são considerados somente os termos lineares:

$$
\begin{aligned}
\mathrm{f}\left(\mathrm{t}_{\mathrm{n}}, \theta\right) \cong & \mathrm{f}\left(\mathrm{t}_{\mathrm{n}}, \theta^{0}\right)+\frac{\mathrm{d}}{\mathrm{d} \theta_{1}}\left(\mathrm{t}_{\mathrm{n}}, \theta^{0}\right)\left(\theta_{1}-\theta_{1}^{0}\right)+\frac{\mathrm{d}}{\mathrm{d} \theta_{2}}\left(\mathrm{t}_{\mathrm{n}}, \theta^{0}\right)\left(\theta_{2}-\theta_{2}^{0}\right)+\cdots+ \\
& \frac{\mathrm{d}}{\mathrm{d} \theta_{\mathrm{p}}}\left(\mathrm{t}_{\mathrm{n}}, \theta^{0}\right)\left(\theta_{\mathrm{p}}-\theta_{\mathrm{p}}^{0}\right)
\end{aligned}
$$

"p" é o número de parâmetros do processo, "n" o número de amostras e $\theta_{\mathrm{p}}^{0}$ são os "p" valores iniciais para os parâmetros da função.

Incorporando as " $n$ " amostras do processo pode-se reescrever a eq.(4.28) em termos matriciais:

$\eta(\theta) \cong\left(\begin{array}{c}f\left(t_{1}, \theta^{0}\right) \\ f\left(t_{2}, \theta^{0}\right) \\ \vdots \\ f\left(t_{n}, \theta^{0}\right)\end{array}\right)+\left(\begin{array}{cccc}\frac{d}{d \theta_{1}}\left(t_{1}, \theta^{0}\right) & \frac{d}{d \theta_{2}}\left(t_{1}, \theta^{0}\right) & \cdots & \frac{d}{d \theta_{p}}\left(t_{1}, \theta^{0}\right) \\ \frac{d}{d \theta_{1}}\left(t_{2}, \theta^{0}\right) & \frac{d}{d \theta_{2}}\left(t_{2}, \theta^{0}\right) & \cdots & \frac{d}{d \theta_{p}}\left(t_{2}, \theta^{0}\right) \\ \vdots & \vdots & \ddots & \vdots \\ \frac{d}{d \theta_{1}}\left(t_{n}, \theta^{0}\right) & \frac{d}{d \theta_{2}}\left(t_{n}, \theta^{0}\right) & \cdots & \frac{d}{d \theta_{p}}\left(t_{n}, \theta^{0}\right)\end{array}\right)\left(\theta-\theta^{0}\right)$

onde:

$$
\left(\theta-\theta^{0}\right)=\left(\begin{array}{c}
\theta_{1}-\theta_{1}^{0} \\
\theta_{2}-\theta_{2}^{0} \\
\vdots \\
\theta_{p}-\theta_{p}^{0}
\end{array}\right)
$$


e

$$
\eta(\theta)=\text { aproximação linear da função } \mathbf{f}\left(t_{n}, \theta\right)
$$

A equação matricial (4.29) pode ser reescrita de forma simplificada como:

$$
\eta(\theta) \cong \eta\left(\theta^{0}\right)+V^{0}\left(\theta-\theta^{0}\right)
$$

onde:

$$
\begin{aligned}
& V^{0}=\left(\begin{array}{cccc}
\frac{d}{d \theta_{1}}\left(t_{1}, \theta^{0}\right) & \frac{d}{d \theta_{2}}\left(t_{1}, \theta^{0}\right) & \cdots & \frac{d}{d \theta_{p}}\left(t_{1}, \theta^{0}\right) \\
\frac{d}{d \theta_{1}}\left(t_{2}, \theta^{0}\right) & \frac{d}{d \theta_{2}}\left(t_{2}, \theta^{0}\right) & \cdots & \frac{d}{d \theta_{p}}\left(t_{2}, \theta^{0}\right) \\
\vdots & \vdots & \vdots & \vdots \\
\frac{d}{d \theta_{1}}\left(t_{n}, \theta^{0}\right) & \frac{d}{d \theta_{2}}\left(t_{n}, \theta^{0}\right) & \cdots & \frac{d}{d \theta_{p}}\left(t_{n}, \theta^{0}\right)
\end{array}\right) \\
& \eta\left(\theta^{0}\right)=\left(\begin{array}{c}
f\left(t_{1}, \theta^{0}\right) \\
f\left(t_{2}, \theta^{0}\right) \\
\vdots \\
f\left(t_{n}, \theta^{0}\right)
\end{array}\right)
\end{aligned}
$$

O erro desta aproximação é definido como:

$$
\mathrm{e}=\mathbf{f}-\eta(\theta)
$$

Este erro será mínimo quando os parâmetros $\theta_{\mathrm{p}}$ estiverem próximos dos seus valores reais. Assim, para se ter esta condição de erro mínimo tem-se que:

$$
\|\mathrm{f}-\eta(\theta)\|^{2}=0
$$


Substituindo a eq.(4.30) na eq.(4.32) tem-se que:

$$
\left\|\mathbf{f}-\eta\left(\theta^{0}\right)-\mathbf{V}^{0}\left(\theta-\theta^{0}\right)\right\|^{2}=0
$$

ou,

$$
\mathbf{V}^{0}\left(\theta-\theta^{0}\right)=\mathbf{f}-\eta\left(\theta^{0}\right)
$$

Resolvendo o sistema formado pela eq.(4.34) em termos de $\theta$, chega-se a seguinte expressão:

$$
\delta=\theta-\theta^{0}=\left(\mathbf{V}^{0}\right)^{-1}\left(\mathbf{f}-\eta\left(\theta^{0}\right)\right)
$$

onde $\delta$ é conhecido como incremento de Gauss.

O valor encontrado para $\delta$ é utilizado como incremento para um novo valor de $\theta\left(\theta=\theta^{0}+\delta\right)$. Calculado este novo valor procede-se uma nova iteração refazendo-se os cálculos anteriormente descritos $\operatorname{com} \theta^{0}$ substituído por esse novo valor estimado.

O número de iterações necessário para que se consiga valores satisfatórios para os parâmetros do sistema dependerá de quão longe estarão os valores iniciais dos parâmetros do processo.

Conforme o exposto no começo do capítulo, para se aplicar esta metodologia de estimação paramétrica é necessário, além de valores iniciais para os parâmetros, um conhecimento prévio das funções que descrevem o sistema a ser estudado.

Através da modelagem do motor de indução trifásico (capítulo 3) chega-se às funções que regem os comportamentos do transitório da corrente de estator para o ensaio degrau (eq.3.32)) e do decaimento da velocidade para o ensaio de desaceleração (eq.(3.46)). Através da observação destas equações nota-se a necessidade de se medir corrente, tensão e velocidade para que se possa estimar os parâmetros elétricos e mecânicos do MIT. 


\subsection{Estimação Paramétrica Utilizando o Método Simplex de Nelder- Mead}

O software gráfico MATLAB dispõe de sub-programas caracterizados em seu "Toolbox" que utilizam algoritmos que podem ser adaptados para a estimação paramétrica do MIT.

Um destes algoritmos é baseado no Método Simplex de Nelder-Mead (MATHWORKS Inc., 1993) que permite aproximar funções não lineares de diversas variáveis, bastando para isso conhecer o comportamento da função a ser aproximada, os valores iniciais dessas variáveis e o conjunto de pontos que descrevem esta função.

A função aproximada é do tipo

$$
y(t)=c(1) e^{\text {lambda(1)t }}+c(2) e^{\text {lambda(2)t }}+\ldots+c(n) e^{\text {lambda }(n) t}
$$

onde $c(1) \ldots . . c(n)$, lambda(1)... lambda(n) são os parâmetros que melhor aproximam a função representada pelo conjunto de pontos inicialmente fornecidos ao algoritmo.

Como no Método de Gauss-Newton, deve-se conhecer "a priori" o comportamento das funções que descrevem o sistema a ser estudado, para que se possa escrevê-la na forma da eq. (4.36). Estas funções são obtidas através da modelagem do MIT, conforme descrito no capítulo 3.

Para a estimação dos parâmetros elétricos, os parâmetros c(1)....c(n), lambda(1)... lambda(n) da eq.(4.36), correspondem-se com aqueles descritos pelas eqs.(3.33); para a estimação dos parâmetros mecânicos, esses parâmetros são relacionados com aqueles evidenciados pelas eqs.(3.48).

Como descrito anteriormente, para iniciar o processo de estimação através deste algoritmo é necessário que se forneçam os vetores que representam as grandezas envolvidas no processo de estimação e os valores iniciais para as variáveis da função.

Assim, no ambiente MATLAB, para o ensaio degrau, são fornecidos os vetores corrente de estator e o vetor tempo, relativos a um ensaio de aquisição. Para a 
estimação dos parâmetros mecânicos, através do ensaio de desaceleração, devem ser fornecidos os vetores tempo e velocidade do rotor, também relativos a um ensaio de aquisição.

A função a ser aproximada - escrita na forma da eq.(4.36) - e os valores iniciais para os parâmetros "lambda" são argumentos da função "FMINS" que basicamente contém o Método Simplex de Nelder-Mead, e que, em conjunto com as amostras de entrada, minimiza o erro da função a ser aproximada e retorna os valores dos parâmetros estimados. 


\section{Simulação}

A simulação mostra-se uma etapa sempre importante na execução de um projeto pois possibilita uma análise teórica e a previsão de possíveis erros na execução do mesmo antes que se realize sua implementação.

Neste trabalho, a etapa de simulação também tem o objetivo de investigar os algoritmos de estimação apresentados no capítulo 4 .

Ao longo dos anos muitas ferramentas e programas especializados foram desenvolvidos para a simulação de máquinas elétricas principalmente no que diz respeito à análise de seu transitório. Estas ferramentas e programas mostram-se cada vez mais eficazes na medida em que procuram expressar um determinado problema não em linguagem computacional mas, o mais próximo possível de sua linguagem natural, ou seja, em sua forma matemática (ALVARADO e CÃNIZARES, 1991).

Neste trabalho as simulações foram realizadas no ambiente MATLAB com auxílio também do sistema SIMULINK (MATHWORKS Inc., 1993). Este software mostrou-se rápido e muito eficiente na determinação do comportamento do motor de indução.

Os modelos matemáticos utilizados para a estimação dos parâmetros elétricos e mecânicos correspondem aos desenvolvidos no capítulo 3, representados pelas eqs.(3.26), (3.32) e (3.46) .

Para a simulação, utilizaram-se os dados de um motor de indução de dois pólos com as características mostradas na tabela 5.1 .

\subsection{Simulação - Parâmetros Elétricos}

Basicamente, para a estimação dos parâmetros elétricos do MIT utilizou-se o diagrama de blocos mostrado na fig.(5.1) onde a função de transferência foi desenvolvida no capítulo 3 (eq.(3.26)). 
Tabela 5.1 - Características do motor de indução utilizado na simulação.

\begin{tabular}{|l|l|}
\hline Potência & $2,2 \mathrm{~kW} / 3$ PS \\
\hline Rotação & $3420 \mathrm{rpm}$ \\
\hline Corrente & $\Delta 8,1 /$ Y 4,7 A \\
\hline Tensão & $\Delta 220 /$ Y 380 V \\
\hline Frequência & $50 \mathrm{~Hz}$ \\
\hline$R_{\mathrm{S}}$ & $3,85(\Omega)$ \\
\hline $\mathrm{L}_{\mathrm{S}}$ & $0,45(\mathrm{H})$ \\
\hline$\sigma$ & 0,099 \\
\hline $\mathrm{T}_{\mathrm{r}}$ & $0,22(\mathrm{~s})$ \\
\hline $\mathrm{J}$ & $0,007\left(\mathrm{Kgm}{ }^{2}\right)$ \\
\hline $\mathrm{K}_{\mathrm{D}}$ & $0,001882(\mathrm{Nms})$ \\
\hline $\mathrm{M}_{\mathrm{f}}$ & $0,025(\mathrm{Nm})$ \\
\hline
\end{tabular}

O degrau de tensão e o tempo de amostragem utilizados são de 10 Vcc e $1 \mathrm{Khz}$ respectivamente. $\mathrm{O}$ intervalo de simulação é escolhido de modo que a corrente de estator atinja seu valor de regime .

No procedimento da simulação, os valores do degrau de tensão e da correspondente corrente de fase, denominados aqui " $u$ " e " $y$ " respectivamente, são armazenados em vetores para posterior processamento pelos algoritmos de estimação descritos no capítulo 4.

Antes porém, multiplicou-se o vetor "y"(corrente de estator ) pelo fator $2 / 3$ uma vez que ela aparece $3 / 2$ vezes maior no modelo do MIT com excitação CC descrito no capítulo 3. Ao invés de se multiplicar o vetor corrente, consegue-se o mesmo resultado multiplicando os valores estimados de $R_{s}$ e $L_{s}$ por $2 / 3$ uma vez que a resistência equivalente na entrada do motor, vista pelo estator (fig.(3.1)), é $3 / 2$ vezes maior. 


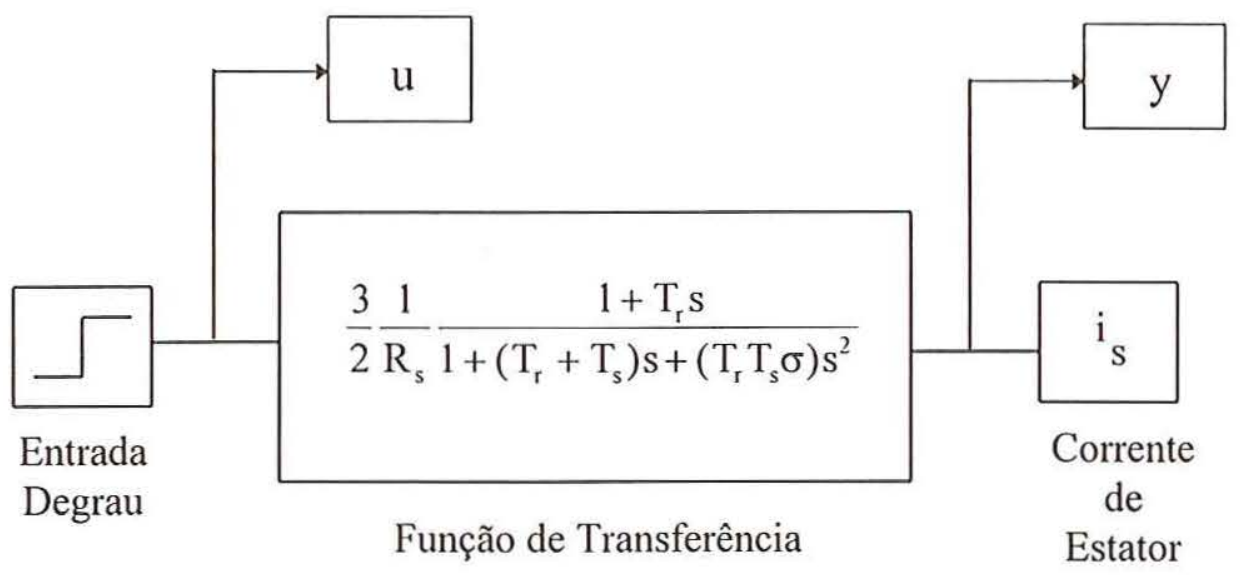

Fig. 5.1 - Diagrama de Blocos - Estimação Parâmetros Elétricos.

A fig. 5.2 abaixo, mostra o transitório da corrente do estator sujeita a um degrau de 10 Vcc:

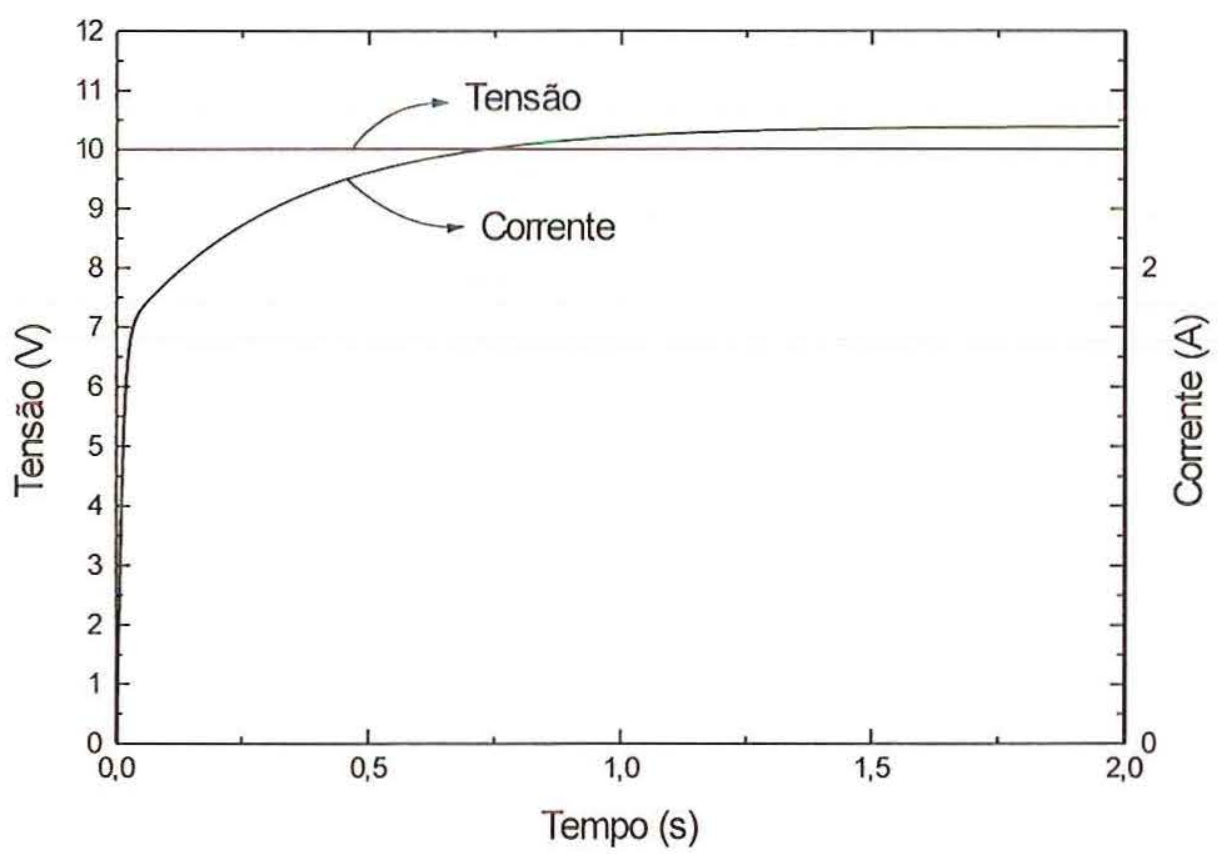

Figura 5.2 - Transitório da corrente do estator para um degrau de tensão de 10 Vcc. 
Essas características de simulação são utilizadas por todos os algoritmos de estimação dos parâmetros elétricos. Nota-se na fig.(5.2) que o transitório da corrente é realmente constituído por duas constantes de tempos distintas, uma mais rápida e uma mais lenta, conforme evidenciado no capítulo 3.

\subsubsection{Método dos Mínimos Quadrados Recursivo (RLS)}

O algoritmo RLS utilizou a sequência de operações mostrada abaixo:

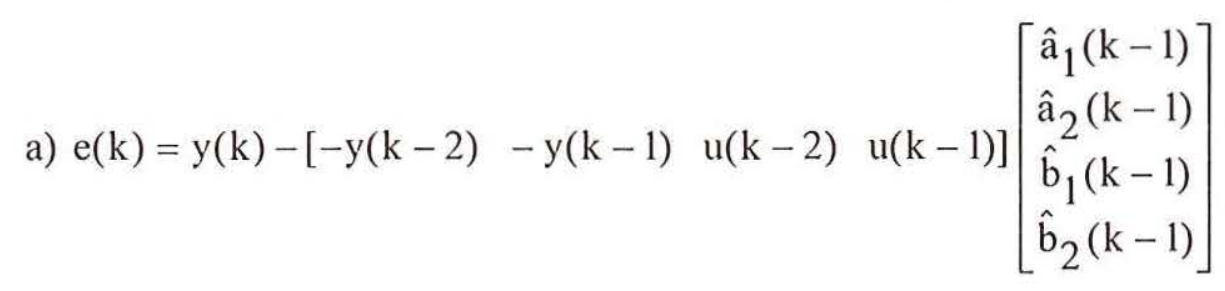

b) $\left[\begin{array}{l}\hat{a}_{1}(k) \\ \hat{a}_{2}(k) \\ \hat{b}_{1}(k) \\ \hat{b}_{2}(k)\end{array}\right]=\left[\begin{array}{c}\hat{a}_{1}(k-1) \\ \hat{a}_{2}(k-1) \\ \hat{b}_{1}(k-1) \\ \hat{b}_{2}(k-1)\end{array}\right]+\left[\begin{array}{c}\gamma_{1}(k-1) \\ \gamma_{2}(k-1) \\ \gamma_{3}(k-1) \\ \gamma_{4}(k-1)\end{array}\right]$ e(k)

c) $\psi^{\mathrm{T}}(\mathrm{k}+\mathrm{l})=[-\mathrm{y}(\mathrm{k}) \mathrm{u}(\mathrm{k})]$

d)

$P(k) \psi(k+1)=\left[\begin{array}{llll}\mathrm{P}_{11}(\mathrm{k}) & \mathrm{P}_{12}(\mathrm{k}) & \mathrm{P}_{13}(\mathrm{k}) & \mathrm{P}_{14}(\mathrm{k}) \\ \mathrm{P}_{21}(\mathrm{k}) & \mathrm{P}_{22}(\mathrm{k}) & \mathrm{P}_{23}(\mathrm{k}) & \mathrm{P}_{24}(\mathrm{k}) \\ \mathrm{P}_{31}(\mathrm{k}) & \mathrm{P}_{32}(\mathrm{k}) & \mathrm{P}_{33}(\mathrm{k}) & \mathrm{P}_{34}(\mathrm{k}) \\ \mathrm{P}_{41}(\mathrm{k}) & \mathrm{P}_{42}(\mathrm{k}) & \mathrm{P}_{43}(\mathrm{k}) & \mathrm{P}_{44}(\mathrm{k})\end{array}\right]\left[\begin{array}{c}-\mathrm{y}(\mathrm{k}-1) \\ -\mathrm{y}(\mathrm{k}) \\ \mathrm{u}(\mathrm{k}-1) \\ \mathrm{u}(\mathrm{k})\end{array}\right]=\left[\begin{array}{c}\mathrm{i}_{1} \\ \mathrm{i}_{2} \\ \mathrm{i}_{3} \\ \mathrm{i}_{4}\end{array}\right]=\mathbf{i}$

e) $\psi^{\mathrm{T}}(\mathrm{k}+1) \mathbf{P}(\mathrm{k}) \psi(\mathrm{k}+1)=[-\mathrm{y}(\mathrm{k}-1) \quad \mathrm{y}(\mathrm{k}) \mathrm{u}(\mathrm{k}-1) \quad \mathrm{u}(\mathrm{k})] \quad \mathbf{i}=\mathbf{j}$ 
f) $\left[\begin{array}{c}\gamma_{1}(k+1) \\ \gamma_{2}(k+1) \\ \gamma_{3}(k+1) \\ \gamma_{4}(k+1)\end{array}\right]=\frac{1}{j+\lambda}\left[\begin{array}{l}i_{1} \\ i_{2} \\ i_{3} \\ i_{4}\end{array}\right]$

g) $\mathbf{P}(\mathrm{k}+1)=\frac{1}{\lambda}\left[\mathbf{P}(\mathrm{k})-\gamma(\mathrm{k}) \psi^{\mathrm{T}}(\mathrm{k}+1) \mathbf{P}(\mathrm{k})\right]$

h) Incrementar o valor de k e voltar ao item a)

Como mostra este algoritmo, neste programa são calculados os parâmetros discretos $\left(\hat{a}_{1}, \hat{a}_{2}, \hat{b}_{1}\right.$ e $\left.\hat{b}_{2}\right)$ de maneira iterativa utilizando o número de amostras armazenados nos vetores de entrada "u" e saída "y".

A matriz $\mathbf{P}$ foi inicializada com valor $10^{6} \mathrm{e} \gamma, \psi$ e $\theta$ com valor zero.

Conhecidos os valores dos parâmetros discretos $\hat{a}_{1}, \hat{a}_{2}, \hat{b}_{1}$ e $\hat{b}_{2}$ através do algoritmo de identificação e o tempo de amostragem $\mathrm{T}_{0}$, pode-se calcular os valores de $T_{1}, T_{2}, z_{1}, z_{2}$ através das eqs. (3.41), (3.42), (3.35) e (3.36) respectivamente.

Calculados esses valores, através das eqs. (3.28) à (3.31) obtém-se os parâmetros elétricos $\mathrm{T}_{\mathrm{r}}, \mathrm{R}_{\mathrm{s}}, \mathrm{T}_{\mathrm{s}}, \mathrm{L}_{\mathrm{s}}$ e $\sigma$ do MIT.

Foram utilizados diversos valores para o fator de esquecimento não sendo observadas mudanças consideráveis na estimação dos parâmetro elétricos do MIT. Para valores inferiores a 0.9 o sistema apresentava-se instável não sendo possível a estimação correta dos parâmetros.

A simulação serviu para se comprovar a eficiência do método RLS na estimação dos parâmetros elétricos.

Como se pode observar na fig.(5.3) os parâmetros discretos $\hat{a}_{1}, \hat{a}_{2}, \hat{b}_{1}$ e $\hat{b}_{2}$ convergiram rapidamente para seus valores finais utilizando um fator de esquecimento com valor fixo $(\lambda=1)$.

Os resultados da estimação dos parâmetros elétricos do MIT utilizando este método são resumidos na tabela (5.2) no final deste capítulo 


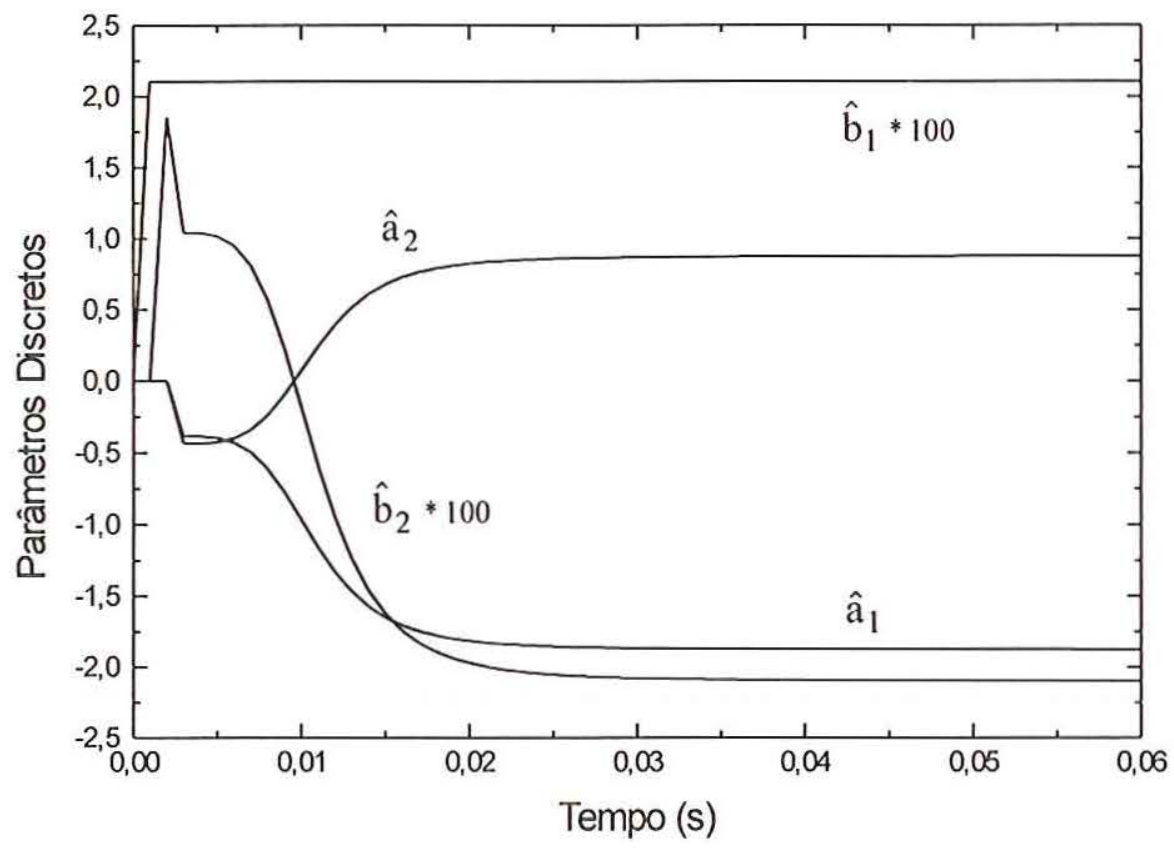

Figura 5.3 - Valores de convergência dos parâmetros discretos $\hat{a}_{1}, \hat{a}_{2}, \hat{b}_{1}$ e $\hat{b}_{2}$.

\subsubsection{Método de Gauss-Newton}

A estimação dos parâmetros elétricos utilizando o Método de Gauss-Newton utilizou os mesmos procedimentos descritos anteriormente para o Método RLS: a tensão e corrente correspondente de estator foram amostradas e armazenadas em vetores para depois serem processados.

$O$ Método de Gauss-Newton estima os valores de $A_{0}, A_{1}, A_{2}, T_{1}$ e $T_{2}$ da eq.(3.32) a partir de valores iniciais para estas variáveis. Como discutido no capítulo 4, estes parâmetros podem ser descobertos dentro de uma certa coerência ou estimados previamente a partir de alguma informação disponível.

Através destes valores e das correspondências evidenciadas pelas eqs.(3.28) à (3.31), chega-se aos valores estimados dos parâmetros elétricos do MIT .

Os parâmetros estimados utilizando o Método de Gauss-Newton são apresentados na tabela (5.2) no final do capítulo. 


\subsubsection{Estimação com o Método Simplex de Nelder-Mead}

Conforme descrito no Capítulo 4, o MATLAB dispõe de algoritmos próprios que podem ser adaptados para estimação dos parâmetros elétricos do MIT.

O algoritmo utilizado neste trabalho é baseado no Método Simplex de Nelder-Mead onde procura aproximar-se uma função qualquer de forma que o erro desta aproximação seja o menor possível. A função a ser aproximada, no caso , é a mesma utilizada no Método de Gauss-Newton (eq.(3.32)) e os procedimentos utilizados na simulação deste método são os mesmos descritos anteriormente.

Da mesma forma que para o Método de Gauss-Newton é necessário também que se forneçam valores iniciais para os parâmetros da função a ser aproximada. Os resultados deste método de estimação também são mostrados na tabela 5.2.

\subsection{Simulação - Parâmetros Mecânicos}

Para a estimação dos parâmetros mecânicos do MIT, não sendo possível simular o seu desligamento através do MATLAB , gera-se através de um programa, a curva de decaimento da velocidade do mesmo.

Com os dados do motor da tabela (5.1) e com o auxílio da eq.(3.46), o comportamento do decaimento da velocidade a partir do desligamento do MIT é tal como representado na fig.(5.4).

O tempo de simulação é escolhido de modo que a velocidade do motor atinja zero.

Conforme se observa na fig.(5.4), o motor é desligado a partir de uma velocidade de regime $\omega_{0}$. Determina-se esta velocidade a partir da simulação do motor, utilizando o modelo vetorial com o sistema de coordenadas fixo no estator (eixo A-B). Também, determina-se a partir deste modelo o conjugado de regime $\mathrm{m}_{\mathrm{d} 0}$ necessário para a estimação dos parâmetros mecânicos conforme discutido no capítulo 3. 


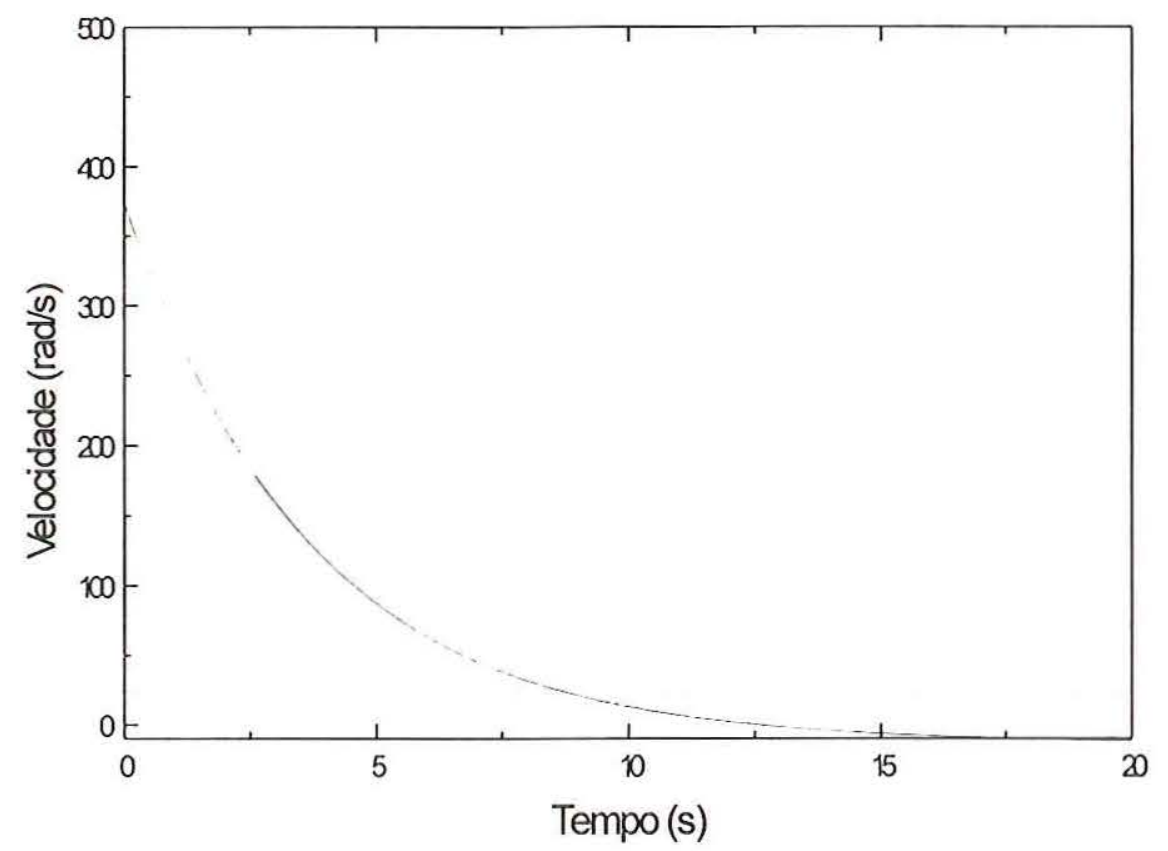

Figura 5.4 - Curva de decaimento da velocidade do motor de indução.

Da mesma forma que, para os parâmetros elétricos, os valores da velocidade do motor e do tempo do processo, são armazenados em vetores para posterior processamento pelos algoritmos de estimação descritos no capítulo 4.

\subsubsection{Método de Gauss-Newton}

O Método de Gauss-Newton processa os dados amostrados e armazenados em vetores e fornece os valores estimados dos parâmetros mecânicos do motor. Basicamente, este algoritmo estima os valores de $\theta_{1}, \theta_{2}$ e $\theta_{3}$ da eq.(3.48).

Como o Método determina, devem ser fornecidos valores iniciais para estas variáveis, devidamente escolhidos, para que se assegure uma rápida e correta convergência dos mesmos. Com os valores dessas variáveis estimadas pelo método, obtêm-se os valores dos parâmetros mecânicos do MIT através das relações descritas pelas eqs.(3.48a) (3.48b) e (3.48c) do capítulo 3. Antes, porém, é necessário ainda 
que se conheça o conjugado e velocidade de regime do motor $\left(m_{d 0}\right.$ e $\omega_{0}$ respectivamente) para se determinarem os parâmetros mecânicos do MIT. Para se conseguir o conjugado e velocidade de regime, simulou-se o modelo vetorial do MIT no sistema de coordenadas A-B, fixo no estator, com uma tensão de alimentação tipo senoidal de 220 Vca de pico e frequência de $60 \mathrm{~Hz}$. O intervalo de simulação foi escolhido de modo a permitir que o motor atingisse sua velocidade de regime.

Os parâmetros estimados utilizando o Método de Gauss-Newton para um $\mathrm{m}_{\mathrm{d} 0}=0.6784 \mathrm{Nm}$ e $\omega_{0}=373.8759 \mathrm{rad} / \mathrm{s}$ são mostrados na tabela (5.2) no final deste capítulo.

\subsubsection{Estimação com o Método Simplex de Nelder-Mead}

Para a simulação com o algoritmo do MATLAB utiliza-se o mesmo procedimento descrito no item 5.2.1 onde inicialmente são determinados os valores do conjugado e velocidade de regime $\left(\mathrm{m}_{\mathrm{d} 0}\right.$ e $\omega_{0}$ respectivamente) através da simulação do motor no sistema de coordenadas fixo no estator (sistema de coordenadas A-B), com uma tensão de alimentação tipo senoidal de 220 Vca de pico e frequência de $60 \mathrm{~Hz}$

Através de um programa contendo a eq.(3.46), gera-se a curva de decaimento da velocidade do motor, representada pela fig.(5.4) com os valores da velocidade e tempo do processo armazenados em vetores. Esses vetores são então processados pelo algoritmo.

Os resultados da simulação utilizando este método, bem como os resultados da simulação utilizando os demais métodos de estimação paramétrica são apresentados na tabela (5.2).

Através dos resultados apresentados na tabela (5.2) acima, conclui-se que os métodos de estimação propostos, são eficazes na determinação dos parâmetros elétricos e mecânicos de um motor de indução trifásico; os valores estimados praticamente igualaram-se aos valores dos parâmetros do motor de indução da tabela(5.1). 
Tabela 5.2 - Tabela comparativa dos parâmetros estimados através de simulação.

\begin{tabular}{lccccccc}
\hline & $\begin{array}{c}\mathrm{R}_{\mathrm{S}} \\
(\Omega)\end{array}$ & $\begin{array}{c}\mathrm{L}_{\mathrm{S}} \\
(\mathrm{H})\end{array}$ & $\sigma$ & $\begin{array}{c}\mathrm{T}_{\mathrm{r}} \\
(\mathrm{s})\end{array}$ & $\begin{array}{c}\mathrm{J} \\
\left(\mathrm{Kgm}^{2}\right)\end{array}$ & $\begin{array}{c}\mathrm{K}_{\mathrm{D}} \\
(\mathrm{Nms})\end{array}$ & $\begin{array}{c}\mathrm{M}_{\mathrm{f}} \\
(\mathrm{Nm})\end{array}$ \\
& & & & & & & \\
\hline Valores Teóricos & 3,8500 & 0,4500 & 0,0990 & 0,2200 & 0,0070 & 0,001882 & 0,0250 \\
RLS & 3,8500 & 0,4499 & 0,0990 & 0,2199 & - & - & - \\
Gauss-Newton & 3,8500 & 0,4499 & 0,0989 & 0,2199 & 0,0070 & 0,001900 & 0,0250 \\
& & & & & & & \\
Matlab & 3,8496 & 0,4501 & 0,0990 & 0,2200 & 0,0070 & 0,001900 & 0,0250 \\
\hline
\end{tabular}

Os resultados obtidos, utilizando o algoritmo RLS básico, foram satisfatórios não sendo necessária a utilização do algoritmo RELS, uma vez que a simulação é um ambiente idealizado sem a influência de ruídos que normalmente se encontram na prática.

Devido à proximidade entre os parâmetros estimados - elétricos e mecânicos pelos métodos descritos neste capítulo, e os parâmetros teóricos da tabela (5.1), não se é possível distinguir diferenças entre as curvas que utilizam valores estimados e aquelas que utilizam valores teóricos, razão pela qual se omitem os gráficos comparativos entre esses dois valores. 


\section{Implementação}

Neste capítulo são descritos os equipamentos e os procedimentos necessários à implementação do processo de identificação dos parâmetros do motor de indução trifásico, bem como o processo de sincronização para leitura de tensão, corrente e velocidade para a identificação dos parâmetros elétricos e mecânicos segundo os procedimentos adotados no capítulo 3.

O equipamento básico constitui-se de uma plataforma de aquisição digital baseado em um microcomputador do tipo PC AT-286.

Os dados são lidos através de uma placa de aquisição de dados disponível no laboratório e depois processados em um programa com um dos algoritmo de identificação como descritos no capítulo 4.

\subsection{Descrição do Sistema para Estimação dos Parâmetros Elétricos}

O diagrama de blocos do equipamento e circuitos necessários para a implementação do método de estimação dos parâmetros elétricos do motor de indução é o esquematizado na fig. 6.1 abaixo:

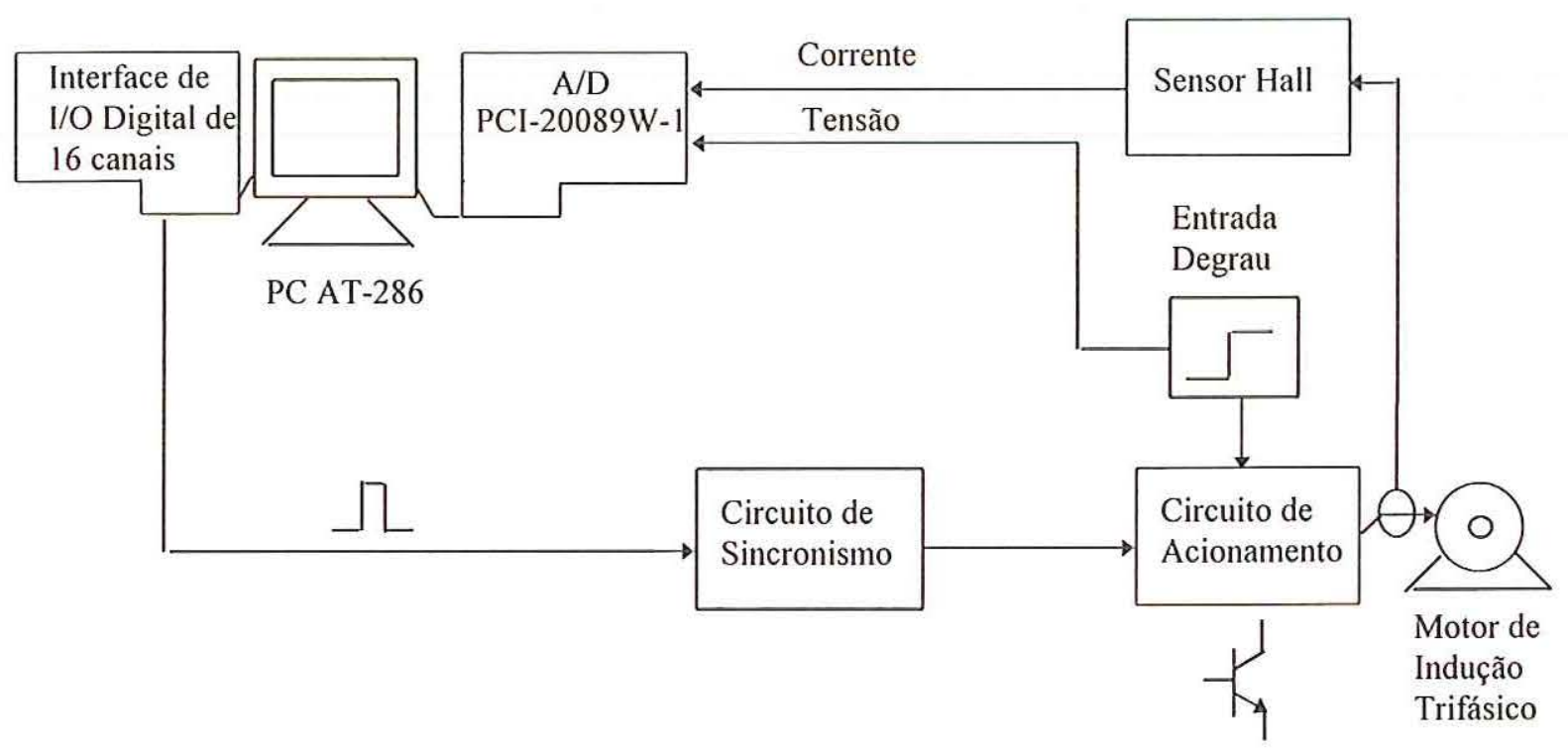

Fig. 6.1 - Diagrama de Blocos para implementação do ensaio degrau. 
Para a identificação dos parâmetros elétricos pelo Método do Mínimos Quadrados Recursivo (RLS) e Recursivo Estendido (RELS) deve-se fazer a leitura sincronizada dos dados a serem processados. É necessário que o circuito de aquisição possua um conversor $\mathrm{A} / \mathrm{D}$ suficientemente rápido para que se possa amostrar as grandezas envolvidas no processo (no caso tensão e corrente) em instantes de tempo praticamente iguais.

O circuito utilizado para a aquisição dos dados foi uma placa PCI-20089W-1 (PCI-20089W-1, da Burr-Brown que é conectada ao barramento PC-AT do microcomputador. Esta placa possui entre outras características a possibilidade de aquisição de 16 canais simples ou 8 diferenciais para leitura de entradas analógicas. Internamente contém um conversor A/D de 12 bits. Possui funções configuráveis via programação ou através de "jumpers" internos.

A placa de aquisição pode também ser programada para fornecer uma saída tipo gerador de onda quadrada ou pulsada. Este gerador é utilizado como uma das formas para se iniciar a conversão de um canal analógico servindo como base, para que o usuário programe a frequência de amostragem desejada. No caso específico desse projeto, programou-se o gerador de forma que ele fornecesse uma onda quadrada a qual foi responsável por todo o processo de sincronização.

Como foi citado, a PCI-20089W-1 permite duas maneira para se iniciar o processo de conversão: a conversão via "software"e a conversão via "hardware". Utilizou-se a conversão via "hardware".

Neste tipo de processo, uma conversão é iniciada a cada transição positiva do gerador de onda ou quando se faz a escrita em um registrador específico da placa .

$\mathrm{Na}$ estimação dos parâmetros elétricos faz-se necessária a leitura de dois canais analógicos: um para o degrau de tensão e o outro para a corrente de estator, respectivamente entrada e saída do processo a ser analisado, segundo enunciado no capítulo 3.

Assim sendo, cada vez que gerador de onda sofre uma transição positiva é necessário, então, uma devida inicialização da placa de aquisição, de modo que ela execute duas amostragens consecutivas. 
O tempo gasto para se processar a leitura de canais sucessivos deve ser muito pequeno para que as grandezas sejam amostradas em instantes próximos. Para a placa utilizada no experimento foi possível amostrar dois sinais em um intervalo de tempo de $100 \mu$ s.

O processo de aquisição de dados deve ser iniciado no instante em que o gerador de onda inicia uma transição positiva. Para se conseguir tal sincronismo utilizou-se uma interface de I/O desenvolvida no laboratório para uso com o PC-AT. Esta interface possui entradas e saídas digitais de 8 bits sendo 8 canais de entrada e 8 canais de saída. É utilizada para fazer a comunicação entre o computador com dispositivos de entrada e saída de dados como encoders, conversores A/D, D/A etc..

Através de uma instrução de escrita para I/O é acionado um módulo a transistores que atuará como uma chave fornecendo a excitação para o MIT.

Finalizando a descrição do sistema, foi utilizado um sensor Hall para a aquisição dos valores de corrente e para se obter um isolamento galvânico entre o processo real (o motor) e o sistema de aquisição digital.

\subsection{Descrição do Sistema para Estimação dos Parâmetros Mecânicos}

A estimação dos parâmetros mecânicos do MIT pelo ensaio de desaceleração requer a leitura da tensão/corrente de estator e velocidade de rotor como descrito no capítulo 3.

Utiliza-se a PCI-20089W-1 para a aquisição de tensão/corrente de regime e a interface de I/O para a leitura da velocidade do máquina.

O motor é alimentado através de um variac trifásico. O processo de aquisição é iniciado com o motor em regime, a partir do qual são lidas a tensão ou a corrente de regime em uma das fases. Após o desligamento das três fases de alimentação simultaneamente processa-se a leitura da velocidade do rotor.

O sensoriamento das grandezas envolvidas neste experimento é efetuado através de um sensor Hall para a leitura de tensão/corrente e um encoder de 1500 pulsos para leitura da velocidade do rotor. 


\section{Resultados Experimentais}

Este capítulo descreve os resultados experimentais obtidos em laboratório para a estimação paramétrica de um motor de indução com parâmetros elétricos e mecânicos desconhecidos, utilizando os ensaios descritos no capítulo 3: degrau de tensão $\mathrm{CC}$ e desaceleração do motor. Também é realizado o ensaio de partida do motor para a validação dos modelos empregados neste trabalho. Para isso, utilizaramse os equipamentos descritos no capítulo 6 onde as grandezas envolvidas são amostradas e armazenadas em vetores para posterior processamento. Todos os programas são desenvolvidos em linguagem C.

Após a estimação, os parâmetros são então simulados novamente no ambiente MATLAB, como descrito no capítulo 5, para comparação com as curvas práticas obtidas em laboratório, tendo em vista à validação dos procedimentos e das grandezas estimadas.

O motor utilizado para os ensaios é o motor modelo 71888 DA da WEG com as características técnicas especificadas na tabela 7.1.

Tabela 7.1 - Características téenicas do motor utilizado nos experimentos.

\begin{tabular}{|l|l|}
\hline Potência & $1 \mathrm{cv}$ \\
\hline Rotação & $3420 \mathrm{rpm}$ \\
\hline Corrente & $\Delta 3,2 /$ Y $1,9 \mathrm{~A}$ \\
\hline Tensão & $\Delta 220 /$ Y $380 \mathrm{~V}$ \\
\hline Frequência & $60 \mathrm{~Hz}$ \\
\hline$\underline{\mathrm{I}_{\mathrm{P}}}$ & 6,8 \\
\hline $\mathrm{I}_{\mathrm{N}}$ & \\
\hline
\end{tabular}




\subsection{Parâmetros Elétricos}

Como descrito anteriormente, o ensaio degrau consiste na aplicação de um degrau de tensão $\mathrm{CC}$ no enrolamento de estator, com registro do correspondente comportamento da corrente.

Os valores de tensão e corrente de estator são então processados utilizando as técnicas descritas no capítulo 4.

O valor da amplitude do degrau de tensão a ser utilizado no ensaio, deve ser tal que o nível da corrente não atinja valores que evidenciem a saturação do motor. Assim, adotou-se um valor de tensão de ensaio, de modo que a corrente não ultrapassasse $50 \%$ do valor nominal em regime. Para o motor sob teste, com valores acima de $50 \%$ da corrente nominal, verificou-se sensível deformação do comportamento transitório da corrente de ensaio, em comparação com níveis inferiores de corrente. O intervalo de simulação é escolhido de modo que a corrente de estator atinja seu valor de regime permanente. Essas características de ensaio são utilizadas por todos os algoritmos de estimação para os parâmetros elétricos.

Mantidas essas características os ensaios são realizados para diversas frequências de amostragem.

\subsubsection{Método dos Mínimos Quadrados Recursivo Estendido (RELS)}

No método RELS são utilizadas as grandezas tensão e corrente amostradas, que são processadas em um programa contendo este algoritmo. A utilização deste método justifica-se, pois o sistema em laboratório apresenta-se muito ruidoso. Os resultados obtidos são mostrados na tabela (7.2). 
Tabela 7.2 - Parâmetros elétricos estimados pelo Método RELS para diversas frequências de amostragem.

\begin{tabular}{cccccc}
\hline $\begin{array}{c}\text { Freqüência de } \\
\text { amostragem }\end{array}$ & $\begin{array}{c}\mathrm{T}_{\mathrm{r}} \\
(\mathrm{s})\end{array}$ & $\begin{array}{c}\mathrm{T}_{\mathrm{s}} \\
(\mathrm{s})\end{array}$ & $\sigma$ & $\mathrm{R}_{\mathrm{s}}$ & $\begin{array}{c}\mathrm{L}_{\mathrm{s}} \\
(\mathrm{Hz})\end{array}$ \\
\hline 500 & 0,3032 & 0,0845 & 0,1312 & 7,5170 & 0,6351 \\
1000 & 0,1509 & 0,0834 & 0,0843 & 7,5543 & 0,6302 \\
2000 & 0,1560 & 0,0805 & 0,0786 & 7,6516 & 0,6159 \\
3000 & 0,1487 & 0,0848 & 0,0764 & 8,0071 & 0,6788 \\
\hline
\end{tabular}

Verifica-se na tabela acima, que o método RELS possui uma dependência direta com a frequência de amostragem, uma vez que esta entra efetivamente nos cálculos dos parâmetros, conforme apresentado no capítulo 3. Para valores menores da frequência de amostragem, o número de amostras adquiridas no intervalo determinado pela constante de tempo mais rápida da eq.(3.32) será menor e, consequentemente, a imprecisão dos resultados será maior. Por outro lado, com frequências de amostragem maiores, se obtém maior precisão dos resultados.

A curva simulada degrau utilizando os parâmetros estimados pelo Método RELS para uma frequência de amostragem de $2000 \mathrm{~Hz}$, e a curva real obtida em laboratório são mostradas na fig.(7.1)

Como evidenciado na eq.(3.32) e já verificado na etapa de simulação, comprova-se experimentalmente que o transitório da corrente de estator é formado por uma constante de tempo rápida e outra mais lenta. Os valores de convergência para os parâmetros discretos $\hat{a}_{1}, \hat{a}_{2}, \hat{b}_{1}$ e $\hat{b}_{2}$ são apresentados na fig.(7.2). 


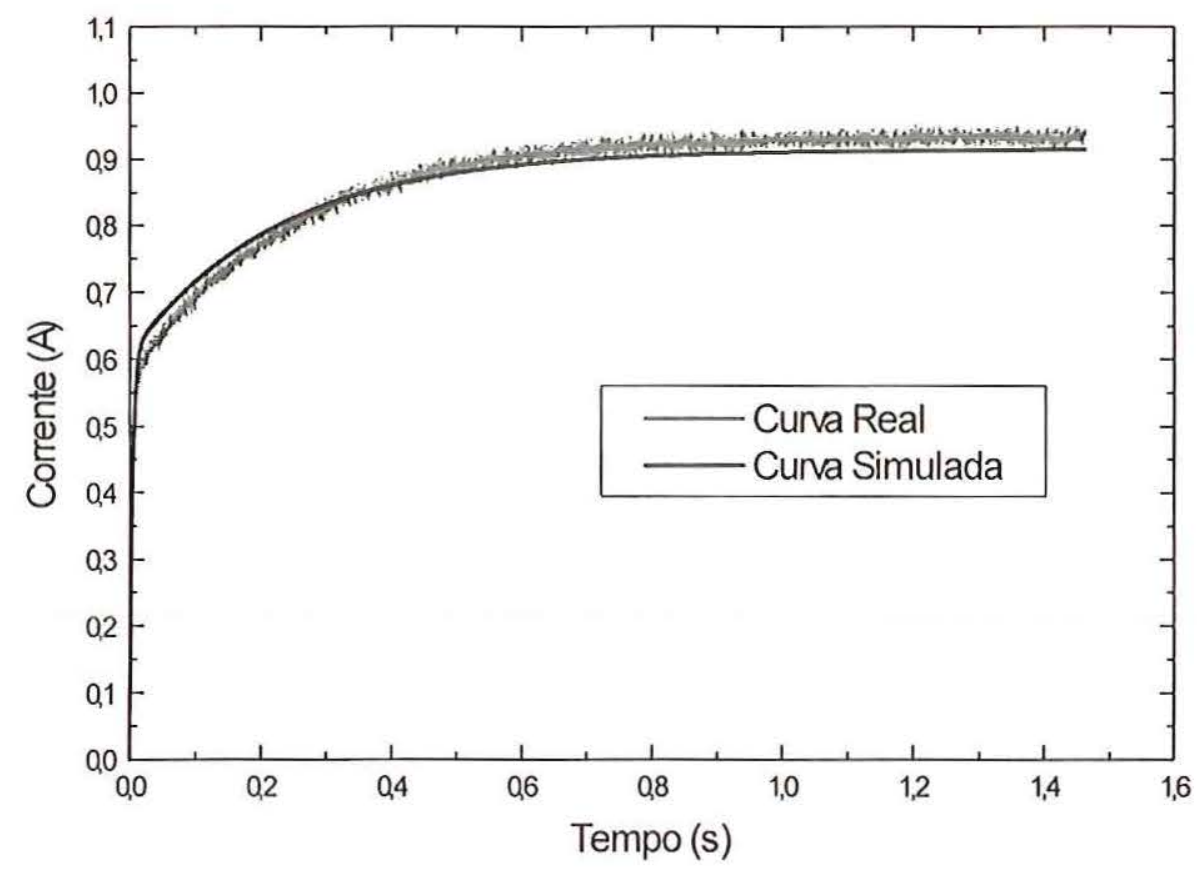

Fig 7.1 - Comparação entre a curva real e a simulada com parâmetros estimados pelo Método RELS.

Na fig.(7.2), a escala de tempo foi expandida em relação a fig.(7.1), para melhor visualização do comportamento das curvas no início do processo. Na fig.(7.2) nota-se uma rápida convergência dos parâmetros discretos para seus valores finais.

\subsubsection{Método de Gauss-Newton}

Os resultados obtidos utilizando o Método de Gauss-Newton para diferentes frequências de amostragem são mostrados na tabela (7.3) . 


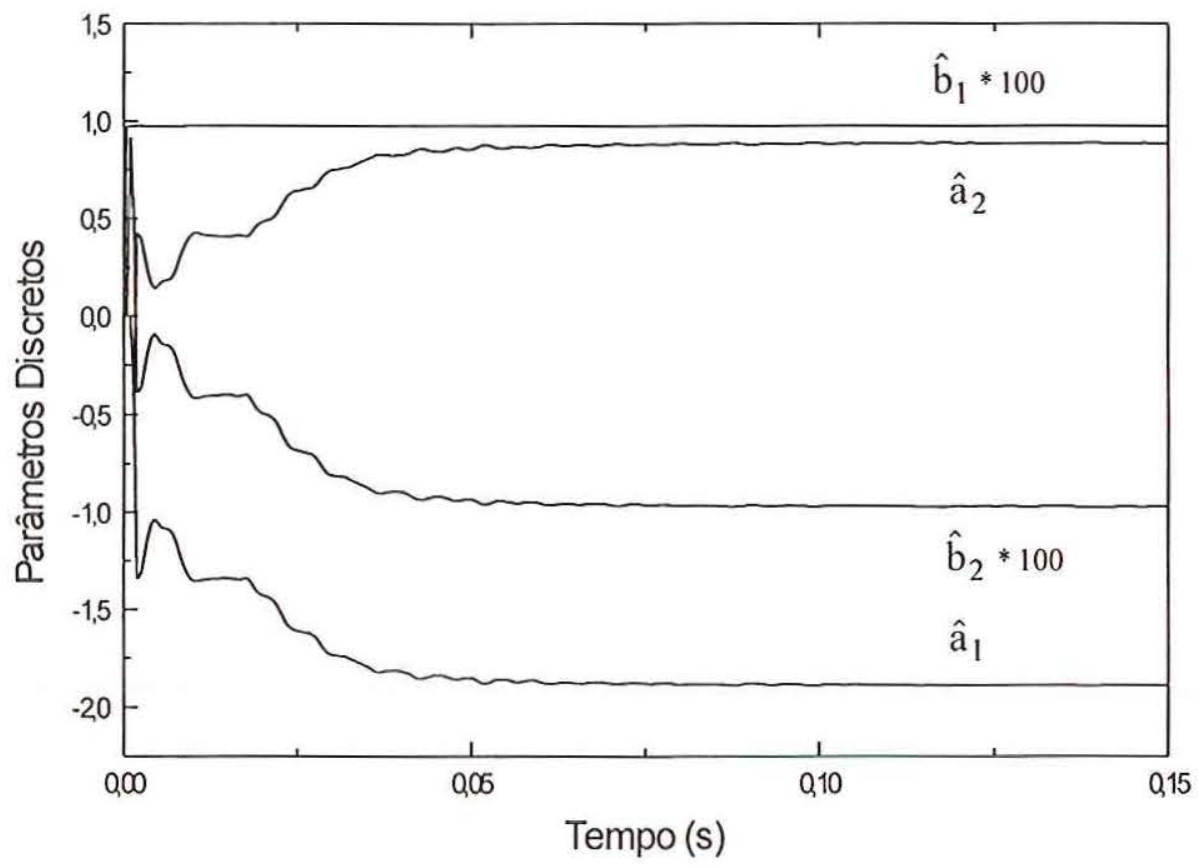

Fig 7.2 - Valores de Convergência dos parâmetros discretos $\hat{a}_{1}, \hat{a}_{2}, \hat{b}_{1}$ e $\hat{b}_{2}$ utilizando o Método RELS.

Como o esperado, os parâmetros estimados através do Método de GaussNewton possuem uma dependência indireta com a frequência de amostragem. De fato, quanto maior o número de amostras, maior a precisão do método nos cálculos.

$\mathrm{O}$ gráfico das curvas real e simulada com os parâmetros estimados à frequência de $1000 \mathrm{~Hz}$ é mostrado na figura (7.3).

Tabela 7.3 - Parâmetros elétricos estimados pelo Método de Gauss-Newton para diversas frequências de amostragem.

\begin{tabular}{cccccc}
\hline $\begin{array}{c}\text { Frequência de } \\
\text { amostragem }\end{array}$ & $\begin{array}{c}\mathrm{T}_{\mathrm{r}} \\
(\mathrm{s})\end{array}$ & $\begin{array}{c}\mathrm{T}_{\mathrm{s}} \\
(\mathrm{s})\end{array}$ & $\sigma$ & $\mathrm{R}_{\mathrm{s}}$ & $\begin{array}{c}\mathrm{L}_{\mathrm{s}} \\
(\mathrm{Hz})\end{array}$ \\
\hline 500 & 0,1611 & 0,0892 & 0,0792 & 7,4847 & 0,6673 \\
1000 & 0,1487 & 0,0958 & 0,0669 & 7,5022 & 0,7185 \\
2000 & 0,1521 & 0,0983 & 0,0604 & 7,4742 & 0,7351 \\
3000 & 0,1499 & 0,1051 & 0,0622 & 7,6818 & 0,8072 \\
\hline
\end{tabular}




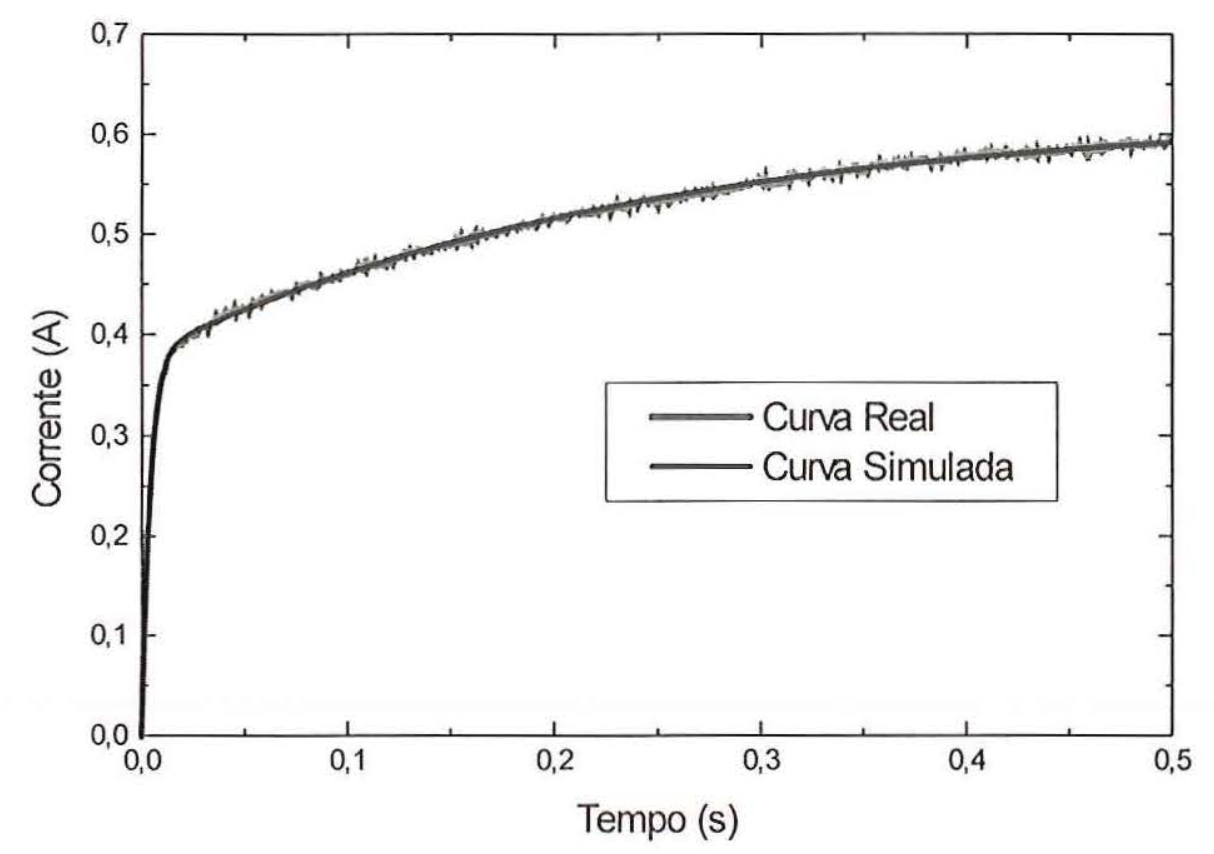

Fig 7.3 - Comparação entre a curva real e a simulada com parâmetros estimados pelo Método de Gauss-Newton.

A fig.(7.3) acima, reforça a eficiência do método já comprovada no capítulo 5 na fase de simulação. Nota-se que não existe diferença entre a curva real e a simulada.

Nesta mesma figura, comprova-se novamente em laboratório que a corrente de estator é realmente constituída de duas constantes de tempo distintas, assegurando que o modelo desenvolvido no capítulo 3 é adequado e coerente para o estudo aqui apresentado.

\subsubsection{Estimação com o Método Simplex de Nelder-Mead}

Os resultados obtidos utilizando o Método Simplex de Nelder-Mead, disponível no MATLAB são mostrados na tabela (7.4) abaixo: 
Tabela 7.4 - Parâmetros elétricos estimados pelo Método Simplex de Nelder-Mead para diversas frequências de amostragem.

\begin{tabular}{cccccc}
\hline $\begin{array}{c}\text { Frequência de } \\
\text { amostragem }\end{array}$ & $\begin{array}{c}\mathrm{T}_{\mathrm{r}} \\
(\mathrm{s})\end{array}$ & $\begin{array}{c}\mathrm{T}_{\mathrm{s}} \\
(\mathrm{s})\end{array}$ & $\sigma$ & $\mathrm{R}_{\mathrm{s}}$ & $\begin{array}{c}\mathrm{L}_{\mathrm{s}} \\
(\mathrm{Hz})\end{array}$ \\
\hline 500 & 0,1594 & 0,0908 & 0,0786 & 7,2243 & 0,6563 \\
1000 & 0,1511 & 0,0935 & 0,0675 & 6,7489 & 0,6307 \\
2000 & 0,1484 & 0,1020 & 0,0597 & 6,3392 & 0,6468 \\
3000 & 0,1542 & 0,1008 & 0,0630 & 6,5434 & 0,6596 \\
\hline
\end{tabular}

Novamente, como no Método de Gauss-Newton, existe apenas uma dependência indireta entre este método e a frequência de amostragem.

A fig. (7.4) apresenta as curvas real e simulada com os parâmetros estimados através desse método à uma frequência de $1000 \mathrm{~Hz}$.

Novamente, nota-se a eficiência deste método na estimação dos parâmetros elétricos do motor uma vez que a curva real e a simulada são praticamente as mesmas.

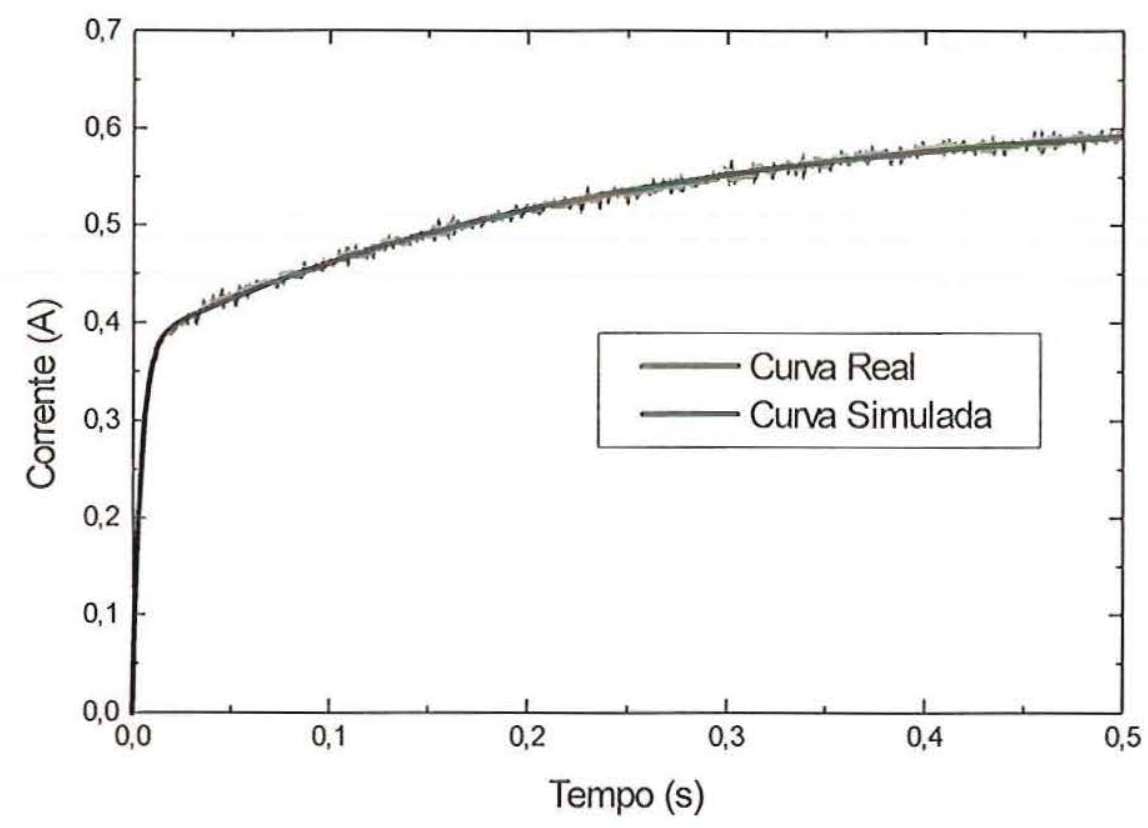

Fig 7.4 -Comparação entre a curva real e a simulada com parâmetros estimados pelo Método Simplex de Nelder-Mead. 


\subsection{Parâmetros Mecânicos}

Os parâmetros mecânicos do motor de indução são estimados através do ensaio de desaceleração do motor conforme discutido no capítulo 3.

Neste ensaio são medidos, através dos equipamentos descritos no capítulo 6, a tensão de alimentação, a velocidade de regime e a velocidade de decaimento do motor.

Os métodos utilizados para a estimação dos parâmetros mecânicos neste trabalho (Gauss-Newton e MATLAB) necessitam do valor do conjugado de regime do motor para cálculo dos parâmetros mecânicos, conforme discutido no capítulo 3 . $\mathrm{O}$ conjugado de regime é calculado pela eq. (3.51). Esta equação utiliza os valores da tensão de alimentação e velocidade de regime do motor, daí a necessidade da medição destas duas grandezas.

Nesta mesma equação, nota-se ainda, a necessidade de um conhecimento prévio dos parâmetros elétricos $T_{\mathrm{r}}, \mathrm{L}_{\mathrm{S}}$ e $\sigma$ para o cálculo do conjugado de regime do motor. Esses valores podem ser obtidos através do ensaio degrau anteriormente descrito no item 7.1.2.

Assim, o ensaio é realizado com uma tensão senoidal de 126,42 Vca (pico) com frequência de $60 \mathrm{~Hz}$ fornecendo uma velocidade de regime de $372,28 \mathrm{rad} / \mathrm{s}$. A frequência de amostragem utilizada é de $500 \mathrm{~Hz}$.

Após o desligamento do motor, o valor da velocidade de decaimento e tempo de ensaio são armazenados em vetores, aqui chamados de "t" e "w". Esses vetores são então processados calculando-se o conjugado de regime (eq.3.51). O tempo de ensaio é escolhido de modo que a velocidade do motor seja zero.

\subsubsection{Método de Gauss-Newton}

Conforme exposto no item 7.2, para se calcular o valor do conjugado de regime do MIT é necessário que se conheçam os parâmetros elétricos $T_{r}, L_{s}$ e $\sigma$. Assim, os valores obtidos para os parâmetros mecânicos e conjugado de regime apresentados na tabela (7.5), utilizam os valores de $T_{r}, L_{s}$ e $\sigma$ da tabela (7.3): 
Tabela 7.5 - Parâmetros mecânicos estimados pelo Método de Gauss-Newton.

\begin{tabular}{ccccccc}
\hline $\begin{array}{c}\mathrm{T}_{\mathrm{r}} \\
(\mathrm{s})\end{array}$ & $\sigma$ & $\begin{array}{c}\mathrm{L}_{\mathrm{s}} \\
(\mathrm{H})\end{array}$ & $\begin{array}{c}\mathrm{m}_{\mathrm{d} 0} \\
(\mathrm{Nm})\end{array}$ & $\begin{array}{c}\mathrm{J} \\
\left(\mathrm{Kgm}^{2}\right)\end{array}$ & $\begin{array}{c}\mathrm{K}_{\mathrm{D}} \\
(\mathrm{Nms})\end{array}$ & $\begin{array}{c}\mathrm{M}_{\mathrm{f}} \\
(\mathrm{Nm})\end{array}$ \\
\hline 0,1611 & 0,0792 & 0,6673 & 0,1761 & $7,7716 \mathrm{e}-4$ & $5,4412 \mathrm{e}-4$ & 0,0265 \\
0,1487 & 0,0669 & 0,7185 & 0,1532 & $6,7608 \mathrm{e}-4$ & $4,7335 \mathrm{e}-4$ & 0,0231 \\
0,1521 & 0,0604 & 0,7351 & 0,1542 & $6,8085 \mathrm{e}-4$ & $4,7669 \mathrm{e}-4$ & 0,0232 \\
0,1499 & 0,0622 & 0,8072 & 0,1382 & $6,0986 \mathrm{e}-4$ & $4,2699 \mathrm{e}-4$ & 0,0208 \\
\hline
\end{tabular}

As curvas real e simulada considerando os parâmetros mecânicos da segunda linha da tabela (7.5) é mostrada na fig. (7.5).

Mais uma vez, na fig.(7.5), a curva real e simulada com os parâmetros estimados por esse método são praticamente iguais. A curva de decaimento da velocidade possui realmente um comportamento exponencial decrescente conforme evidenciado no capítulo 3.

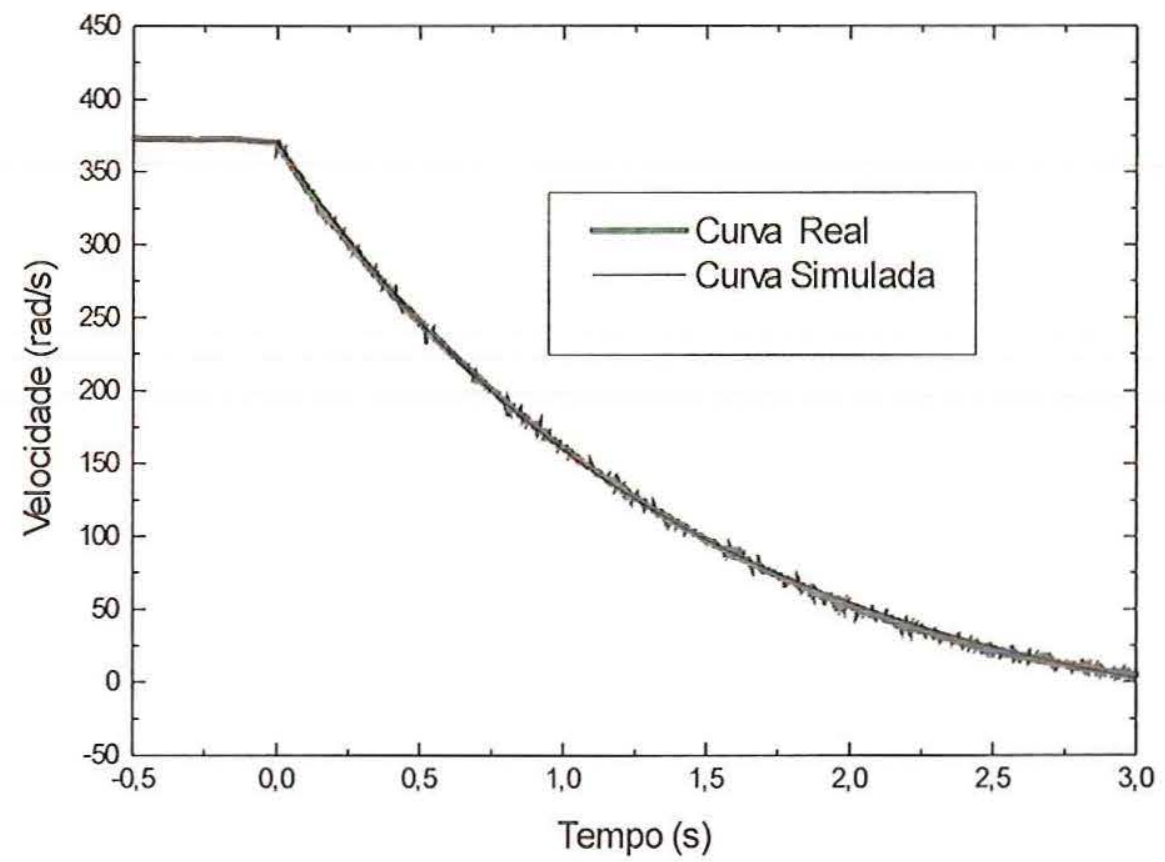

Fig 7.5 - Comparação entre a curva real e a simulada com parâmetros estimados pelo Método de Gauss-Newton. 


\subsubsection{Estimação com o Método Simplex de Nelder-Mead}

Utilizando o algoritmo disponível no MATLAB (Método Simplex de NelderMead) consegue-se os seguintes valores para os parâmetros mecânicos do motor de indução:

Tabela 7.6 - Parâmetros mecânicos estimados pelo Método Simplex de Nelder-Mead.

\begin{tabular}{ccccccc}
\hline $\begin{array}{c}\mathrm{T}_{\mathrm{r}} \\
(\mathrm{s})\end{array}$ & $\sigma$ & $\begin{array}{c}\mathrm{L}_{\mathrm{s}} \\
(\mathrm{H})\end{array}$ & $\begin{array}{c}\mathrm{m}_{\mathrm{d} 0} \\
(\mathrm{Nm})\end{array}$ & $\begin{array}{c}\mathrm{J} \\
\left(\mathrm{Kgm}^{2}\right)\end{array}$ & $\begin{array}{c}\mathrm{K}_{\mathrm{D}} \\
(\mathrm{Nms})\end{array}$ & $\begin{array}{c}\mathrm{M}_{\mathrm{f}} \\
(\mathrm{Nm})\end{array}$ \\
\hline 0.1594 & 0,0786 & 0,6563 & 0,1778 & $6,6537 \mathrm{e}-4$ & $4,6585 \mathrm{e}-4$ & 0,0266 \\
0.1511 & 0,0675 & 0,6307 & 0,1772 & $6,7857 \mathrm{e}-4$ & $4,7509 \mathrm{e}-4$ & 0,0271 \\
0.1484 & 0,0597 & 0,6468 & 0,1712 & $6,6560 \mathrm{e}-4$ & $4,5901 \mathrm{e}-4$ & 0,0262 \\
0.1542 & 0,0630 & 0,6596 & 0,1738 & $6,6555 \mathrm{e}-4$ & $4,6598 \mathrm{e}-4$ & 0,0266 \\
\hline
\end{tabular}

Da mesma forma que no Método de Gauss-Newton, utilizam-se os valores dos parâmetros elétricos $T_{r}, L_{s} e \sigma$, agora da tabela (7.4), para o cálculo do conjugado de regime do motor.

Esses valores são praticamente os mesmos dos estimados utilizando o Método de Gauss-Newton. As curvas real e simulada são mostradas na fig. (7.6) .

Os resultados experimentais obtidos pelos métodos descritos no capítulo 4, comprovam a eficiência já demostrada na fase de simulação, bem como validam os modelos empregados nos dois tipos de ensaio utilizados neste trabalho, para a estimação paramétrica de um MIT. 


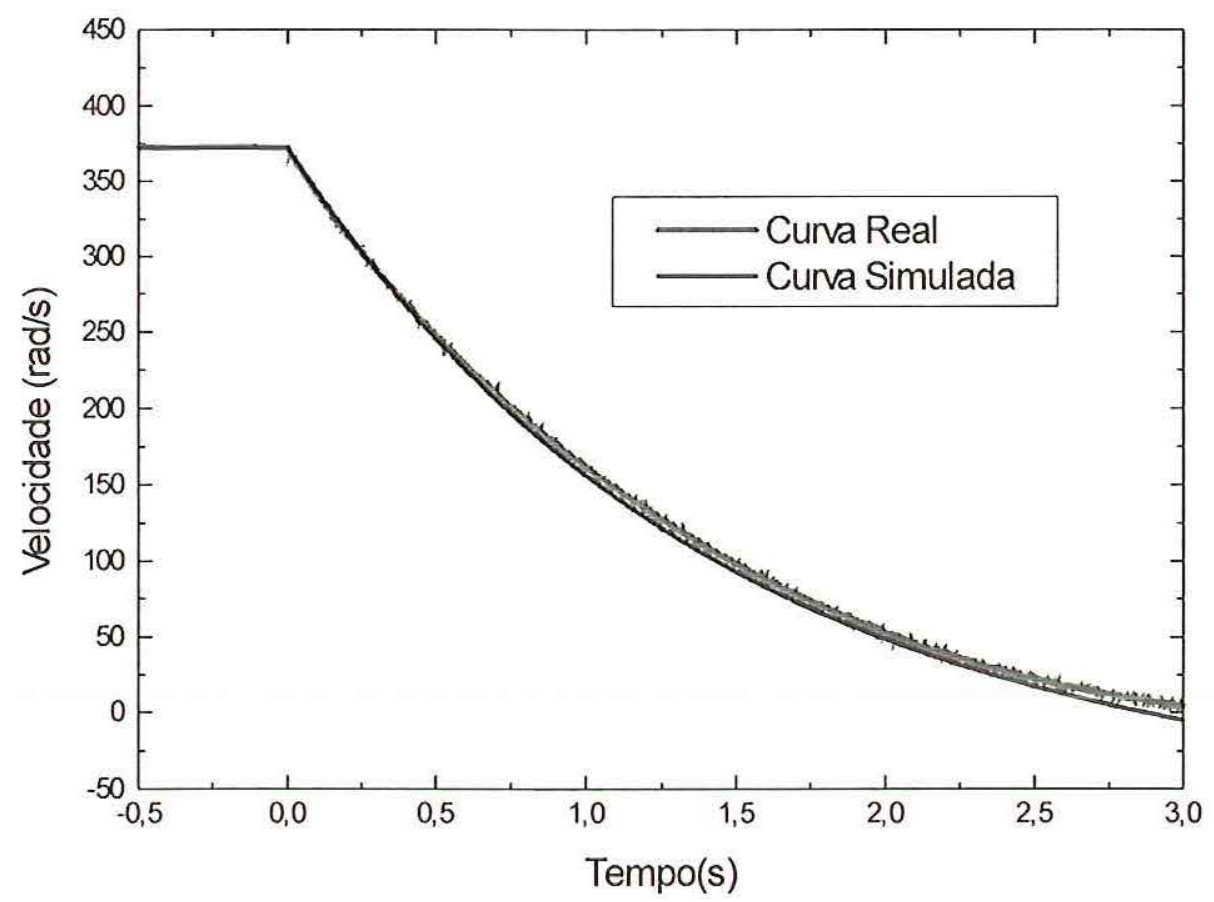

Fig 7.6 - Comparação entre a curva real e a simulada com parâmetros estimados pelo Método Simplex Nelder-Mead.

\subsection{Validação do Modelo}

Até agora, os ensaios realizados, ou excitavam somente o parte elétrica do motor (ensaio em degrau), ou somente a parte mecânica (ensaio de desaceleração). Para a validação completa dos modelos desenvolvidos e empregados neste trabalho, torna-se necessária a realização de um ensaio de partida, objetivando envolver, ao mesmo tempo, as grandezas elétricas e as mecânicas do MIT. Assim, o motor é alimentado com tensão trifásica (205 Vpico) onde então são amostrados os valores de sua velocidade até que se atinja condição de regime permanente. O gráfico das curvas real e da simulada, utilizando os parâmetros estimados à frequência de $1000 \mathrm{~Hz}$ pelo método de Gauss-Newton, são apresentadas na fig.(7.7). 


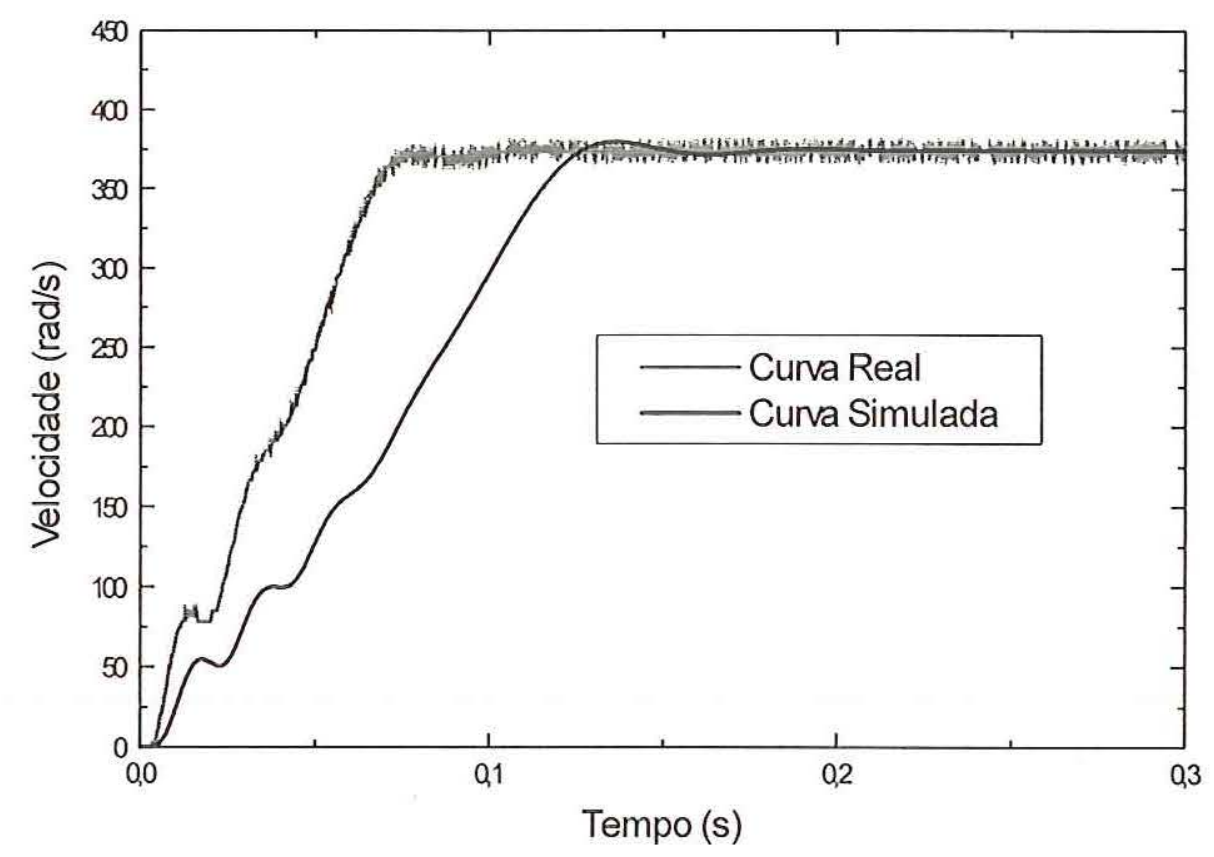

Fig 7.7 - Comparação entre a curva real e a simulada para o ensaio de aceleração.

Nota-se, através da figura acima, que os resultados entre as curvas real e a simulada são diferentes. Tal diferença foi constatada para uma série grande de ensaios de partida sob diferentes condições de alimentação do MIT. Desde que a comparação entre o comportamento real e o simulado dos ensaios individuais, ou seja, do ensaio degrau e de desaceleração, revelaram diferenças pequenas, o fato da diferença notada nos ensaios de partida motivou uma investigação de possíveis incoerências no modelo dinâmico de simulação do MIT.

Como resultado desta investigação, verificou-se que de fato, algumas considerações iniciais estipuladas na fase de elaboração do modelo do MIT não procedem. O principal fato reside na desconsideração da influência do chamado Efeito Pelicular, que no caso do MIT, ocasiona um aumento efetivo da resistência de rotor (RUPPERT FILHO e DE ALMEIDA, 1994). A ocorrência do Efeito Pelicular torna-se ainda mais pronunciada em estruturas de rotor em gaiola, com ranhura retangular profunda ou em estruturas de rotor em dupla gaiola (ORLICH, 1991). Desde que o motor sob teste é de baixa potência, isto implica em uma estrutura de rotor em gaiola do tipo com ranhura profunda. A ocorrência do Efeito Pelicular pode 
ser interpretada portanto, como uma alteração da estrutura do rotor, tal que seja refletida em forma de um aumento da resistência efetiva de rotor, bem como da dispersão de rotor. A frequência efetiva das grandezas de rotor tem o valor da frequência de escorregamento, de tal forma que no instante de partida, o escorregamento é unitário e a frequência no rotor tem seu valor máximo e igual à frequência da rede.

Para uma correta simulação do ensaio de partida, torna-se necessário introduzir nas equações do modelo do MIT descritas no capítulo 2, as devidas variações dos parâmetros relacionados com a variação da resistência e da dispersão do rotor. A consideração do Efeito Pelicular, por exemplo nas eqs.(2.47) à (2.52), podem ser colocados em forma de parâmetros variáveis com a frequência de escorregamento.

A quantização ou lei de variações dos parâmetros do MIT devido ao Efeito Pelicular foi conseguida através dos estudos realizados por BAILEY (1951) e GOLDEMBERG (1992), resultando nas seguintes expressões para o variação da constante de tempo do rotor $T_{\mathrm{r}}$ e do fator de dispersão global $\sigma$ :

$$
\begin{aligned}
\frac{T_{r}}{T_{r A C}}=a h\left(\frac{\sinh (2 a h)+\sin (2 a h)}{\cosh (2 a h)-\cos (2 a h)}\right) \\
\frac{\sigma_{A C}}{\sigma}=\frac{\left(1+e^{-10 S}\right)}{2}
\end{aligned}
$$

onde:

$$
\begin{aligned}
& \mathrm{a}=\sqrt{\frac{\mathrm{f}}{6.9} \frac{\mathrm{k}}{\mathrm{m}}} \\
& \mathrm{f}=\text { Frequência em Hertz } \\
& \mathrm{h}=\text { Profundidade da barra em polegada } \\
& \mathrm{k}=\text { Largura da barra } \\
& \mathrm{m}=\text { Largura da ranhura } \\
& \mathrm{S}=\text { Escorregamento }
\end{aligned}
$$


$\mathrm{T}_{\mathrm{rAC}}=$ Constante de tempo do rotor variável devido ao Efeito Pelicular $\sigma_{\mathrm{AC}}=$ Fator de dispersão global variável devido ao Efeito Pelicular

Incluindo as eqs.(7.1) e (7.2) nas equações que descrevem o MIT, apresentadas no capítulo 2, obtém-se o resultado de simulação mostrado na fig. (7.8).

Nesta figura, nota-se que a inclusão do Efeito Pelicular no ambiente de simulação, possibilita uma situação mais realista do que ocorre com o motor utilizado, neste tipo de ensaio.

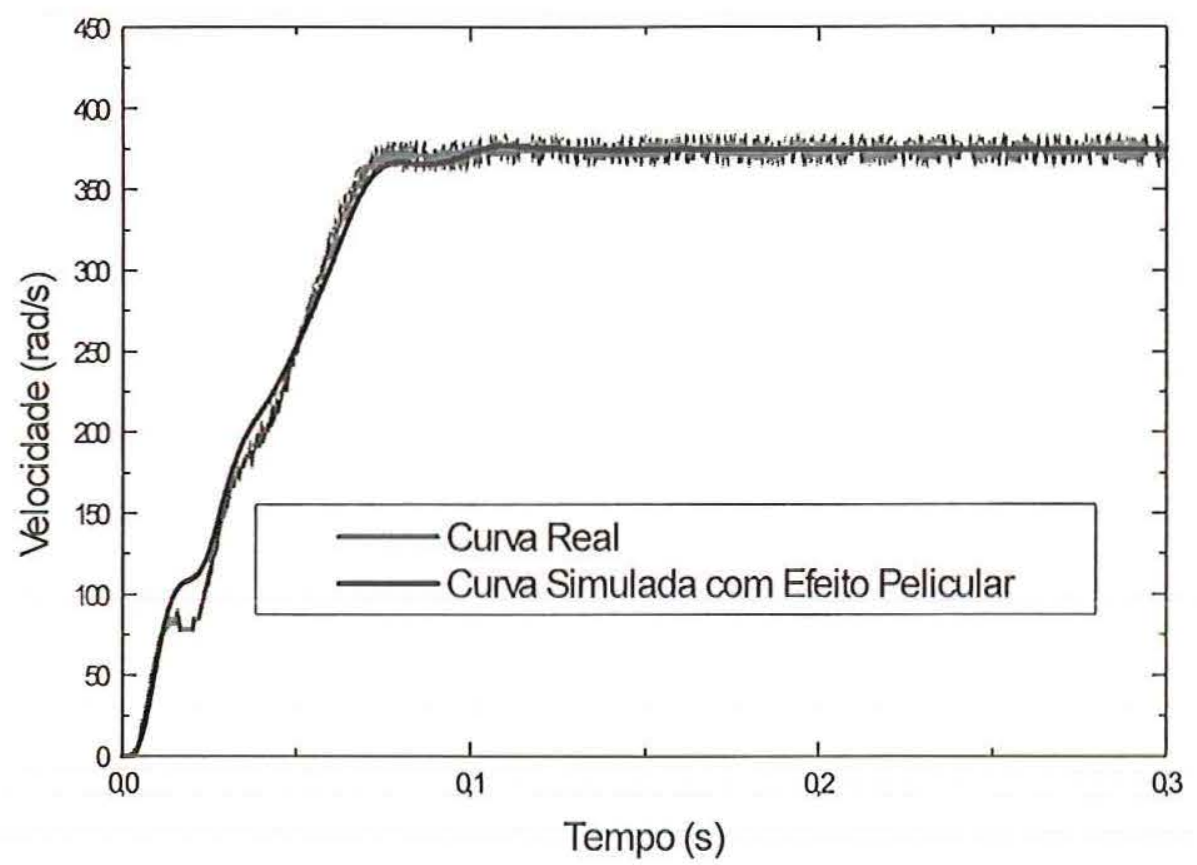

Fig 7.8 - Comparação entre a curva real e a simulada para o ensaio de aceleração considerando o Efeito Pelicular.

De maneira geral, os valores estimados para as grandezas elétricas são mais confiáveis, quando comparados com os resultados dos ensaios clássicos com rotor bloqueado e em vazio, apresentados no apêndice $A$ e repetidos aqui por conveniência. 
Tabela 7.7 - Parâmetros estimados através dos ensaios em vazio e com rotor bloqueado.

\begin{tabular}{cccc}
\hline $\mathrm{R}_{\mathrm{S}}(\Omega)$ & $\mathrm{L}_{\mathrm{S}}(\mathrm{mH})$ & $\mathrm{T}_{\mathrm{r}}(\mathrm{ms})$ & $\sigma$ \\
\hline 7,44 & 559,6 & 89,44 & 0,040 \\
\hline
\end{tabular}

Isto se deve, principalmente, a não disponibilidade de equipamentos adequados à realização destes ensaios, dentro dos padrões especificados pela Associação Brasileira de Normas Técnicas (ABNT) que prevê para o ensaio com rotor bloqueado, a utilização de uma frequência não superior a $25 \%$ do valor da frequência nominal $(60 \mathrm{~Hz})$. Como o ensaio foi realizado sob frequência nominal, os parâmetros elétricos do MIT são determinados sob influência do Efeito Pelicular o que ocasiona certa imprecisão nos resultados. A tabela (7.8) resume os parâmetros elétricos e mecânicos estimados pelos métodos apresentados neste trabalho:

Tabela 7.8 - Tabela resumo dos parâmetros estimados através dos métodos propostos.

\begin{tabular}{lccccccc}
\hline & $\mathrm{R}_{\mathrm{s}}$ & $\mathrm{L}_{\mathrm{s}}$ & $\sigma$ & $\mathrm{T}_{\mathrm{r}}$ & $\mathrm{J}$ & $\mathrm{K}_{\mathrm{D}}$ & $\mathrm{M}_{\mathrm{f}}$ \\
& $(\Omega)$ & $(\mathrm{H})$ & & $(\mathrm{s})$ & $\begin{array}{c}\left(\mathrm{Kgm}^{2}\right) \\
(\mathrm{Nms})\end{array}$ & $(\mathrm{Nm})$ \\
& & & & & $\times 10^{-4}$ & $\times 10^{-4}$ & \\
\hline RELS & 7,5543 & 0,6302 & 0,0843 & 0,1509 & - & - & - \\
Gauss-Newton & 7,5022 & 0,7185 & 0,0669 & 0,1487 & 6,7608 & 4,7335 & 0,0231 \\
& & & & & & & \\
MATLAB & 6,7489 & 0,6307 & 0,0675 & 0,1511 & 6,7857 & 4,7509 & 0,0271
\end{tabular}




\section{Conclusão}

Os métodos aqui apresentados mostram-se eficientes para a identificação dos parâmetros elétricos e mecânicos de um motor de indução trifásico, além de serem bastante flexíveis, podendo ser utilizados em qualquer máquina de indução, bastando para isso, se efetuar algumas modificações a nível de hardware. Também oferecem a possibilidade de automatização.

A estratégia de excitação tipo degrau, aplicado aos enrolamentos de estator, constitui-se em um ensaio simples e rápido, sem a necessidade de se colocar o motor em operação. Este ensaio, como se verificou, pode ser analisado com base na Função de Transferência do motor e na função descritiva do comportamento transitório da corrente de ensaio. Dependendo do caso, diferentes procedimentos podem ser aplicados.

Dentre os métodos propostos, o Método dos Mínimos Quadrados Recursivo (RLS/RELS) é o único que possui uma dependência direta com a frequência de amostragem para o cálculo dos parâmetros elétricos do MIT. Além disso, é necessário que se conheça o grau do sistema cujos parâmetros se deseja estimar e que haja uma perfeita sincronização no processo de aquisição das grandezas, no caso, degrau de tensão e corrente de estator.

Para sistemas muito ruidosos é necessário ainda uma pré-filtragem das grandezas envolvidas no processo para posterior processamento pelo algoritmo.

Tanto o Método de Gauss-Newton como o Método Simplex de Nelder-Mead, disponível no MATLAB, apresentam o inconveniente de se ter que trabalhar com vetores de muitos elementos, dispendendo grandes quantidades de memória para o processamento. Também necessitam do conhecimento da função que rege o comportamento do sistema em estudo, e de valores iniciais coerentes para se iniciar o processo de estimação. Casos esses valores sejam fixados erroneamente, os parâmetros levarão mais tempo para convergirem para seus valores finais. 
Esses Métodos são eficientes na estimação paramétricas de sistemas ruidosos, uma vez que são baseados na aproximação de uma função, cuja expressão já é conhecida, não dependendo do nível de ruído do sistema.

O processo de validação proposto, baseado no ensaio de partida do motor, revelou que o Efeito Pelicular exerce considerável influência sobres alguns parâmetros do motor. 


\section{Referências Bibliográficas}

AGUIAR, M. L. (1994). Ein Beitrag zur adaptiven Lageregelung von Asynchronmaschinen bei variablem Trägheitsmoment. Tese de Doutoramento - Universidade Técnica de Berlim.

ASSOCIAÇÃO BRASILEIRA DE NORMAS TÉCNICAS. (1982). NBR 5383, Máquinas Elétricas Girantes-Máquinas de Indução-Determinação das Características - Método de Ensaio. Rio de Janeiro.

ALVARADO , F. L. and CÃNIZARES (1991). Instructional use of declarative languages for the study of machine transients. IEEE Transactions on Power Systems, Vol. 6, N.1, p.407 - 413, feb.

ATKINSON, D.J., ACARNLEY, P.P.e FINCH, J.W, (1991). Observers for Induction Motor State and Parameter Estimation. IEEE Transactions on Industry Applications, Vol. 27, N.6, p.1119 - 1127, nov-dec.

BAILEY, B . F. \& GAULT, J. S. (1951). Alternating - Current Machinery. Mc Graw Hill company INC, Cap.23, p.403-405.

BEIERKE, S. (1992). Vergleichende Untersuchungen von Unterschiedlich Feldorientierten Lagereglerstrukturen für Asynchron-Servomotoren mit einem Multi - Transputer System. Tese de Doutoramento -Universidade Técnica de Berlin.

BLASCHKE, F.(1972) The principle of field orientation as applied to the new transvector closed loop control system for rotating machines, Siemens Review, vol.39, p.217 - 220. 
DAVIS, M. H. A. \& VINTER, R. B. (1985). Stochastic modelling and control. University printing house, Cambrige.

DE DONKER, R. W., NOVOTNY, D. W. (1994). The Universal Field Oriented Controller. IEEE Transactions on Industry Applications, Vol.30, N.6, p.92-100, jan-feb.

FORTESCUE, T. R. KERSHENBAUM, L. S. and YDSTIE, B. E. (1981). Implementation of self-tuning regulators with variable forgetting factors. Automática, vol 17, N6, p.831-835.

GARCIA, G.O. STEPHAN, R. M.e WATANABE, E. H.(1994). Comparing the indirect field-oriented control with a scalar method. IEEE Transactions on Industrial Electronics, Vol.41, N.2, p.201 - 207, apr.

GOLDEMBERG, C. (1992). Determinação de parâmetros funcionais de motores de indução a partir de catálogos de fabricantes. Disssertação de mestrado - Unicamp.

HEIDRICH, H. P. (1991), Feldorientierte Regelung einer Asynchronmashine dursh einen Parallelisierten und geschwindigkeitsoptimierten Kaskadenregler mit einen Multitransputersystem. Tese de Doutoramento. Universidade Técnica de Berlin.

ISERMANN, R. Vol.1 e Vol. 2 (1989). Digital Control System. Springer. Verlag, Berlim Vol.1, cap3 p. 17-37 e Vol.2 cap.24, p. 141-154.

KLAES, N.R.(1993), Parameter identification of an induction machine with regard to dependencies on saturation, IEEE Transactions on Industry Applications, Vol. 29, N.6, p. 1135 - 1140, nov-dec. 
LEONHARD, W, (1990), Control of Electrical Drives, Berlim, SpringerVerlag

LOURO, A.C. (1995), Comparação e Implementação de Estruturas de Controle Adaptativo, Dissertação de mestrado. Escola de Engenharia de São Carlos, Universidade de São Paulo.

MATHWORKS Inc (1993), "MATLAB with SIMULINK", Version 4.0 -PC.

MOON, S . e KEYHANI, A. (1994), Estimation of Induction Machine Parameters from Standstill Time-Domain Data. IEEE Transactions on Industry Application, vol.30, n.6, p.1609-1615, nov-dec.

ORLICH, C.(1991) Entwurf, Simulation und Realisierung eines digitalen kaskadierten Zustandsreglers für Asynchronmaschine auf der Basis eines Multitransputersystems, Diplomarbeit - Trabalho de formatura. Instituto de Eletrônica da Universidade Técnica de Berlim.

PCI-20089W-1 ANALOG INPUT BOARD USER MANUAL (1989), BurrBrown Corporation.

ROBBA, E. J. (1973). Introdução a Sistemas Elétricos de Potência Componentes Simétricas, cap. 1, p. 51-59, Editora Edgard Blucher Ltda.

RUPPERT FILHO, E. e de ALMEIDA, A. T. L. (1994). Estimação de parâmetros e determinação de características de desempenho de motores de indução trifásicos de rotor em gaiola, $10^{\circ}$ CONGRESSO BRASILEIRO DE AUTOMÁTICA, Rio de Janeiro -RJ, 1994, p. 795 - 800.

SEBER, G. A. F. e WILD, C. J. (1989) . Nonlinear Regression, Wiley Interscience \& Sons Inc., cap 14. 
VAS, P. (1994). Vector Control of AC Machines. Clarendon Press-Oxford. 


\section{Apêndice A - Identificação paramétrica a partir do ensaio com rotor bloqueado e em vazio}

A determinação dos parâmetos elétricos do MIT, através da realização dos ensaios com rotor bloqueado e em vazio, servem como uma referência inicial para os resultados conseguidos pelos métodos propostos neste trabalho. O motor utilizado possui as mesmas características que às apresentadas no capítulo 7 .

O algorítmo para a identificação dos parâmetros elétricos do MIT é o empregado por HEIDRICH (1991), baseado em medidas experimentais, resultantes dos ensaios com rotor bloqueado e em vazio. Assim, os dados são coletados em laboratório, para depois serem processados em um programa, contendo esse algoritmo.

Sabe-se que o motor de indução trifásico com rotor em gaiola, quando em regime permanente, pode ser representado por um circuito equivalente monofásico como mostra a fig.A1 abaixo (LEONHARD, 1990; RUPPERT FILHO, E. e de ALMEIDA, A. T.L., 1994):

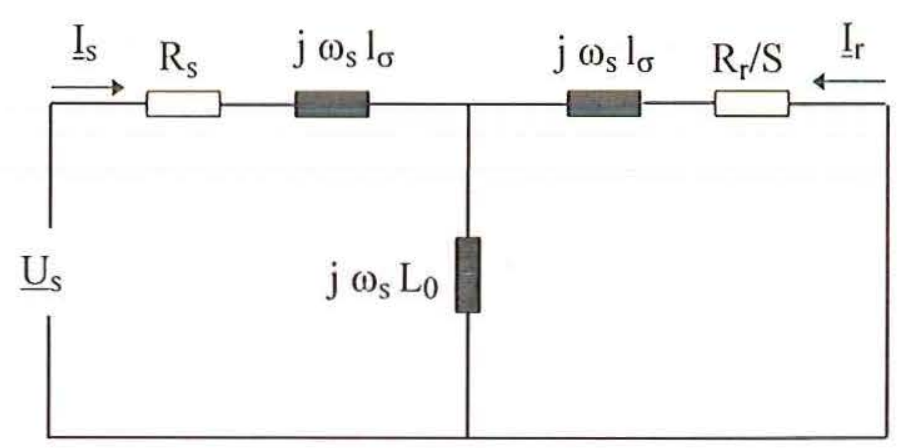

Fig. Al - Circuito equivalente por fase do MIT em regime permanente.

No ensaio em vazio, o rotor gira livremente (escorregamento $\mathrm{S}$ nulo). Portanto, pode-se desprezar o ramo do rotor uma vez que a impedância total será infinita. 
Aplicando a lei das tensões de Kirchhoff no ramo da esquerda tem-se:

$$
\underline{\mathrm{U}}_{\mathrm{v}}=\left(\mathrm{R}_{\mathrm{S}}+\mathrm{jX} \mathrm{S}_{\mathrm{S}} \underline{\mathrm{I}}_{\mathrm{v}}\right.
$$

onde:

$\mathrm{S}=$ Escorregamento;

$\underline{\mathrm{U}}_{\mathrm{V}}=$ Fasor tensão de estator no ensaio a vazio;

$\underline{I}_{v}=$ Fasor corrente de estator no ensaio a vazio;

Por definição tem-se que:

$$
\begin{aligned}
& X_{\mathrm{S}}=\omega_{\mathrm{S}}\left(1_{\sigma}+\mathrm{L}_{0}\right) \Rightarrow \text { Reatância de Estator; } \\
& \mathrm{X}_{0}=\omega_{\mathrm{S}} \mathrm{L}_{0} \Rightarrow \text { Reatância Mútua; } \\
& \mathrm{X}_{\sigma}=\omega_{\mathrm{S}} \mathrm{l}_{\sigma} \Rightarrow \text { Reatância de Dispersão (aqui considerada igual no }
\end{aligned}
$$

estator e rotor);

Dividindo a eq.(A.1) em parte real e parte imaginária e considerando uma defasagem $\varphi_{v}$ radianos entre os fasores $\underline{U}_{v}$ e $\underline{I}_{v}$ tem-se:

$$
\begin{aligned}
& U_{v}=R_{S} I_{v} \cos \varphi_{v}+X_{S} I_{v} \operatorname{sen} \varphi_{v} \\
& 0=-R_{S} I_{v} \operatorname{sen} \varphi_{v}+X_{S} I_{v} \cos \varphi_{v}
\end{aligned}
$$

Das eqs.(A.3) e (A.4) tem-se que:

$$
X_{s}=\frac{U_{v}}{I_{v}} \operatorname{sen} \varphi_{v}
$$




$$
\mathrm{R}_{\mathrm{s}}=\mathrm{X}_{\mathrm{s}} \frac{\operatorname{sen} \varphi_{\mathrm{v}}}{\cos \varphi_{\mathrm{v}}}
$$

No ensaio com rotor bloqueado,o escorregamento tem valor unitário. Pela análise das malhas do rotor e estator, tem-se que:

$$
\underline{U}_{K}=\left[R_{S}+j X_{\sigma}+\frac{j X_{0}\left(R_{r}+j X_{\sigma}\right)}{R_{r}+j\left(X_{\sigma}+X_{0}\right)}\right] \underline{I}_{K}
$$

onde:

$$
\begin{aligned}
& \underline{U}_{K}=\text { Fasor tensão de estator no ensaio com rotor bloqueado } \\
& \underline{I}_{K}=\text { Fasor corrente de estator no ensaio com rotor bloqueado }
\end{aligned}
$$

Dividindo a a eq. (A7) em parte real e parte imaginária, considerando uma defasagem $\varphi_{K}$ radianos entre $\underline{U}_{K}$ e $\underline{I}_{K}$, tem-se:

$$
\begin{aligned}
& \frac{U_{K}}{I_{K}} \cos \varphi_{K}=R_{s}+\frac{R_{r} x_{0}^{2}}{R_{r}^{2}+X_{s}^{2}} \\
& \frac{U_{K}}{I_{K}} \operatorname{sen} \varphi_{K}=X_{\sigma}+\frac{X_{0}\left(R_{r}^{2}+l_{\sigma} X_{s}\right)}{R_{r}^{2}+X_{s}^{2}}
\end{aligned}
$$

Sabendo que:

$$
X_{\sigma}=\sigma X_{0}
$$

e substituindo este resultado na eq.(A.2) tem-se:

$$
\mathrm{X}_{0}=\frac{1}{1+\sigma} \mathrm{X}_{\mathrm{s}}
$$


Através da eq.(A.8) pode-se determinar uma expressão para a resistência de rotor $\mathrm{R}_{\mathrm{r}}$ :

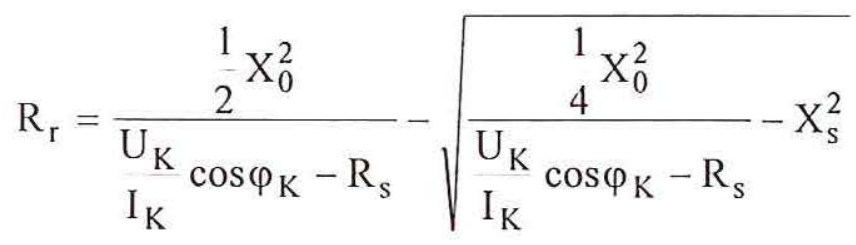

Analogamente pode-se obter uma expressão para $\mathrm{X}_{\sigma}$ :

$$
X_{\sigma}=\frac{R_{r}^{2}\left(\frac{U_{K}}{I_{K}} \operatorname{sen} \varphi_{K}-X_{0}\right)+\frac{U_{K}}{I_{K}} \operatorname{sen} \varphi_{K} X_{s}^{2}}{R_{r}^{2}+X_{s}\left(X_{s}+X_{0}\right)}
$$

Os ensaios foram realizados utilizando o método dos dois wattímetros (ROBBA, 1973). Segundo a Associação Brasileira de Normas Técnicas (ABNT), no ensaio a vazio, faz-se girar o motor livremente (sem carga acoplada) com tensão e frequência nominais, anotando-se os valores de tensão, corrente e potência absorvida quando esta última permanecer constante. Além disso, deve-se repetir o ensaio para diferentes valores de tensão e na frequência nominal, partindo de um máximo de $125 \%$ da tensão nominal do motor e decrescendo-a até que uma redução de tensão ocasione uma elevação de corrente da ordem de $15 \%$ à $30 \%$ da tensão nominal.

Para o ensaio com rotor bloqueado, com o motor aproximadamente à temperatura ambiente, trava-se o eixo do rotor e aumenta-se a tensão até que a corrente atinja seu valor nominal com uma frequência não superior a $25 \%$ do valor da frequência nominal. Este procedimento, procura eliminar a influência do Efeito Pelicular na estimação dos parâmetros do MIT. Em seguida, anotam-se os valores de 
tensão, corrente e potência absorvida. Estas leituras devem ser rápidas para se evitar o aquecimento do motor e consequentemente, a alteração dos parâmetros internos do mesmo.

A não disponibilidade de equipamentos adequados em laboratório, impossibilitou a realização dos ensaios conforme especifica a ABNT. Assim, repetiu-se o ensaio a vazio cinco vezes, aplicando-se tensão e frequência nominais $(60 \mathrm{~Hz})$. Para o ensaio com rotor bloqueado, realizaram-se dez leituras utilizando frequência nominal. A média destas medidas são apresentados nas tabelas A.1 e A.2 onde W1 e W2 representam as potências lidas pelos wattímetros.

Tabela A.1 - Resultados do ensaio com rotor bloqueado.

\begin{tabular}{cccc}
\hline $\mathrm{U}_{\mathrm{v}}(\mathrm{V})$ & $\mathrm{I}_{\mathrm{v}}(\mathrm{A})$ & $\mathrm{W} 1(\mathrm{~W})$ & $\mathrm{W} 2(\mathrm{~W})$ \\
\hline 35,79 & 3,171 & 10,47 & 2,38 \\
\hline
\end{tabular}

Tabela A.2 - Resultados do ensaio em vazio.

\begin{tabular}{cccc}
\hline $\mathrm{U}_{\mathrm{K}}(\mathrm{V})$ & $\mathrm{I}_{\mathrm{K}}(\mathrm{A})$ & $\mathrm{W} 1(\mathrm{~W})$ & $\mathrm{W} 2(\mathrm{~W})$ \\
\hline 220,46 & 1,878 & 43,92 & 12,76 \\
\hline
\end{tabular}

Os valores apresentados nas tabelas (A.1) e (A.2) são inseridos no algorítmo empregado por HEIDRICH (1991), fornecendo os seguintes parâmetros elétricos para o MIT:

Tabela A.3 - Parâmetros calculados.

\begin{tabular}{cccc}
\hline $\mathrm{R}_{\mathrm{S}}(\Omega)$ & $\mathrm{L}_{\mathrm{s}}(\mathrm{mH})$ & $\mathrm{T}_{\mathrm{r}}(\mathrm{ms})$ & $\sigma$ \\
\hline 7.44 & 559.6 & 89.44 & 0.040 \\
\hline
\end{tabular}


Devido à não observância da norma que rege estes tipos de ensaios, os parâmetros elétricos determinados principalmente através do ensaio com rotor bloqueado $\left(\mathrm{T}_{\mathrm{r}}\right.$ e $\left.\sigma\right)$, realizado com frequência nominal, estão sujeitos à influência do Efeito Pelicular. 